NUREG/CR-6266

ANL-94/35

\title{
Analysis of Boron Dilution in a Four-Loop PWR
}

Manuscript Completed: February 1995

Date Published: March 1995

Prepared by

J. G. Sun, W. T. Sha

Argonne National Laboratory

9700 South Cass Avenue

Argonne, IL 60439

Prepared for

Safety Programs Division

Office for Analysis and Evaluation of Operational Data

U.S. Nuclear Regulatory Commission

Washington, DC 20555-0001

NRC Job Code A2195

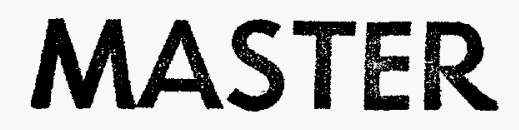




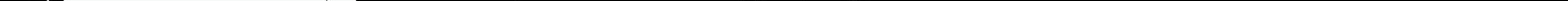




\section{DISCLAIMER}

This report was prepared as an account of work sponsored by an agency of the United States Government. Neither the United States Government nor any agency thereof, nor any of their employees, make any warranty, express or implied, or assumes any legal liability or responsibility for the accuracy, completeness, or usefulness of any information, apparatus, product, or process disclosed, or represents that its use would not infringe privately owned rights. Reference herein to any specific commercial product, process, or service by trade name, trademark, manufacturer, or otherwise does not necessarily constitute or imply its endorsement, recommendation, or favoring by the United States Government or any agency thereof. The views and opinions of authors expressed herein do not necessarily state or reflect those of the United States Government or any agency thereof. 


\section{DISCLAIMER}

Portions of this document may be illegible in electronic image products. Images are produced from the best available original document. 


\title{
ANALYSIS OF BORON DILUTION IN A FOUR-LOOP PWR
}

\author{
J. G. Sun and W. T. Sha
}

\section{Abstract}

Thermal mixing and boron dilution in a pressurized water reactor were analyzed with COMMIX codes. The reactor system was the four-loop Zion reactor. Two boron dilution scenarios were analyzed. In the first scenario, the plant is in cold shutdown and the reactor coolant system has just been filled after maintenance on the steam generators. To flush the air out of the steam generator tubes, a reactor coolant pump (RCP) is started, with the water in the pump suction line devoid of boron and at the same temperature as the coolant in the system. In the second scenario, the plant is at hot standby and the reactor coolant system has been heated to operating temperature after a long outage. It is assumed that an RCP is started, with the pump suction line filled with cold unborated water, forcing a slug of diluted coolant down the downcomer and subsequently through the reactor core. The subsequent transient thermal mixing and boron dilution that would occur in the reactor system is simulated for these two scenarios. The reactivity insertion rate and the total reactivity are evaluated and a sensitivity study is performed to assess the accuracy of the numerical modeling of the geometry of the reactor coolant system. 


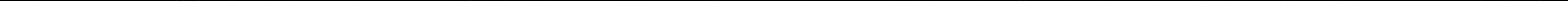




\section{Contents}

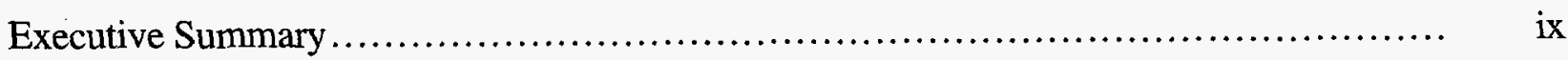

$1 \quad$ Introduction ...................................................................

2 Objectives............................................................... 2

3 Thermal Mixing and Boron Dilution in a Four-Loop PWR ........................ 2

3.1 Layout of Four-Loop Zion Reactor .................................... 2

3.2 The Numerical Model ................................................... 3

3.2.1 Geometry .................................................... 3

3.2.2 Volume and Surface Porosities ................................... 3

3.2.3 Flow Resistances .............................................. 4

3.2.4 Heat Transfer to Walls ............................................. 4

3.2.5 Fluid Physical Properties ...................................... 5

3.3 Initial Conditions.......................................................... 5

3.4 Boundary Conditions.................................................... 5

3.4 .1 Inlet............................................................. 5

3.4 .2 Outlet ......................................................... 6

3.4.3 Solid Walls ..................................................... 6

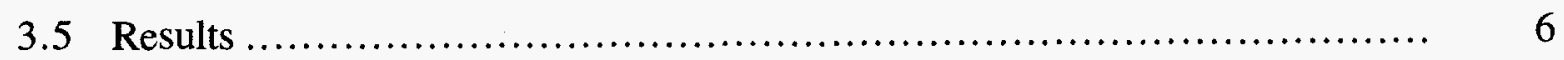

3.5.1 Analysis of Boron Dilution under Isothermal-RCP-Start Conditions .... 6

3.5.2 Analysis of Thermal Mixing and Boron Dilution under Hot-RCP-Start

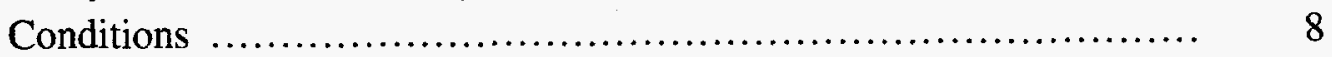

4 Sensitivity Study for Modeling Geometry of Reactor Vessel ............................ 10

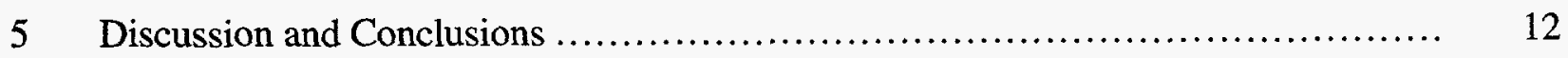

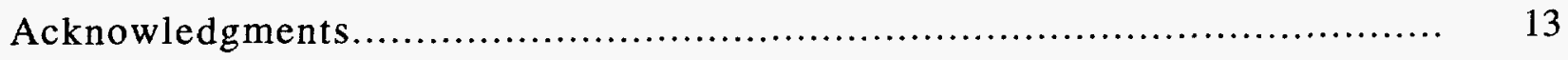

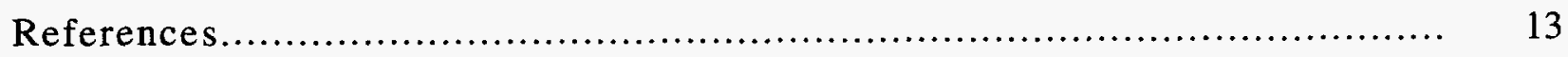




\section{Figures}

1 Schematic representation of Zion reactor coolant system .......................... 15

2 Side view of layout of Zion reactor coolant loops ................................ 16

3 Top view of layout of Zion reactor coolant loops.......................................... 17

4 Schematic layout of internal structures of Zion reactor...................................... 18

5 Cross section of reactor vessel................................................. 19

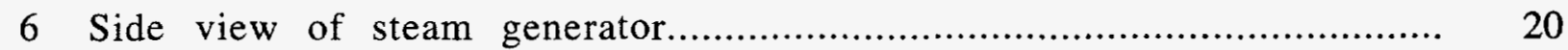

7 Schematic layout of three-dimensional model for Zion reactor loop 4 ............... 21

8 Top view of numerical model of Zion reactor coolant loops ........................ 22

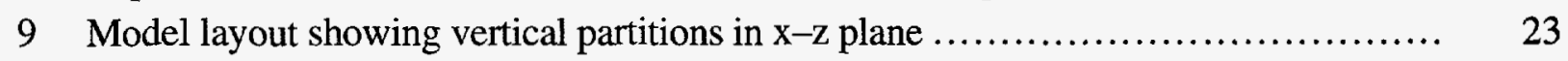

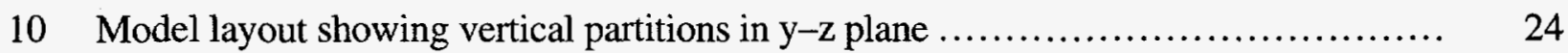

11 Model layout showing horizontal partitions in $x-y$ plane .......................... 25

12 Vertical partitions of reactor vessel ............................................. 26

13 Horizontal partitions of reactor vessel..................................................... 27

14 Vertical partitions of steam generator..................................................... 28

15 Increase in flow rate with time at start of RCP................................... 29

16 Velocity distributions in cold legs and reactor vessel for isothermal-RCP-start calculation ........................................... 30

17 Velocity distributions in downcomer for isothermal-RCP-start calculation............... 31

18 Velocity distributions in reactor vessel, hot legs, and steam generators for isothermal-RCP-start calculation ........................................ 32

19 Velocity distributions in reactor vessel and cold and hot legs for isothermal-RCP-start calculation .......................................... 33

20 Variation of mass flow rates with time in four loops for isothermal-RCP-start calculation .......................................... 34

21 Distributions of boron concentration in cold legs and reactor vessel for isothermal-RCP-start calculation .....

22 Distributions of boron concentration in reactor core at $20 \mathrm{~s}$ into transient for isothermal-RCP-start calculation.

23 Contours of boron concentration in reactor vessel for isothermal-RCP-start calculation

24 Variation of boron concentration along the axis of reactor vessel at 16, 18, 20, and $22 \mathrm{~s}$ into transient for isothermal-RCP-start calculation

25 Variation of mean boron concentration with time in reactor core for isothermal-RCP-start calculation .

26 Mean and local minimum boron concentration variation with time in reactor core for isothermal-RCP-start calculation.

27 Variation of mean reactivity insertion rate with time in reactor core for isothermal-RCP-start calculation 
28 Variation of mean reactivity with time in reactor core for isothermal-RCP-start calculation.............................................. 42

29 Velocity distributions in cold legs and reactor vessel for hot-RCP-start calculation....

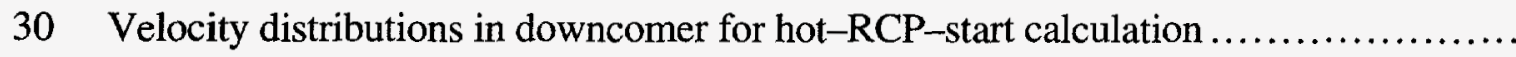

31 Velocity distributions in reactor vessel, hot legs, and steam generators for hot-RCP-start calculation.

32 Velocity distributions in reactor vessel and cold and hot legs for hot-RCP-start calculation

33 Variation of mass flow rates with time in four loops for hot-RCP-start calculation....

34 Temperature distributions in cold legs and reactor vessel for hot-RCP-start calculation

35 Temperature contours in reactor vessel for hot-RCP-start calculation

36 Variations of mean and local minimum temperature with time in reactor core for hot-RCP-start calculation

37 Distributions of boron concentration in cold legs and reactor vessel for hot-RCP-start calculation

38 Distributions of boron concentration in reactor core at $20 \mathrm{~s}$ into transient for hot-RCP-start calculation

39 Contours of boron concentration in reactor vessel for hot-RCP-start calculation

40 Variation of mean boron concentration along axis of reactor vessel at $16,18,20$, and $22 \mathrm{~s}$ into the transient for hot-RCP-start calculation.

41 Variation of mean and local minimum boron concentrations with time

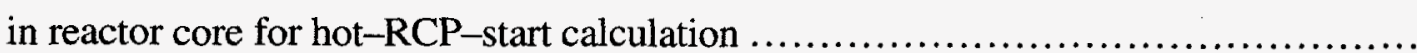

42 Variation of mean reactivity insertion rate with time in reactor core for hot-RCP-start calculation

43 Variation of mean reactivity with time in reactor core

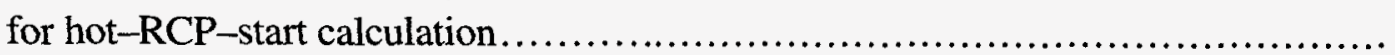

44 Top view of computational geometry with multicoordinate model .....................

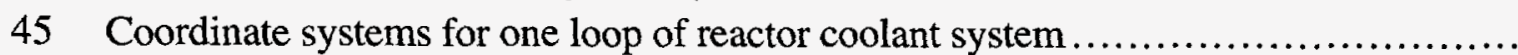

46 Horizontal partitions in reactor vessel with multicoordinate model.....................

47 Velocity distributions in reactor vessel for hot-RCP-start calculation with multicoordinate model.

48 Velocity distributions in downcomer for hot-RCP-start calculation with multicoordinate model.

49 Variation of mass flow rates with time in four loops for hot-RCP-start calculation with multicoordinate model.

50 Temperature distributions in reactor vessel for hot-RCP-start calculation with multicoordinate model.

51 Temperature contours in reactor vessel for hot-RCP-start calculation with multicoordinate model. 
52 Temperature variation along axis of reactor vessel at 16, 18, 20, and $22 \mathrm{~s}$ into transient for hot-RCP-start calculation with and without multicoordinate model .......

53 Mean temperature variation with time in reactor core for hot-RCP-start calculation with and without multicoordinate model 
Recent studies of hypothetical pressurized water reactor reactivity accidents have identified mechanisms by which the concentration of boron in the core-coolant moderator is diluted. One mechanism is to quickly pump a slug of cold unborated water through the core, and cause insertion of positive reactivity and thus power excursion and fuel damage. The most conservative assumption in terms of reactivity insertion is that the cold unborated inlet water does not mix with the hot boron-rich water initially in the reactor vessel and the reactor coolant pipes. Therefore, the extent of mixing of cold unborated water with hot boron-rich water is important in realistically quantifying the reactivity insertion due to thermal mixing and boron dilution.

Thermal mixing and boron dilution in the four-loop Zion reactor were analyzed with COMMIX codes. The major objective of these analyses was to determine the reactivity insertion due to the change of coolant density and boron concentration in the reactor core. A threedimensional numerical model, based on Cartesian coordinates, was developed for the four-loop reactor system.

Two boron dilution scenarios were analyzed. In the first scenario, the plant is in cold shutdown and the reactor coolant system has just been filled after maintenance on the steam generators. To flush the air out of the steam generator tubes, a reactor coolant pump (RCP) is started. It is assumed that the water in the pump suction line (or crossunder line) is at the same temperature as the coolant in the system but is devoid of boron. Our transient calculation showed that there is moderate boron mixing in the reactor vessel: The mixing occurs mainly in the downcomer and also in the lower plenum and the core. Flow bypasses through the other three loops also contributed to reduced dilution of boron in the reactor core. As a result, the maximum mean reactivity insertion rate in the core is $\approx 0.0043 \mathrm{~s}^{-1}$, or $\approx \$ 0.96 / \mathrm{s}$, at $16.5 \mathrm{~s}$ into the transient. The maximum mean reactivity is $\approx 0.016$ (or $\approx \$ 3.5$ ) at $19 \mathrm{~s}$ into the transient.

In the second scenario, the plant is at hot standby and the reactor coolant system has been heated to operating temperature after a long outage. It is assumed that boron dilution took place in one of the four pump suction lines during the outage. When the RCP in the diluted loop is started (with the suction line filled with cold unborated water), a slug of diluted coolant will be forced down the downcomer and subsequently through the reactor core. From the transient calculation, we found that the boron mixing was not as good as that in the isothermal calculation because the cold unborated water is heavier and the extent of the flow recirculation in the downcomer is reduced. We also found that the cold slug does not have enough time to mix with the coolant in the lower plenum. The mean reactivity insertion rate due to both the coolant density change and boron concentration change reached a maximum of $\approx 0.012 \mathrm{~s}^{-1}$, or $\approx \$ 2.7 / \mathrm{s}$, at $14.5 \mathrm{~s}$ into the transient. The maximum mean reactivity is $\approx 0.035$, or $\approx \$ 7.7$, at $17 \mathrm{~s}$ into the transient, which is very high. 
Finally, we performed a preliminary sensitivity study to assess the accuracy of the numerical modeling of the geometry of the reactor vessel. An initial phase of a multicoordinate model was developed. The reactor vessel was then modeled as a cylindrical column, rather than the square column used in the above analyses, and all of the pipe bends in the cold legs, hot legs, and crossunder lines were modeled exactly, based on the plant layout. We found that, with the new model, we obtained a better resolution, but the overall results are similar as those obtained with the computation geometry based on Cartesian coordinates. 


\section{Introduction}

Recent studies of hypothetical pressurized water reactor (PWR) reactivity accidents have identified mechanisms by which the concentration of boron in the core-coolant moderator can be diluted.* One mechanism is to quickly pump a slug of cold unborated water through the core. In a recent analysis ${ }^{1}$ of the thermal mixing and boron dilution in a PWR with the COMMIX code, ${ }^{2-5}$ it was shown that a large reactivity insertion rate arises when the reactor coolant pumps (RCPs) start after a dilution in the pump suction line has occurred. However, the estimation was extremely conservative because the analysis used 1/4 of a reactor coolant system, which contains only one loop, and a symmetric condition was assumed for the other loops. This, in effect, assumed that all four loops are diluted and that all four RCPs start at the same time, an unlikely event. Therefore, to realistically assess the reactivity insertion in the reactor core due to boron dilution, an analysis with a four-loop reactor model is needed.

In this study, boron dilutions in a four-loop PWR were analyzed with COMMIX codes. The numerical model for the four-loop reactor system was an extension of that for the one-loop reactor system developed in Ref. 1. Two boron dilution scenarios were analyzed. In the first scenario, the plant is in cold shutdown and the reactor coolant system has just been filled after maintenance on the steam generators. To flush the air out of the steam generator tubes, an RCP is started. The process is commonly termed dynamic venting. ${ }^{* *}$ It is assumed that the other three pumps are not running, and the coolant in the pump suction line (crossunder line that connects the RCP suction to the outlet of the steam generator) is devoid of boron.

In the second scenario, it is assumed that all RCPs were recently tripped, and conditions for a restart have been met. The plant is at hot standby and the reactor coolant system has been heated to operating temperature after a long outage. Therefore, natural circulation does not exist because adequate decay heat is lacking. This condition will lead to stagnation of the coolant in the reactor system. During the trip, normal charging and letdown remained in service. Some fraction of the charging water is routed to the RCP seals. Under stagnant conditions, this water will flow downward into the crossunder line. Because the charging water is assumed to be devoid of boron, the dilution will take place in the crossunder pipe and in the RCP. When an RCP is started, with the coolant in the pump suction line completely diluted, a slug of the diluted coolant will be forced down the downcomer and subsequently through the reactor core.

In these two analyses, the transient flow and boron distribution, and, for the second analysis, the temperature distribution, are computed with the COMMLX code. Then the reactivity insertion due to the boron dilution and the density change is estimated.

${ }^{*}$ G. Lanik, U.S. Nuclear Regulatory Commission, private communication, 1991.

** D. Redden, Commonwealth Edison Company, private communication, 1992. 
Finally, a preliminary sensitivity study is performed to assess the accuracy of the numerical modeling of the geometry of the reactor vessel. In this study, several cylindrical and Cartesian coordinates are used to model the four-loop reactor coolant system. The reactor vessel is modeled as a cylindrical column, instead of the square column used in the above analyses, and all the pipe bends in the cold legs, hot legs, and crossunder lines are modeled exactly, based on the plant layout. However, because the new geometry package has not been implemented in the multispecies version of the COMMIX used in the above analyses, only a comparison of the temperature is available.

\section{Objectives}

The objectives of these analyses are to (1) realistically determine reactivity insertion due to coolant density change that is the result of thermal mixing between cold and hot water and (2) realistically analyze reactivity insertion due to boron dilution that is the result of mixing between unborated and borated water.

\section{Thermal Mixing and Boron Dilution in a Four-Loop PWR}

\subsection{Layout of Four-Loop Zion Reactor}

Figure 1 is a schematic representation of the layout of the Zion reactor coolant system. Figure 2 shows a side view of the plant layout, and Fig. 3 shows a top view of the plant layout. The layout of the internal structures of the Zion reactor vessel is illustrated in Fig. 4. A crosssectional view of the reactor vessel is shown in Fig. 5. A side view of the steam generator is shown in Fig. 6. Because our interest is in the primary coolant region, we need only model the 11.26-m-long cylindrical section and the lower hemispherical section for the steam generator.

At normal operation, inlet coolant flow from the cold leg enters the vessel inlet nozzles and proceeds down the annulus between the core barrel and the vessel wall, flows on both sides of the thermal shield, and then into the plenum at the bottom of the vessel. It then turns and flows up through the lower support plate, passes through the intermediate diffuser plate and through the lower core plate. After passing through the core, the coolant enters the area of the upper support structure and then flows generally radially to the outlet nozzles of the core barrel and directly through the vessel outlet nozzles to the hot leg.

A small amount of water also flows between the baffle plates and core barrel. Similarly, a small amount of the entering flow is directed into the vessel head plenum. Both of these flows eventually are directed into the upper support structure plenum and exit through the vessel outlet nozzles to the hot leg. 


\subsection{The Numerical Model}

\subsubsection{Geometry}

The numerical model of the four-loop Zion reactor coolant system is an extension of the oneloop model developed in Ref. 1. A schematic layout of the three-dimensional model for one loop is shown in Fig. 7. A top view of the model is shown in Fig. 8. The model partitions in the vertical planes $\mathrm{x}-\mathrm{z}$ (containing the inlet pipe or cold leg) and $\mathrm{y}-\mathrm{z}$ (containing the outlet pipe or hot leg), and in the horizontal plane $x-y$ are shown in Figs. 9-11, respectively. The model contains $20 \times 28$ horizontal partitions and 20 vertical partitions, for a total of 3334 computational cells.

The vertical partitions of the model shown in Fig. 12 correspond to the major components of the reactor vessel, as illustrated in Fig. 4. From Figs. 4 and 12 it is evident that most of the axial partitions match in a natural way. The axial height of the upper and lower domes of the reactor vessel were adjusted to ensure correct fluid volume.

The horizontal partitions of the model shown in Fig. 13 correspond to the major components of the reactor vessel in horizontal cross section, as shown in Fig. 5. Five components were considered: the inlet and outlet nozzles, the thermal shield, the core barrel, and the fuel assembly. The dimensions of the grids indicated in Fig. 13 were determined from the cross-sectional areas of the major components and from the areas between the components.

The vertical partitions for the steam generator are shown in Fig. 14. The fluid volume of the lower hemispherical dome seen in Fig. 7 was used to determine the axial height of that section.

All circular pipes, i.e., cold legs, hot legs, and crossunder lines, are modeled with rectangular cross sections. The cross-sectional areas of the modeled pipes are the same as those of the corresponding circular pipes.

\subsubsection{Volume and surface porosities}

To account for the surfaces and volumes occupied by the solid structures in the flow domain, the directional surface porosity used in the COMMIX code is defined by the equation

$$
\gamma_{x_{i}}=\frac{\text { Fluid flow area in direction } x_{i}}{\text { Total area in direction } x_{i}} \text {, }
$$

and the volume porosity is defined by

$$
\gamma_{v}=\frac{\text { Fluid volume of a cell }}{\text { Total volume of a cell }} \text {. }
$$


These parameters have been evaluated ${ }^{6}$ and are listed below

For the reactor vessel,

core: $\gamma_{\mathrm{V}}=0.514, \gamma_{\mathrm{Z}}=0.514$

core bypass: $\gamma_{\mathrm{v}}=0.05, \gamma_{\mathrm{z}}=0.05$.

lower plenum: $\gamma_{\mathrm{v}}=0.896, \gamma_{\mathrm{z}}=0.896, \gamma_{\mathrm{x}}=\gamma_{\mathrm{y}}=0.707$

upper plenum: $\gamma_{\mathrm{v}}=0.45, \gamma_{\mathrm{z}}=0.45, \gamma_{\mathrm{x}}=\gamma_{\mathrm{y}}=0.40$

top cover: $\gamma_{\mathrm{v}}=0.97, \gamma_{\mathrm{x}}=\gamma_{\mathrm{y}}=0.40$

For the steam generator,

$$
\gamma_{\mathrm{v}}=0.237, \gamma_{\mathrm{z}}=0.237
$$

\subsubsection{Flow resistances}

To account for the frictional resistance of the solid structures in the reactor vessel, a set of seven resistance correlations of the form

$$
\begin{aligned}
& f=a_{1} R^{b_{1}}+c_{1} \quad \text { (for laminar flow, } \operatorname{Re}<2300 \text { ) } \\
& =a_{t} \operatorname{Re}^{b_{t}}+c_{t} \quad \text { (for turbulent flow, } \operatorname{Re} \geq 2300 \text { ) }
\end{aligned}
$$

has been implemented in the model. In these correlations, a, b, and c are correlation coefficients, $\operatorname{Re}$ is the Reynolds number, and $\mathrm{f}$ is the friction factor. These correlations are used to compute frictional resistances in the $\mathrm{x}, \mathrm{y}$, and $\mathrm{z}$ directions in the reactor core, core bypass, upper plenum, upper plenum bypass, upper core plate, and in steam generators.

\subsubsection{Heat transfer to walls}

The core power and heat capacity of both the reactor and pipe walls were not considered in this model. However, they can easily be implemented. We believe these effects are of secondary importance in terms of assessing reactivity insertion due to thermal mixing and boron dilution. 


\subsubsection{Fluid physical properties}

In the analyses, boron and water are treated as separate components. Because the boron concentration in the system is very small, the thermophysical property of the boron/water mixture is essentially the same as that of unborated water.

\subsection{Initial Conditions}

For the isothermal-RCP-start or the dynamic venting calculation, the reactor coolant system was initially filled with borated water at $25^{\circ} \mathrm{C}, 155$ bars, and zero velocity. A boron concentration of $2200 \mathrm{ppm}$, corresponding to a mass fraction of $1.32 \times 10^{-3}$, was uniformly distributed in the entire reactor coolant system.

For the hot-RCP-start calculation, the reactor coolant system was initially filled with borated water at $297^{\circ} \mathrm{C}, 155$ bars, and zero velocity. A boron concentration of $1200 \mathrm{ppm}$, corresponding to a mass fraction of $7.209 \times 10^{-4}$, was uniformly distributed in the entire reactor coolant system.

\subsection{Boundary Conditions}

\subsubsection{Inlet}

The inlet is at the suction side of the RCP in the second loop, as shown in Fig. 8. The inlet conditions for the two calculations, the isothermal- and the hot-RCP-start, are listed below.

(1) In the isothermal-RCP-start calculation, we assume that a slug of unborated water, initially in the crossunder pipe and half the volume of the RCP, is pumped into the cold leg in Loop 2. The temperature of the inlet water is the same as that in the system. The volume of the slug is $4.87 \mathrm{~m}^{3}\left(168.9 \mathrm{ft}^{3}\right)$, and the increase of pump flow rate with time* is shown in Fig. 15 . The pump reaches its normal operating flow rate of $130,000 \mathrm{gpm}$ in $25 \mathrm{~s}$. From Fig. 15, it can be determined that the slug of cold unborated water will pass through the pump in $8 \mathrm{~s}$. After $8 \mathrm{~s}$, the boron concentration in the inlet water becomes normal (2200 ppm).

(2) In the hot-RCP-start calculation, the temperature of the inlet slug is low, i.e. $25^{\circ} \mathrm{C}$. The unborated slug has the same volume as that in the above calculation. After the slug passes through the pump, boron concentration at the inlet returns to $1200 \mathrm{ppm}$, and the temperature to $297^{\circ} \mathrm{C}$, which is the initial temperature of the system.

\footnotetext{
* D. Redden, Commonwealth Edison Company, private communication, 1992.
} 
It should be noted that in these two calculations, the slug water is assumed only in Loop 2. There is no boron dilution in the other three loops and those RCPs are assumed open for coolant pass through.

\subsubsection{Outlet}

The outlet is located at the exit side of the steam generator in the second loop, as shown in Fig. 8. The velocity and temperature gradients at the outlet were set to zero, i.e.,

$$
\frac{\partial \mathrm{u}_{\mathrm{z}}}{\partial \mathrm{z}}=0, \quad \frac{\partial \mathrm{T}}{\partial \mathrm{z}}=0
$$

\subsubsection{Solid Walls}

Velocity and heat flux were zero on the surfaces of all solid walls.

\subsection{Results}

\subsubsection{Analysis of Boron Dilution under Isothermal- RCP-Start Conditions}

After the start of the RCP, the slug of unborated water, initially in the crossunder pipe, will be forced through the reactor core. The pump flow rate increases with time, as shown in Fig. 15, and it takes $8 \mathrm{~s}$ to pump the slug into the cold leg. The slug in the crossunder pipe has a volume $\sim 1.4$ times that of the cold leg.

The transient of the boron dilution in the four-loop reactor coolant system is simulated for $35 \mathrm{~s}$. At $35 \mathrm{~s}$ into the transient, most of the slug has been pushed out of the reactor vessel. Figures 16a-d show the velocity distributions in the cold legs (Loops 1 and 2) and reactor vessel at $6,9,13$, and $18 \mathrm{~s}$ into the transient, respectively. At 6 and $9 \mathrm{~s}$ into the transient, the inlet velocity is lower. Water in the reactor core and lower plenum is simply pushed upward with nonuniform velocity distribution. At $13 \mathrm{~s}$ into the transient, a small recirculation can be observed at the left corner in the lower plenum, Fig. 16c. Flow recirculation commonly occurs at high flow rates, or at high Reynolds numbers. At later times, the magnitude of the recirculating velocity increases, as shown in Fig. 16d for $18 \mathrm{~s}$ into the transient. This recirculation will improve the boron mixing in the reactor lower plenum.

The velocity distributions in the downcomer are shown in Figs. $17 \mathrm{a}$ and $\mathrm{b}$ at times 9 and $13 \mathrm{~s}$ into the transient, respectively. The vertical plane indicated by $\mathrm{I}=5$ is the outer layer between the thermal shield and the reactor vessel wall, and that indicated by $I=6$ is the inner layer between the 
thermal shield and the core barrel. It is seen that the inlet water flows mainly in the inner layer of the downcomer, because of the large momentum of the inlet flow. Some flow circulation also occurs in both the inner and outer layers of the downcomer.

Figures $18 \mathrm{a}$ and $\mathrm{b}$ show the velocity distribution in the reactor vessel, hot legs, and steam generators (Loops 2 and 3) at 9 and $12 \mathrm{~s}$ into the transient, respectively. At $12 \mathrm{~s}$ into the transient, Fig. 18b, recirculations appear at the two corners in the lower plenum. These recirculations also exist at later times. In Loop 2, water flows from the reactor vessel to the hot leg and then to the steam generator. In Loop 3 (also in Loops 1 and 4), however, the flow is reversed. This reversal occurs because only the RCP in Loop 2 is running, and the other loops become bypass routes for the inlet flow. The bypasses in Loops 1,3, and 4 can be clearly seen in Fig. 19. The flow rates from the cold legs into the reactor vessel are plotted in Fig. 20. The bypass flow reduces the volume of the slug flowing through the core and, therefore, mitigates the boron dilution in the core. The total bypass flow rate accounts for $20.6 \%$ of the inlet flow rate. It should be pointed out that the bypass flow rates depend on the modeling of the flow resistance in the steam generator and the pipes.

Figures 21a-d show the distribution of boron concentration in the cold legs and the reactor vessel at 7,9,14, and $20 \mathrm{~s}$ into the transient, respectively. At $7 \mathrm{~s}$ into the transient, boron dilution takes place only in the cold leg. The unborated slug is mainly in the downcomer at $9 \mathrm{~s}$, in the lower plenum at $14 \mathrm{~s}$, and in the core at $20 \mathrm{~s}$ into the transient. From an examination of the boron distributions in this vertical section, it is evident that little boron mixing occurs in the cold leg (Figs. $21 \mathrm{a}-\mathrm{b}$ ). This finding was also observed in a previous analysis. ${ }^{1}$

Strong boron mixing occurs in the downcomer. For instance, at $14 \mathrm{~s}$ into the transient, Fig. $21 \mathrm{c}$, the lowest boron concentration in the lower plenum is $1849 \mathrm{ppm}$. Therefore, after the downcomer, the boron concentration in the slug has recovered to $\approx 84 \%$ of the initial 2000 -ppm boron concentration of the system. The strong mixing is due partially to the large volume of the downcomer and partially to the flow circulations in the downcomer. Additional mixing takes place in the lower plenum and in the reactor core, resulting in an increase of the minimum boron concentration to $2006 \mathrm{ppm}$ in the core at $20 \mathrm{~s}$ into the transient, Fig. 21d. Figures $22 \mathrm{a}-\mathrm{d}$ show the distribution of the boron concentration in the four levels of the core at $20 \mathrm{~s}$ into the transient. The figures show that the boron concentration is not uniform at each level in the core. The travel of the slug through the core is shown in Figs. $23 \mathrm{a}$-d, which show that the slug enters the core at $\approx 16 \mathrm{~s}$ and exits the core at $\approx 22 \mathrm{~s}$ into the transient.

Although the boron concentration is not uniform, a mean boron concentration at each horizontal level is helpful in estimating the overall boron dilution in the reactor vessel. The mean boron concentration as a function of vessel height $\mathrm{z}$ is shown in Fig. 24 for the transient at 16, 18, 20 , and 22 s. Figure 24 also identifies the location of the slug and shows that the mean boron 
concentration in the core is always higher than $2046 \mathrm{ppm}$. Therefore, the mean boron concentration in the core is reduced by $<154 \mathrm{ppm}$, or $7 \%$, which indicates moderate mixing in the downcomer and lower plenum. In the most conservative estimation, by assuming no mixing, the boron concentration in the core would have been reduced to zero when the slug entered the core. The variation of mean boron concentration in the four levels of the core as a function of time is plotted in Fig. 25. At any location in the core, the rate of change of boron concentration can be deduced from this figure. The local minimum boron concentration in the core is much lower than the mean. The local minimum and mean boron concentrations in the core are compared in Fig. 26.

If we denote the boron concentration as $\mathrm{B}$, the mean rate of boron concentration change $(\Delta \mathrm{B} / \Delta \mathrm{t})$ can be obtained from Fig. 25. The reactivity insertion rate due to boron concentration change $\Delta K_{B} / \Delta t$ as a function of time is obtained by multiplying $\Delta B / \Delta t$ with the reactivity coefficient $\partial \mathrm{K}_{\mathrm{B}} / \partial \mathrm{B}$. For the condition of this analysis, $\partial \mathrm{K}_{\mathrm{B}} / \partial \mathrm{B}$ is $10.2 \times 10^{-5} \mathrm{ppm}^{-1}$. The variation of the reactivity insertion rate $\Delta \mathrm{K} / \Delta \mathrm{t}\left(=\Delta \mathrm{K}_{\mathrm{B}} / \Delta \mathrm{t}\right)$ with time is plotted in Fig. 27 at four levels in the core. It is seen that the reactivity insertion rate in the core increases rapidly after $12 \mathrm{~s}$ into the transient and reaches a maximum of $\approx 0.0043 \mathrm{~s}^{-1}\left(1 \mathrm{pcm}=10^{-5} \mathrm{~s}^{-1}\right)$, or $\approx \$ 0.96 / \mathrm{s}$ with the conversion factor $\beta=0.0045$, at $16.5 \mathrm{~s}$ into the transient. The total reactivity $\mathrm{K}$ is the integration of $\Delta \mathrm{K} / \Delta \mathrm{t}$ with time and it is plotted in Fig. 28. The maximum reactivity is $\approx 0.016$ (or $\approx \$ 3.5$ ), which is high. Because of the nonuniformity of the boron distribution, the maximum local reactivity rate and reactivity are even higher, by 50 and $44.5 \%$, respectively. The local reactivity rate and reactivity represent the local power density change (or local temperature change with respect to time) and local power density (or local temperature), respectively.

\subsubsection{Analysis of Thermal Mixing and Boron Dilution under Hot-RCP-Start Conditions}

The transient of the thermal mixing and boron dilution in the reactor coolant system is simulated for $35 \mathrm{~s}$. Figures $29 \mathrm{a}$-d show the velocity distributions in the cold legs (Loops 1 and 2) and reactor vessel at $6,9,13$, and $18 \mathrm{~s}$ into the transient, respectively. When we compare Figs. 29a-d with Figs. 16a-d, we see that the overall velocity distributions are similar at corresponding times. However, because the temperature of the slug is much lower than that of the water in the reactor vessel, local velocities may change because of the buoyancy effect. The small recirculation at the left corner in the lower plenum now appears earlier, at $9 \mathrm{~s}$ into the transient (compare Fig. $29 \mathrm{~b}$ with Fig. 16c, in the isothermal calculation). This is so because the velocity of the local flow in the downcomer is greater. The increase of the vertical flow velocity due to a buoyancy effect can be seen clearly in Figs. 30a and b, as compared with Figs. 17a and b. As a result, the cold unborated inlet slug will not mix well in the downcomer. From Fig. 29c, at $13 \mathrm{~s}$ into the transient,

\footnotetext{
${ }^{*}$ S. Ahmend, Commonwealth Edison Company, private communication, 1992.
} 
the horizontal flow at the bottom of the lower plenum reaches the right wall. Therefore, the slug is pushed to the right corner because the slug is in the lower plenum at this time. Figures $31 \mathrm{a}$ and $\mathrm{b}$ show the velocity distribution in the reactor vessel, hot legs, and steam generators (Loops 2 and 3 ) at 9 and $12 \mathrm{~s}$ into the transient, respectively. The horizontal flow in all loops is shown in Fig. 32. The velocity distributions in Figs. 31a and b and 32 are similar to those in Figs. 18a and b and 19, respectively. The flow rates from the cold legs into the reactor vessel are plotted in Fig. 33 . The decrease of the slope immediately after $8 \mathrm{~s}$ into the transient is due to the decrease of water density at a high temperature. The total flow bypassed through Loops 1,3 , and 4 is $20.5 \%$ of the inlet flow in Loop 2.

Calculated temperature distributions in the reactor vessel and cold legs are shown in Figs. $34 \mathrm{a}-\mathrm{d}$ for the transient at 7,9, 14, and $20 \mathrm{~s}$, respectively. The cold slug is mainly seen in the cold leg at $7 \mathrm{~s}$, in the downcomer at $9 \mathrm{~s}$, in the lower plenum at $14 \mathrm{~s}$, and in the core at $20 \mathrm{~s}$ into the transient. The temperature contours are plotted in Figs. 35a-d for 16, 18, 20, and $22 \mathrm{~s}$ into the transient. Near the slug front, the isotherms are approximately horizontal, as observed in Figs. $35 \mathrm{a}$ and $35 \mathrm{~b}$, indicating good mixing of the front portion of the slug in the lower plenum. Before the remainder of the slug is mixed, the larger inlet flow pushes it to the right corner in the lower plenum, as shown in Figs. 29c, 34c, and 35a. The slug then rises at the right side, as shown in Figs. 35b-d. The mean and the local minimum temperatures at the four horizontal levels in the reactor core are plotted against time in Fig. 36. Because the temperature change will cause water density changes that affect reactivity, Fig. 36 may be used to evaluate the reactivity rate due to density change.

Figures $37 \mathrm{a}-\mathrm{d}$ show the distribution of boron concentration in the cold legs and the reactor vessel at 7,9,14, and $20 \mathrm{~s}$ into the transient, respectively. The locations of the cold unborated slugs at these times are approximately same as those in the isothermal calculation (Fig. 21), except that the slug is pushed to the right corner in the lower plenum in this calculation. The slug does not mix well with the vessel water in the downcomer because of the buoyancy effect, and in the lower plenum because of the short residence time. The minimum boron concentration in the lower plenum at $14 \mathrm{~s}$ into the transient, Fig. $37 \mathrm{c}$, is $902 \mathrm{ppm}, \approx 75 \%$ of the initial boron concentration, compared with $84 \%$ in the isothermal calculation. Figures $38 \mathrm{a}-\mathrm{d}$ show the distributions of the boron concentration in the four levels of the core at $20 \mathrm{~s}$ into the transient. The travel of the slug through the core is shown in Figs. 39a-d. The mean boron concentration as a function of vessel height $\mathrm{z}$ is shown in Fig. 40 for the transient at 16, 18,20, and $22 \mathrm{~s}$. The mean boron concentration in the core is always $>1025 \mathrm{ppm}$. The maximum decrease of the mean boron concentration in the core is $14.6 \%$, compared with $7 \%$ in the isothermal calculation. Or, from the view point of boron mixing of the slug that was initially unborated, its boron concentration reached only $85.4 \%$ of the initial boron concentration of the system in this calculation, whereas, in the isothermal case, it reached $93 \%$. Therefore, the boron mixing for the slug in this calculation is 
worse than that in the isothermal calculation. The variation of the mean and local minimum boron concentrations in the four levels of the core as a function of time is plotted in Fig. 41.

The total rate of reactivity insertion $(\Delta \mathrm{K} / \Delta \mathrm{t})$ is the sum of that due to the change in boron concentration $\left(\Delta \mathrm{K}_{\mathrm{B}} / \Delta \mathrm{t}\right)$ and that due to change in coolant density $\left(\Delta \mathrm{K}_{\rho} / \Delta \mathrm{t}\right)$. The reactivity rate due to boron concentration change $\Delta \mathrm{K}_{\mathrm{B}} / \Delta \mathrm{t}$ is obtained by multiplying the reactivity coefficient $\partial \mathrm{K}_{\mathrm{B}} / \partial \mathrm{B}$ by $\Delta \mathrm{B} / \Delta \mathrm{t}$ determined from Fig. 41 . The reactivity rate due to density change $\Delta \mathrm{K}_{\rho} / \Delta \mathrm{t}$ is the product of density change per second $(\Delta \rho / \Delta t)$ multiplied by the reactivity coefficient due to density change $\left(\partial \mathrm{K}_{\rho} / \partial \rho\right)$. For the condition of this analysis, $\partial \mathrm{K}_{\rho} / \partial \rho=31.15 \times 10^{-5} \mathrm{~m}^{3} / \mathrm{kg}$ (or $\left.0.00499 \mathrm{ft}^{3} / \mathrm{lb}\right){ }^{*}$ The rate of change in coolant density $(\Delta \rho / \Delta t)$ can be obtained by multiplying $\Delta T / \Delta t$, determined from Fig. 36 , by $\partial \rho / \partial \mathrm{T}$, which is $-1.61 \mathrm{~kg} / \mathrm{m}^{3} /{ }^{\circ} \mathrm{C}$ for water. The variation of the total reactivity insertion rate with time $\Delta \mathrm{K} / \Delta \mathrm{t}$ is plotted in Fig. 42 at four levels in the core. The plots in Fig. 42 show that the reactivity insertion rate in the core increases rapidly after $12 \mathrm{~s}$ into the transient and reaches a maximum of $\approx 0.012 \mathrm{~s}^{-1}$ (or $\approx \$ 2.7 / \mathrm{s}$ ) at $14.5 \mathrm{~s}$ into the transient. The variation of total reactivity $\mathrm{K}$ with time is plotted in Fig. 43 . The maximum reactivity is $\approx 0.035$ (or $\approx \$ 7.7$ ), which is very high. Again, because of the nonuniformity of boron distribution, the maximum local reactivity rate and reactivity are even higher, by $20.5 \%$ and $24.3 \%$, respectively. The local reactivity rate and reactivity represent the local power density change (or local temperature change with respect to time) and local power density (or local temperature), respectively.

\section{Sensitivity Study for Modeling Geometry of Reactor Vessel}

At present, the COMMIX modeling of a complete system may use one of the two coordinate systems, Cartesian or cylindrical. Any component in the system whose geometry surface is not coincident with the coordinate planes must be approximated. For the boron dilution calculations in the four-loop Zion reactor coolant system described in the previous section, the geometry of all components in the system is modeled with Cartesian coordinates, Figs. 7 and 8. By comparing the modeled geometry with the real geometry of the reactor coolant system, shown in Figs. 2 and 3, it is evident that we have considerably simplified the geometry of the reactor vessel, steam generators, and the arrangement of the piping. To assess the accuracy of the calculations and to improve the modeling geometry, we developed for the COMMIX code a new geometry capability, the multicoordinate model, which makes use of combined Cartesian and cylindrical coordinates for various components in a system so that the geometries of the components can be closely matched. With the multicoordinate model, only the temperature variation in the reactor vessel due to an inlet cold slug is calculated, because the model was implemented only in COMMIX-1C, which can only perform single-phase calculations.

\footnotetext{
${ }^{*}$ S. Ahmend, Commonwealth Edison Company, private communication, 1992.
} 
The computational geometry obtained with the multicoordinate model for the four-loop Zion reactor coolant system is shown is Fig. 44. Because the geometry of the steam generators is not important for the analysis of boron dilution in the reactor core, a simplified Cartesian system was used for the steam generators. However, it is easy to model the steam generators by cylindrical geometry. Twenty coordinate systems are used in this analysis. Figure 45 shows the coordinates for one loop of the reactor system. The first (cylindrical) coordinate $\left(\mathrm{x}_{1}, \mathrm{y}_{1}, \mathrm{z}_{1}\right)$ is used to model the cylindrical reactor vessel. A detailed horizontal partition of the reactor vessel is shown in Fig. 46. Five coordinates are used to model the hot leg, steam generator, crossunder pipe, and cold leg. The pipe elbows are explicitly modeled with the cylindrical coordinate systems. Note that the inlet and outlet are now in the Loop 4.

The initial and boundary conditions are the same as those for the hot-RCP-start calculation, except that there is no boron in the system. The transient calculation was carried out for $35 \mathrm{~s}$. Figures $47 \mathrm{a}$-d show the velocity distributions in the reactor vessel at $6,9,13$, and $18 \mathrm{~s}$ into the transient, on the vertical plane passing through the reactor inlets from Cold Legs 2 and 4, corresponding to $\mathrm{J}=8$ and 20 , respectively. Compared with Figs. 29a-d, the overall velocity distributions are similar at those times. Because of the buoyancy effect, the flow is dominantly downward in the downcomer at $9 \mathrm{~s}$ into the transient, Fig. 48a; however, because of the smoothed curve around the circumference of the downcomer, as the buoyancy effect diminishes with time, a large circulation exists over the entire downcomer, as seen in Fig. 48b. As a result, flow may go upward immediately below the reactor inlet of Loop 4, as shown in Figs. 47d and 48b. The flow rates from the cold legs into the reactor vessel are plotted in Fig. 49. Compared with the calculation obtained by Cartesian modeling of the reactor geometry, the total bypass flow changed from $20.5 \%$ to $24.2 \%$ in this calculation.

Calculated temperature distributions in the reactor vessel on the vertical plane indicated by $\mathbf{J}=$ 8 and $\mathrm{J}=20$ are shown in Figs. 50a-d for the transient at 7, 9, 14, and $20 \mathrm{~s}$, respectively. The temperature contours are plotted in Figs. 51a-d for 16,18, 20, and $22 \mathrm{~s}$ into the transient, respectively. These results show similar features of thermal mixing in the vessel when compared to counterpart results in Figs. 34a-d and 35a-d, respectively. Mean temperature as a function of vessel height $\mathrm{z}$ is shown in Fig. 52 for the transient at 16, 18, 20, and $22 \mathrm{~s}$. The mean temperatures at four horizontal levels in the reactor core are plotted against time in Fig. 53. From Figs. 52 and 53 it is evident that the use of cylindrical coordinates in the modeling of the reactor geometry gives better resolution of the flow and temperature. However, based on this preliminary comparison, the difference is relatively small. Only the initiating phase of the multicoordinate model is complete. Additional development work and a thorough check of this model were not performed because of the lack of funding for this project. 


\section{Discussion and Conclusions}

1. Transient calculations for thermal mixing and boron dilution in a four-loop PWR coolant system were performed with the COMMIX code. In the isothermal-RCP-start calculation, or the dynamic venting simulation, large flow recirculations were found in the downcomer and small flow recirculations were found in the lower plenum of the reactor vessel. These flow recirculations improved the boron mixing of the unborated inlet slug with the coolant in the reactor vessel. As a result, there was strong boron mixing in the downcomer and moderate boron mixing in the lower plenum and reactor core. As the slug passed through the downcomer, its boron concentration recovered from 0 to $84 \%$ of the system boron concentration. Additional boron mixing took place in the lower plenum and reactor core. Furthermore, the bypass of the inlet flow through the other three loops (reverse flows) reduced the volume of the slug passing through the core. The total bypass accounted for $20.6 \%$ of the inlet flow rate. The slug was in the core at $\approx 20 \mathrm{~s}$ into the transient. The mean reactivity insertion rate $(\Delta \mathrm{K} / \Delta \mathrm{t})$ increased quickly after $12 \mathrm{~s}$ into the transient and reached a maximum of $\approx 0.0043 \mathrm{~s}^{-1}$, or $\approx \$ 0.96 / \mathrm{s}$, at $16.5 \mathrm{~s}$ into the transient. The maximum reactivity $\mathrm{K}$ was $\approx 0.016$ (or $\approx \$ 3.5$ ) at $19 \mathrm{~s}$ into the transient, which is high. However, the maximum local reactivity rate and reactivity are even higher, by $50 \%$ and $44.5 \%$ respectively, because of the nonuniformity of the boron distribution in the core.

2. In the hot-RCP-start calculation, boron mixing was not as good as that in the isothermal calculation. Although large flow recirculations existed in the downcomer, the flow was dominantly downward as the cold slug was passing through the downcomer, which was due to the buoyancy effect. As the slug passed through the downcomer, its boron concentration recovered from 0 to $75 \%$ of the system boron. It was also found that the cold slug does not have enough time to mix with the vessel coolant in the lower plenum. It was pushed to the opposite side of the inlet loop by the large inlet flow rate. Moderate thermal and boron mixing occurs in the lower plenum and in the reactor core. The total bypass accounted for $20.5 \%$ of the inlet flow rate. The mean reactivity insertion rate $(\Delta \mathrm{K} / \Delta \mathrm{t})$ due to both the coolant density change and boron concentration change also increased quickly after $12 \mathrm{~s}$ into the transient and reached a maximum of $\approx 0.012 \mathrm{~s}^{-1}$, or $\approx \$ 2.7 / \mathrm{s}$, at $14.5 \mathrm{~s}$ into the transient. The maximum reactivity $\mathrm{K}$ was $\approx 0.035$, or $\approx \$ 7.7$, at $17 \mathrm{~s}$ into the transient, which is very high. Again, it should be noted that the maximum local reactivity rate and reactivity are even higher, by $20.5 \%$ and $24.3 \%$, respectively, because of the nonuniformity of temperature and boron concentration distributions in the core.

3. The accuracy of the modeling of the reactor coolant system geometry was assessed with a newly developed multicoordinate model. With this new model, the reactor vessel and the piping system are better represented in the computation partitions. In the calculation under hot-RCP-start conditions, better resolution was obtained, but the overall results are similar to those obtained with the computation geometry from Cartesian coordinate partitioning, 
which is described in the previous paragraph. However, it would be essential to use the new model to realistically determine the detailed velocity, boron concentration, and temperature distributions in the reactor vessel and especially to find the location of maximum local reactivity (or local temperature), which may cause structure failure.

4. The results presented here appear reasonable. To enhance the credibility of our prediction, we strongly recommend validation of the COMMIX code with pertinent experimental boron dilution data. Thus, the issue of boron dilution can be resolved with confidence.

\section{Acknowledgments}

The authors gratefully acknowledge the encouragement and support of Gene Trager, George Lanik, and Jack Rosenthal of the Office for Analysis and Evaluation of Operational Data, U.S. Nuclear Regulatory Commission, and thank K. Ramsden, D. Redden, and S. Ahmend of Commonwealth Edison Company for useful discussions.

\section{References}

1. J. G. Sun, and W. T. Sha, Analysis of Thermal Mixing and Boron Dilution in a PWR, NUREG/CR-5822, Argonne National Laboratory Report ANL-91/43 (1993).

2. W. T. Sha, H. M. Domanus, R. C. Schmitt, J. J. Oras, and E. I. H. Lin, COMMIX-1: A Three-Dimensional Transient Single-Phase Computer Program for Thermal-Hydraulic Analysis, NUREG/CR-0785, Argonne National Laboratory Report ANL-77-96 (Sept. 1978).

3. H. M. Domanus, R. C. Schmitt, W. T. Sha, and V. L. Shah, COMMIX-1A: A ThreeDimensional Transient Single-Phase Computer Program for Thermal-Hydraulic Analysis of Single and Multicomponent Systems: Vol. I User's Manual, and Vol. II Assessment and Verification, NUREG/CR-2896, Argonne National Laboratory Report ANL-82-25 (Dec. 1983).

4. F. F. Chen, H. M. Domanus, C. C. Miao, R. C. Schmitt, V. L. Shah, and W. T. Sha, COMMIX-1B: A Three-Dimensional Transient Single-Phase Computer Program for Thermal-Hydraulic Analysis of Single and Multicomponent Systems: Vol. I Equations and Numerics, and Vol. II User's Manual, NUREG/CR-4348, Argonne National Laboratory Report ANL-85-42 (Sept. 1985). 
5. H. M. Domanus, Y. S. Cha, T. H. Chien, R. C. Schmitt, and W. T. Sha, COMMIX-1C: A Three-Dimensional Transient Single-Phase Computer Program for Thermal-Hydraulic Analysis of Single and Multicomponent Engineering Systems: Vol. I Equations and Numerics, and Vol. II User's Manual, NUREG/CR-5649, Argonne National Laboratory Report ANL-90/33 (Nov. 1990).

6. V. L. Shah, Thermal Hydraulic Simulation of Zion Power Plant under Normal Operating Conditions, Argonne National Laboratory Report ANL/ATHRP-36 (1985). 


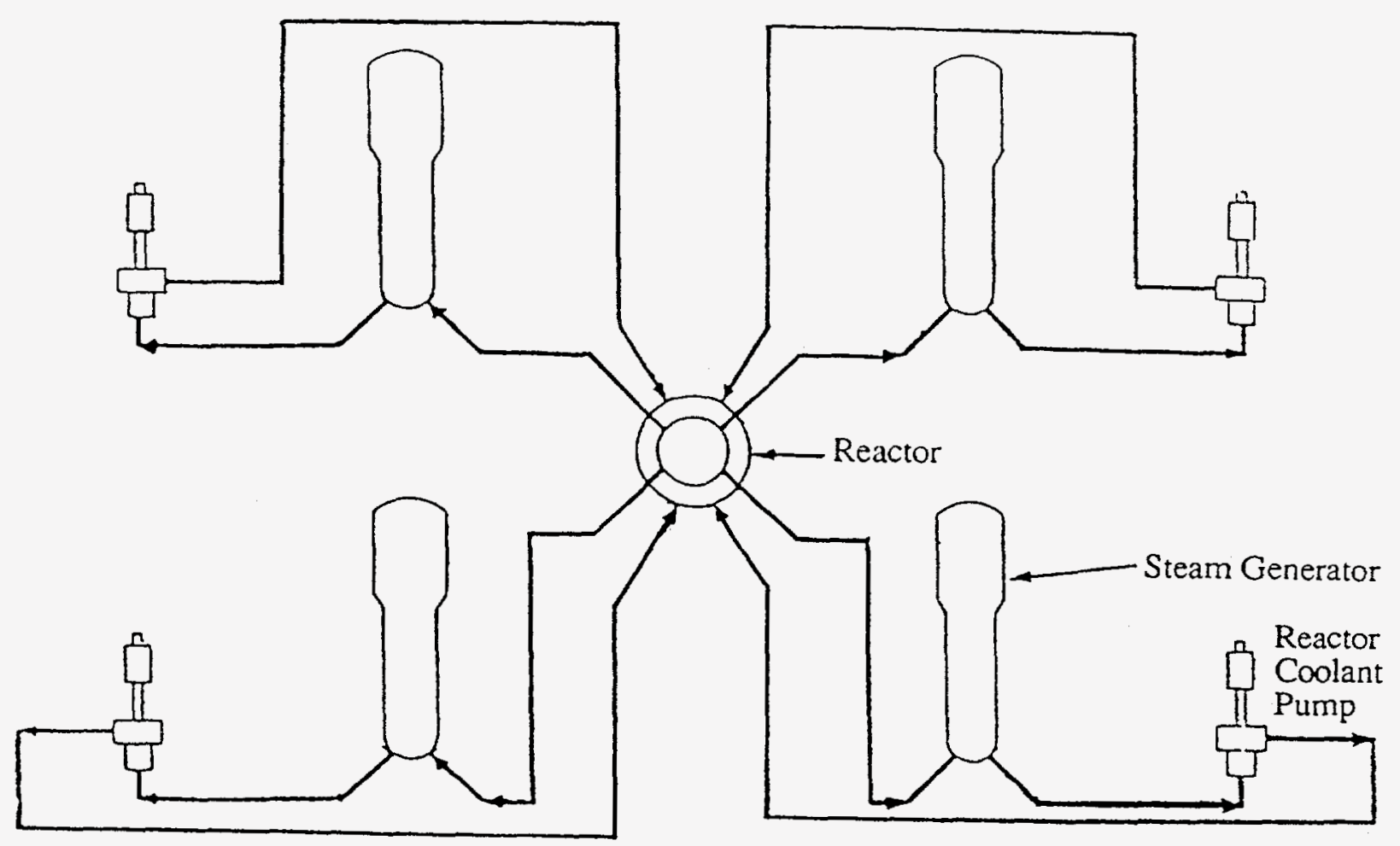

Fig. 1. Schematic representation of Zion reactor coolant system 


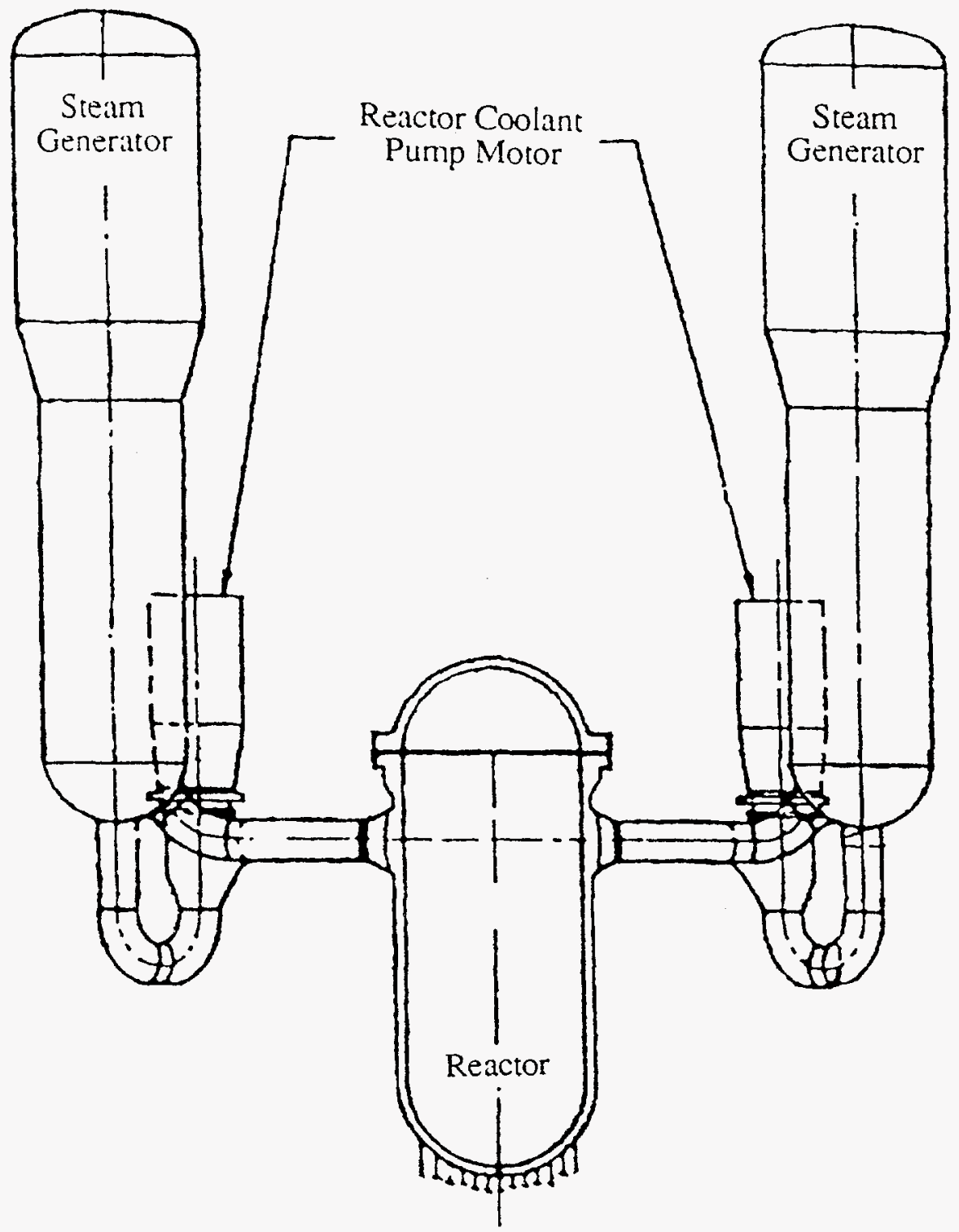

Fig. 2. Side view of layout of Zion reactor coolant loops 


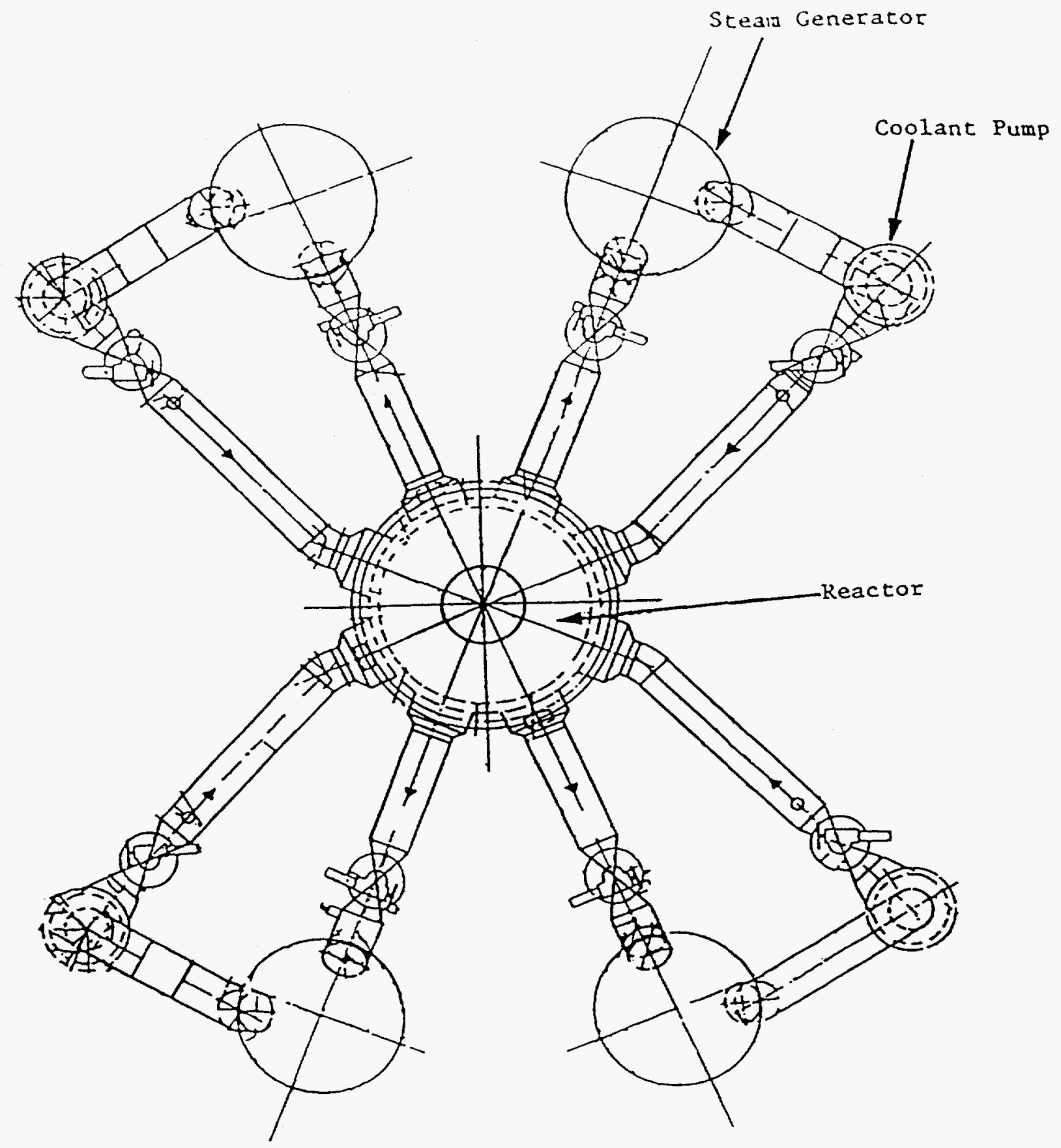

Fig. 3. Top view of layout of Zion reactor coolant loops 


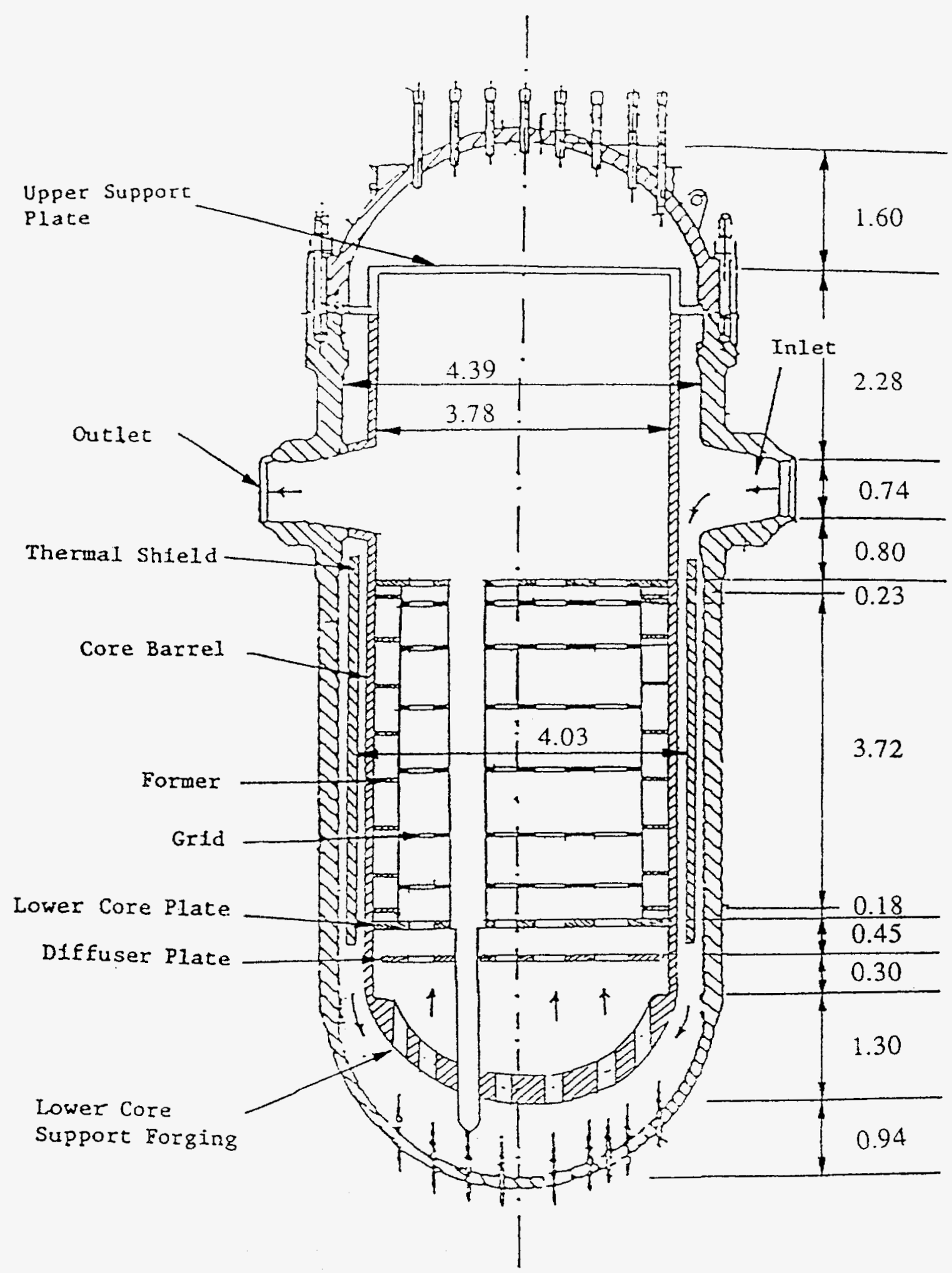

Fig. 4. Schematic layout of internal structures of Zion reactor

(Dimensions in meters) 


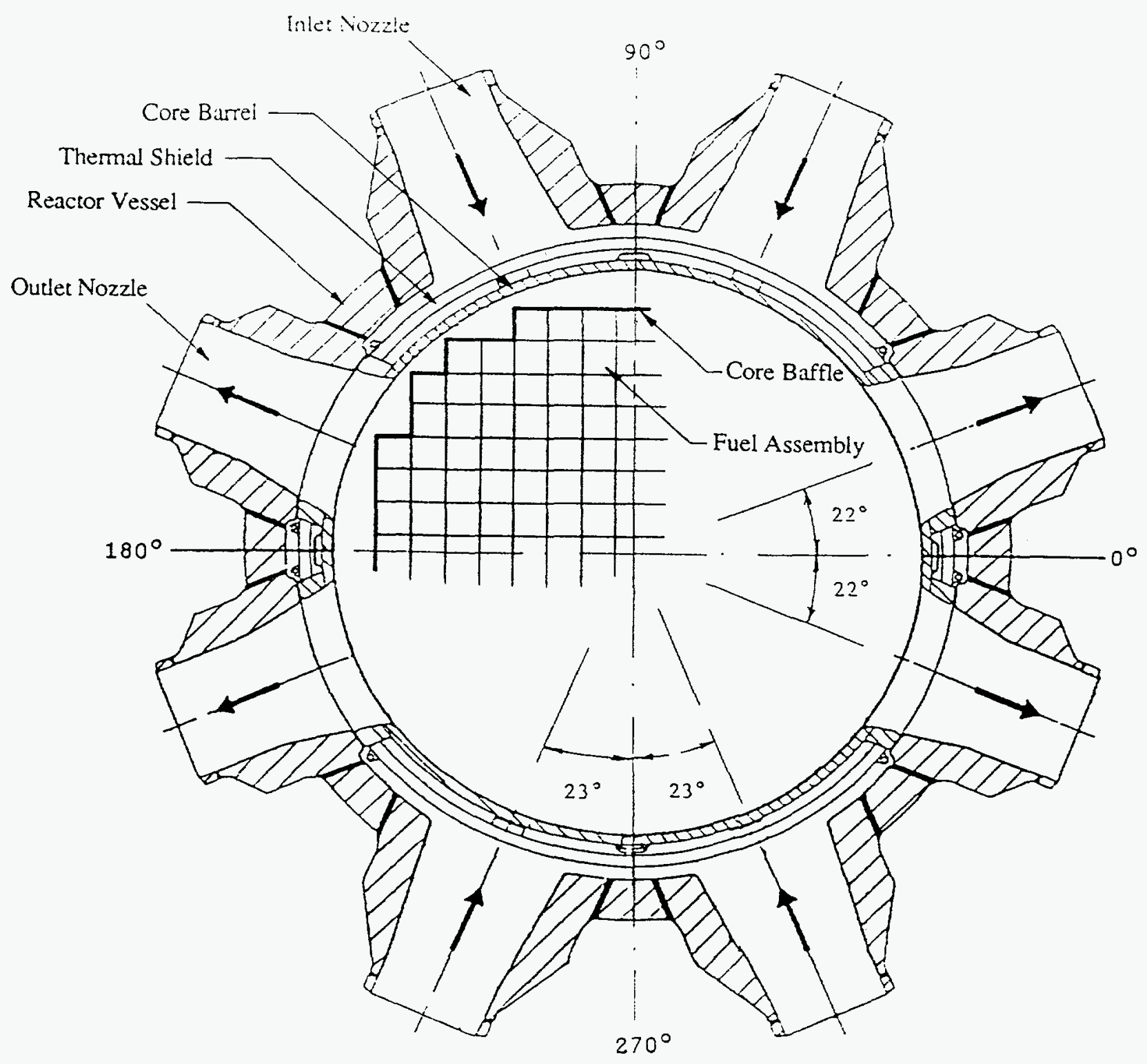

Fig. 5. Cross section of reactor vessel 


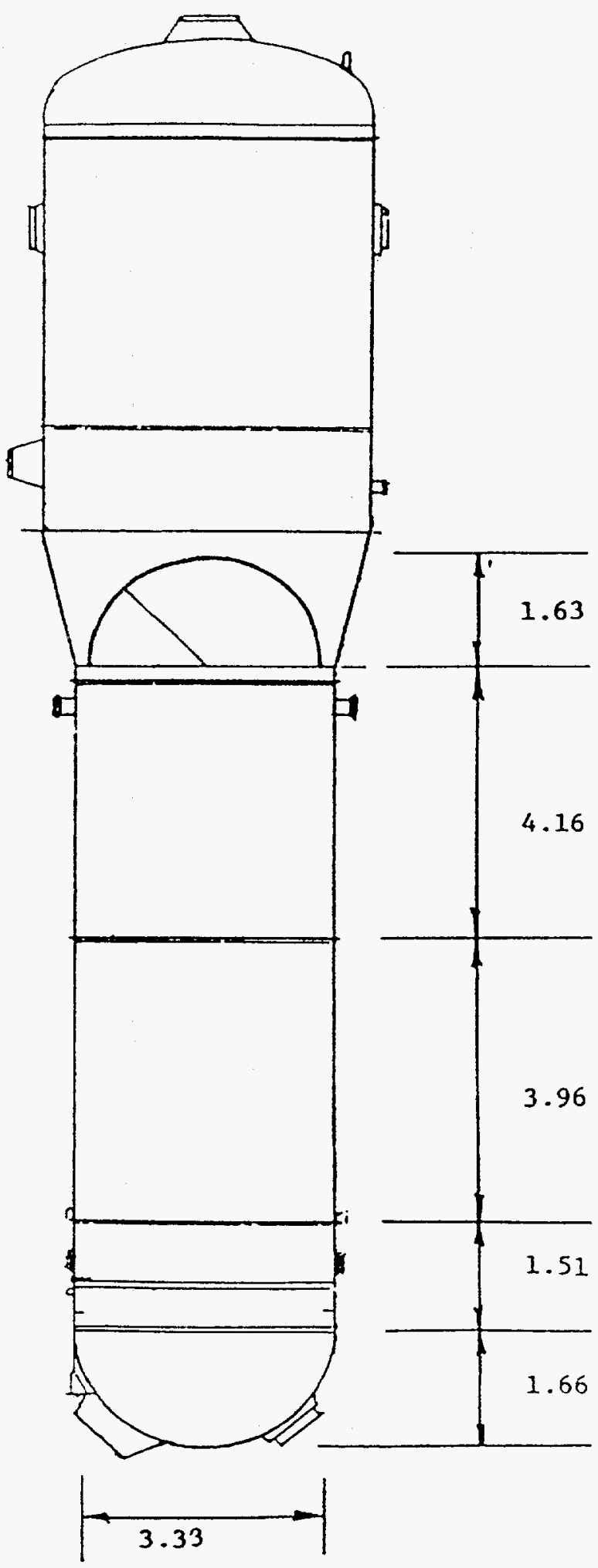

Fig. 6. Side view of steam generator (Dimensions in meters) 


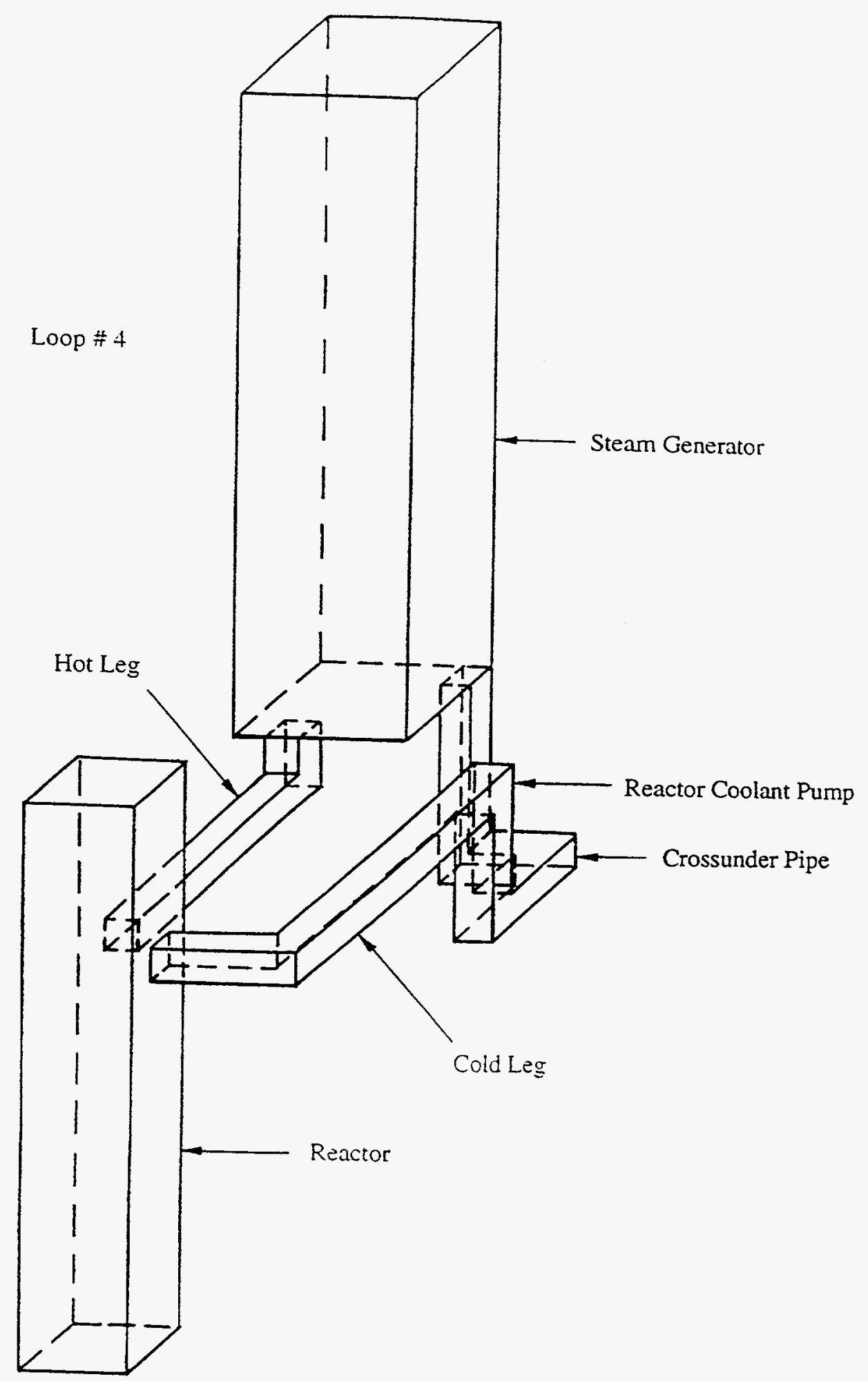

Fig. 7. Schematic layout of three-dimensional model for Zion reactor Loop 4 


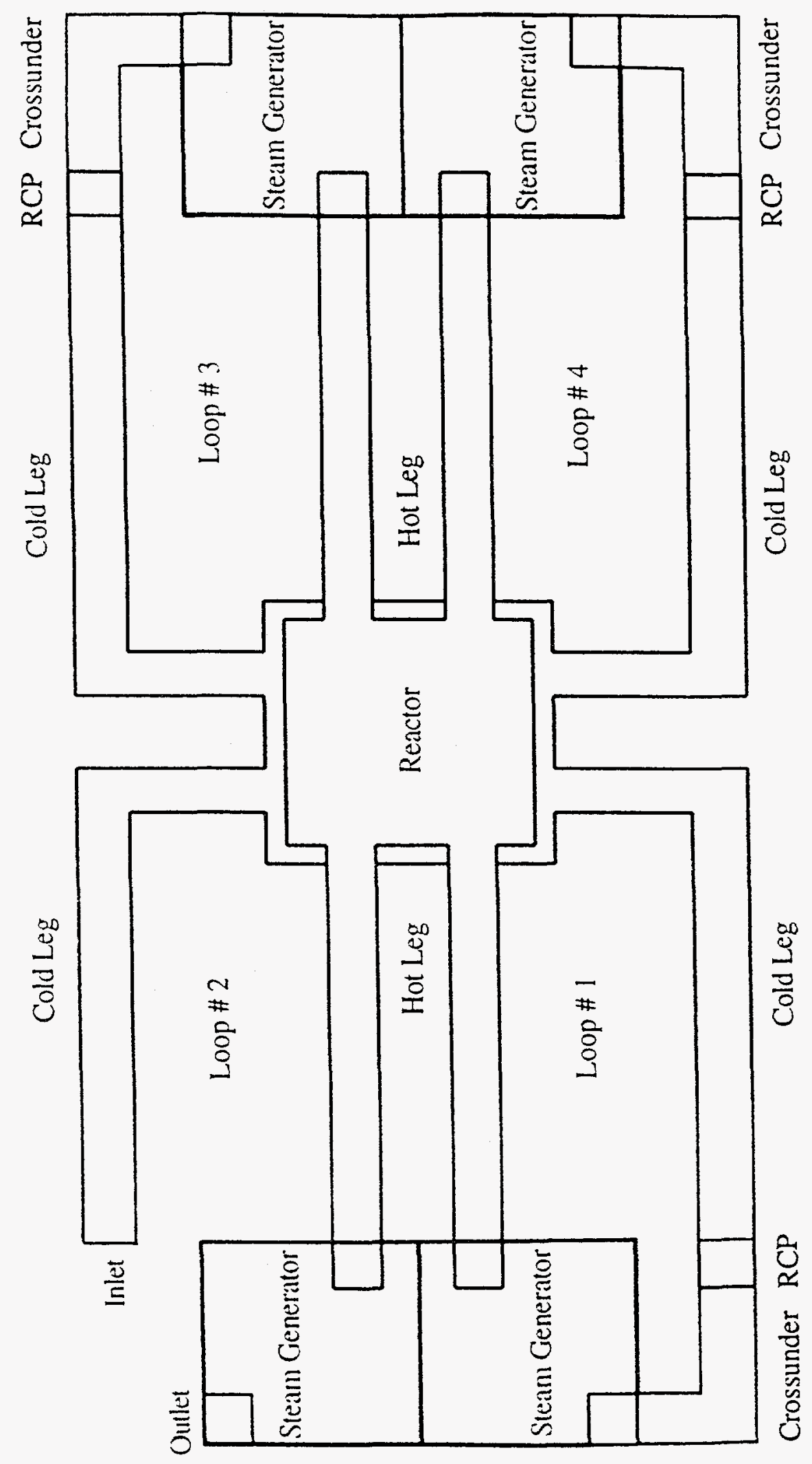

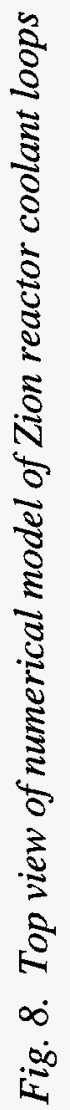




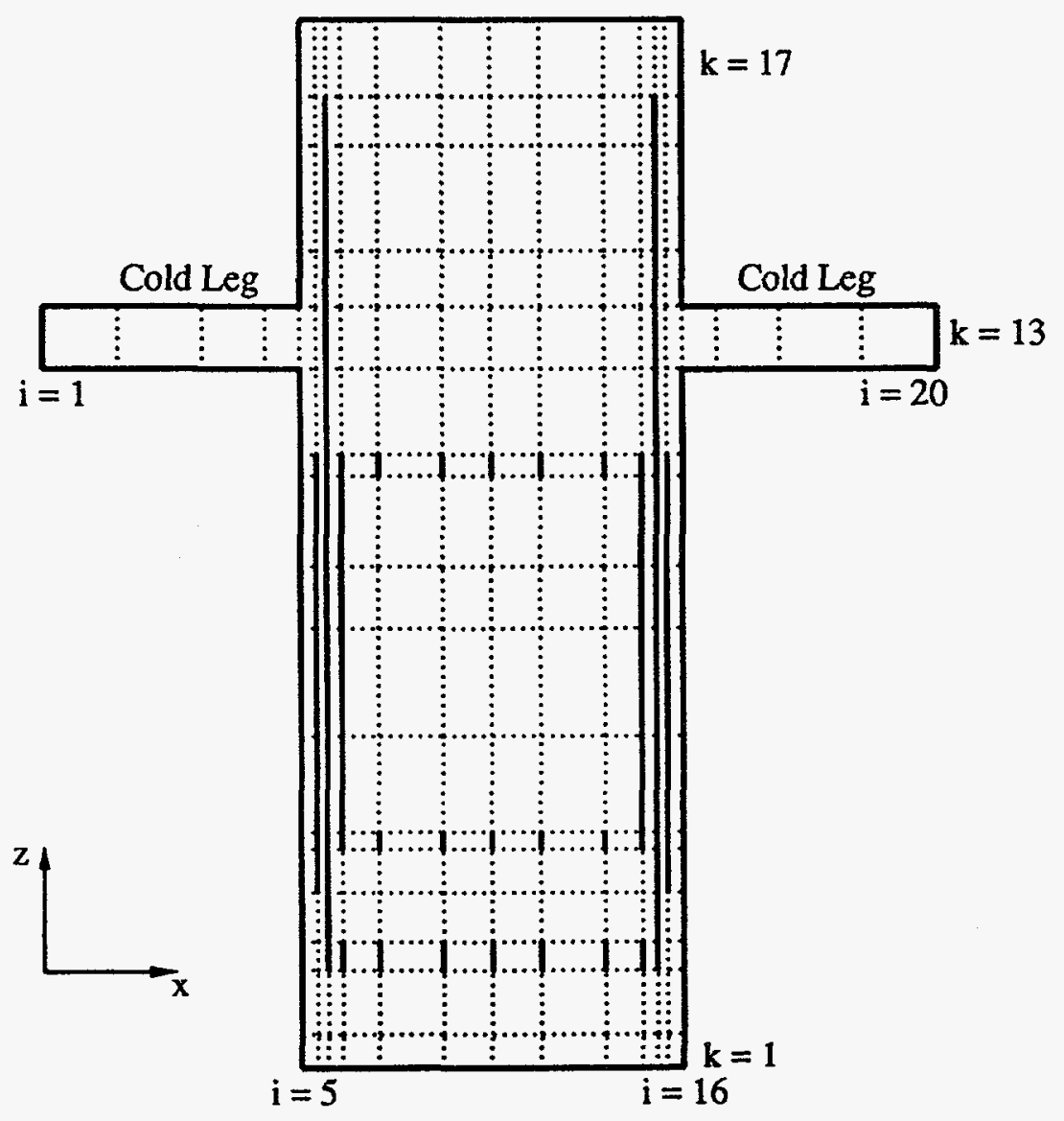

Fig. 9. Model layout showing vertical partitions in $x-z$ plane 


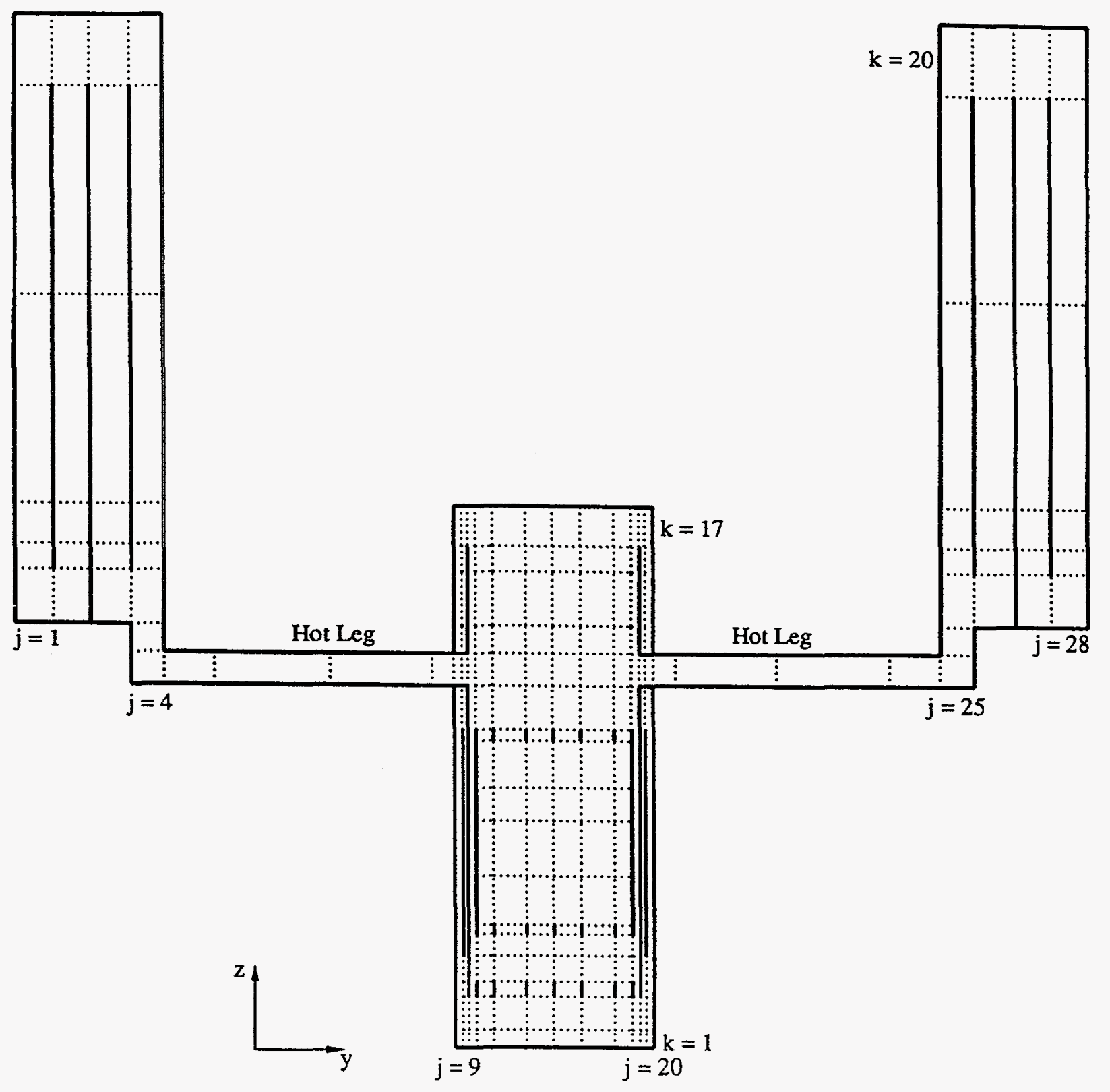

Fig. 10. Model layout showing vertical partitions in $y-z$ plane 


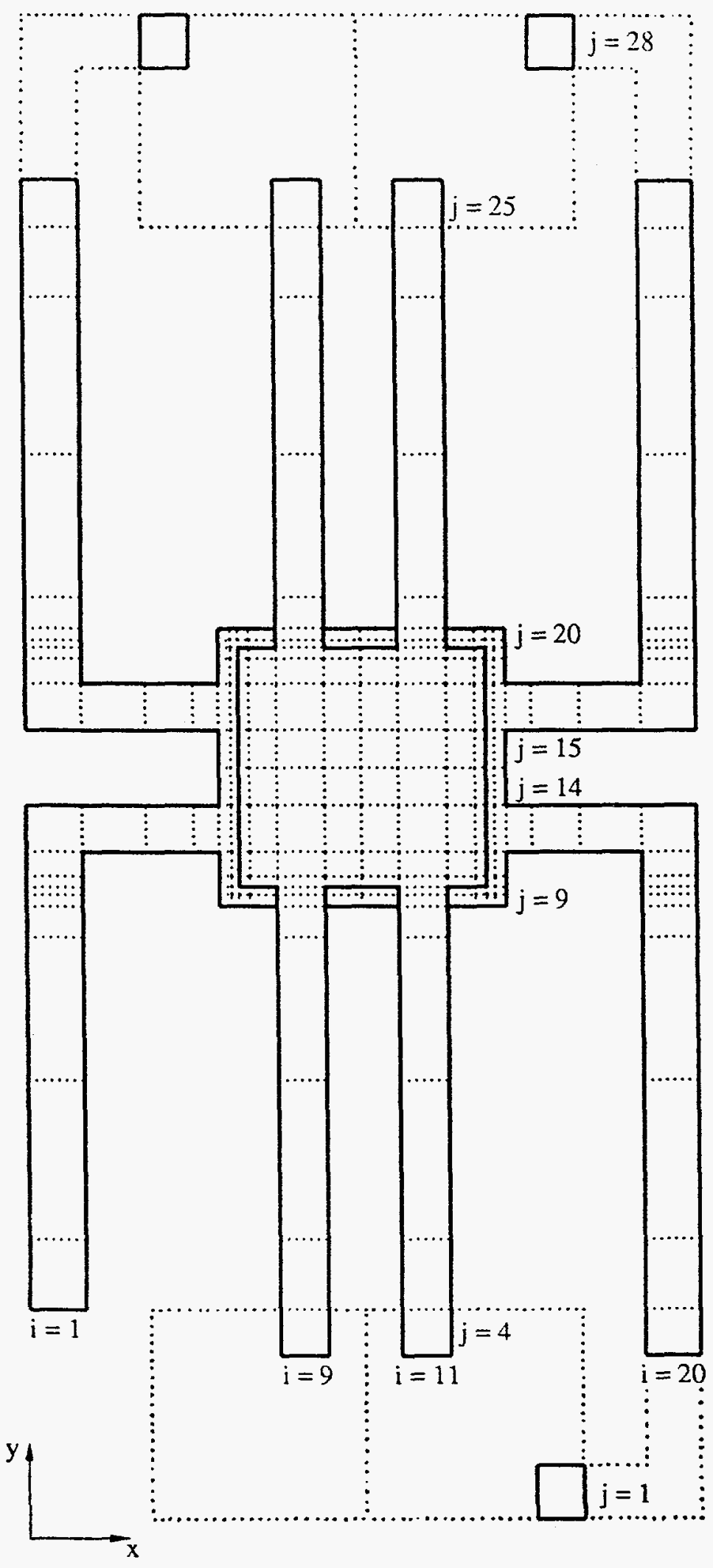

Fig. 11. Model layout showing horizontal partitions in $x-y$ plane 


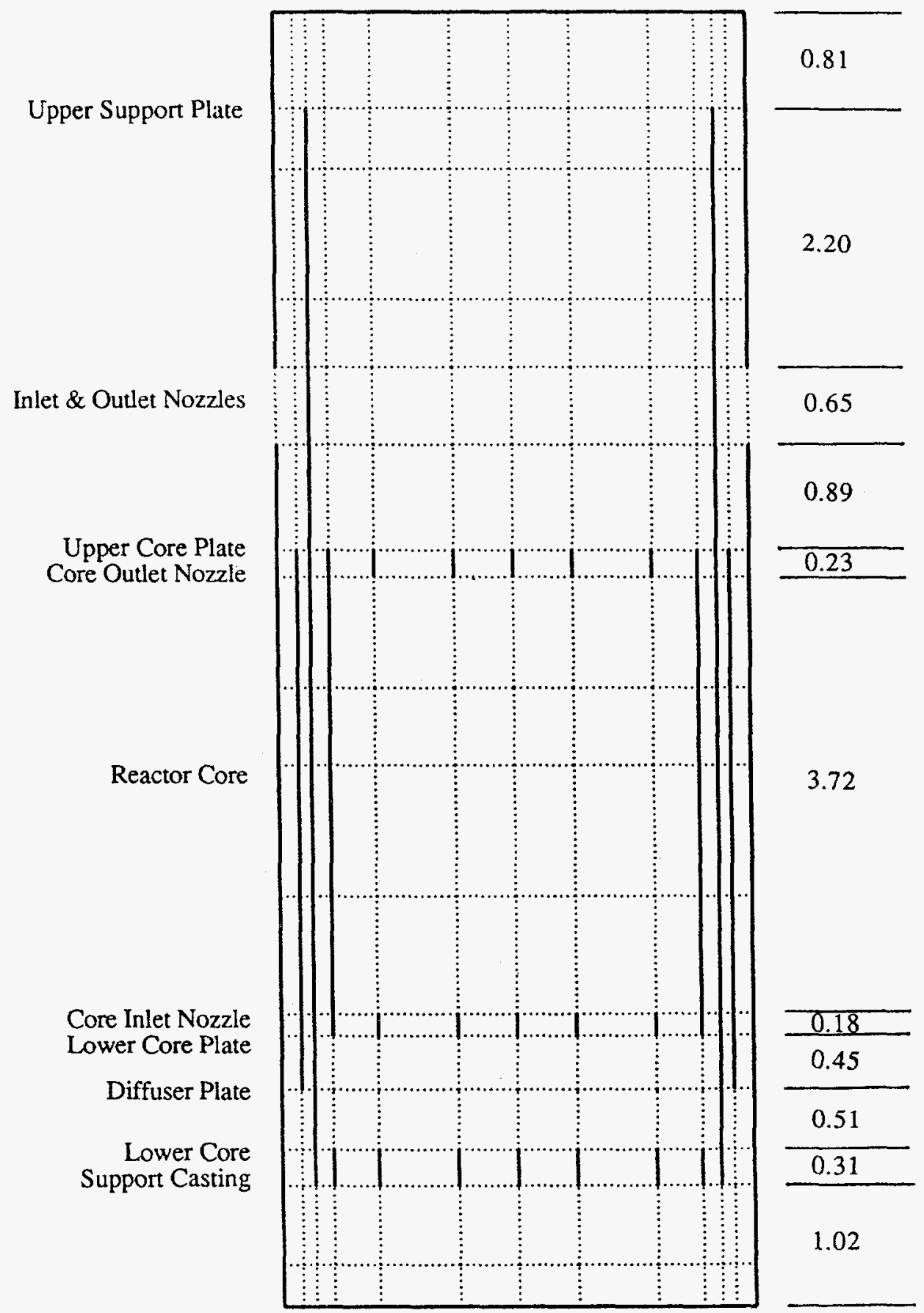

Fig. 12. Vertical partitions of reactor vessel (Dimensions in meters) 


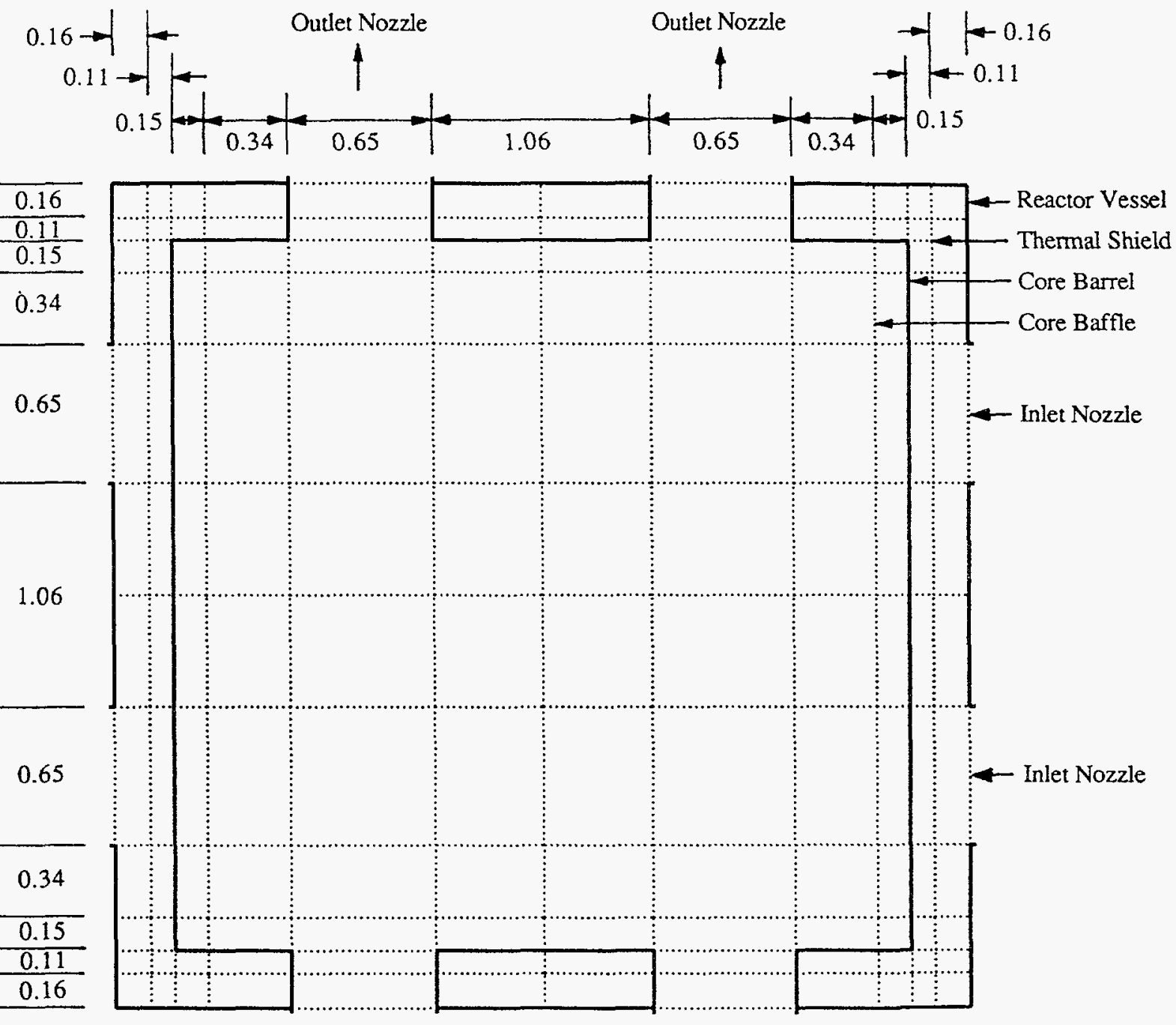

Fig. 13. Horizontal partitions of reactor vessel (Dimensions in meters) 


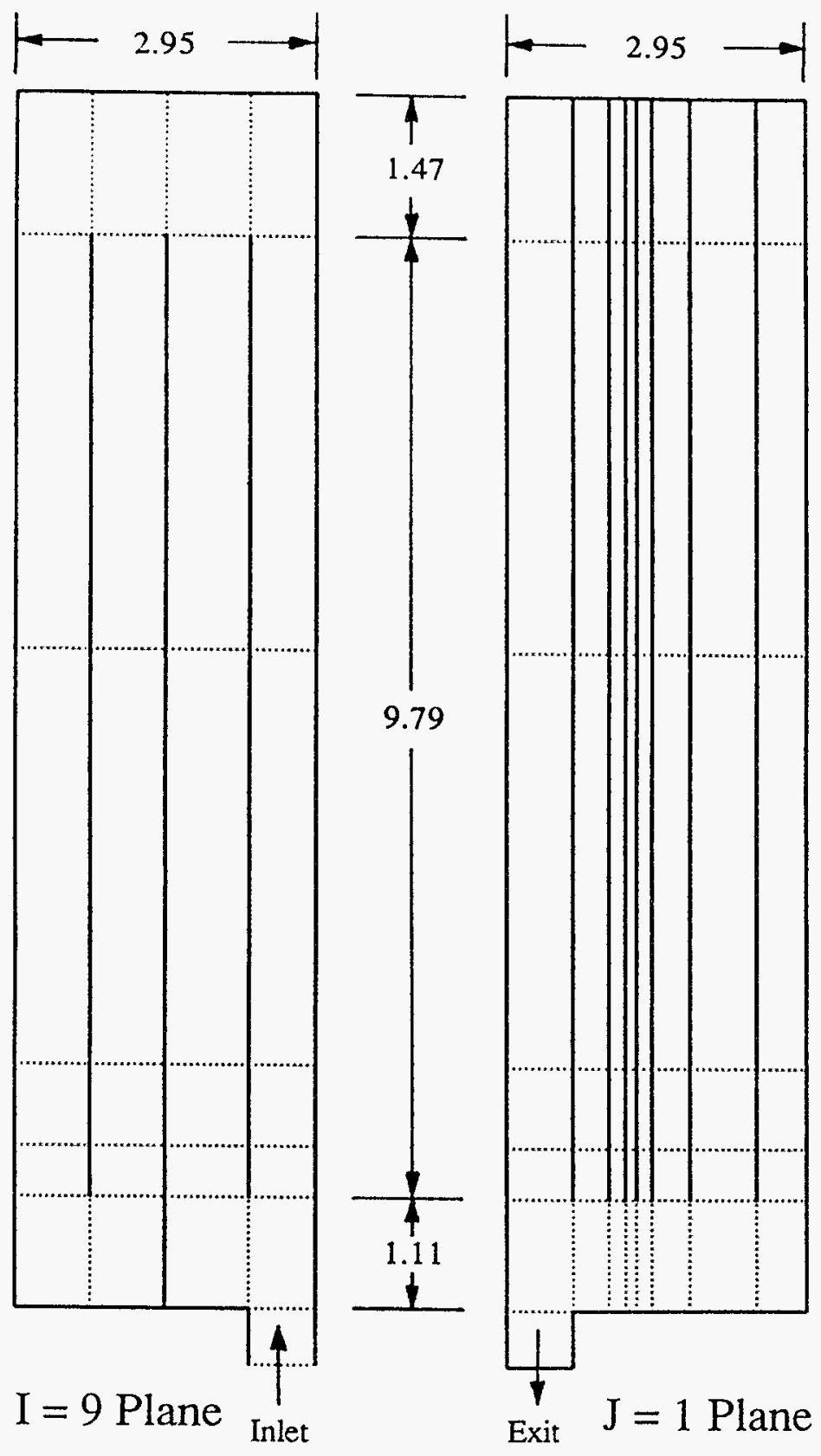

Fig. 14. Vertical partitions of steam generator (Dimensions in meters) 


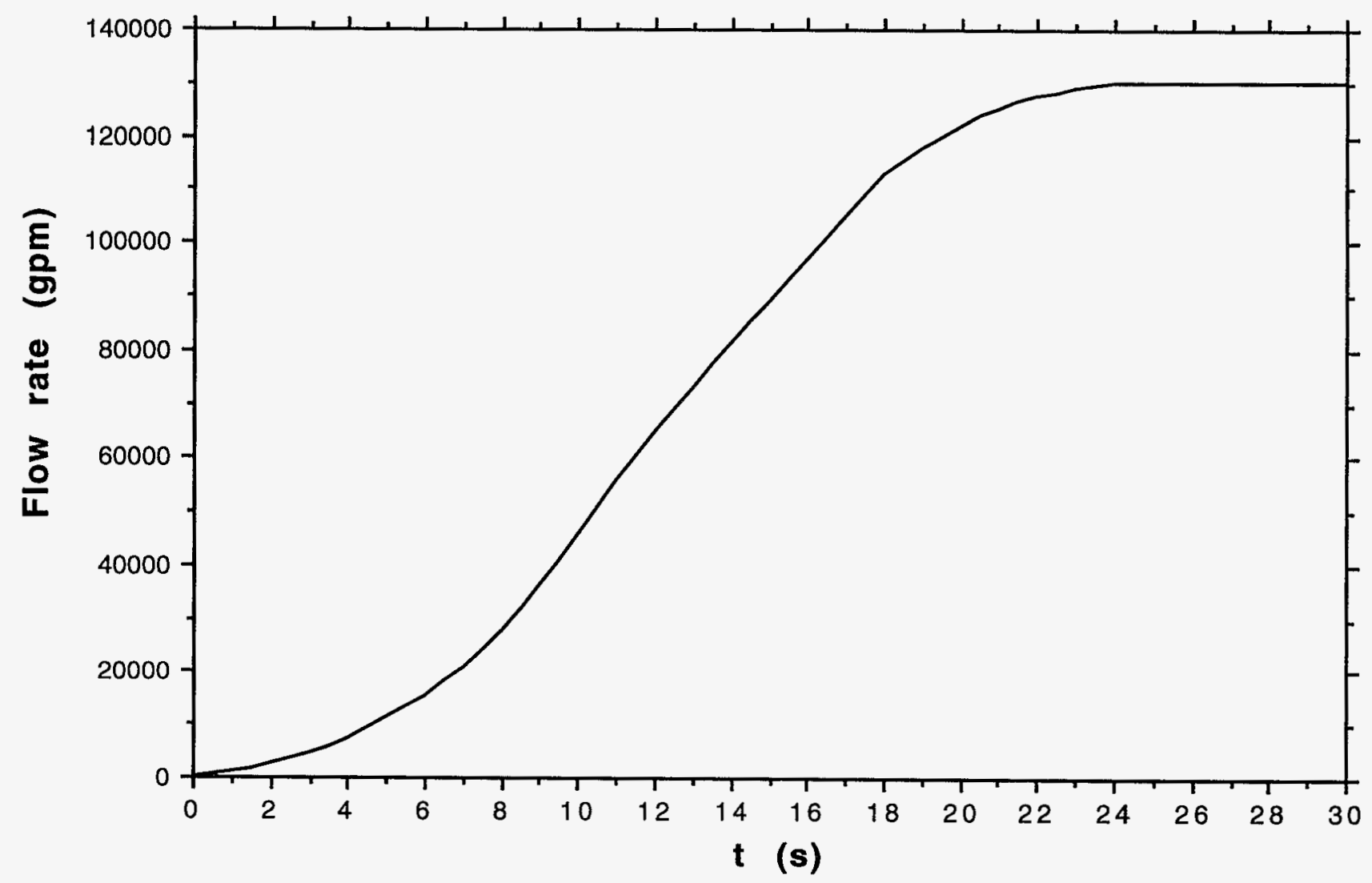

Fig. 15. Increase in flow rate with time at start of $R C P$ 


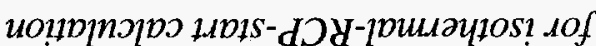

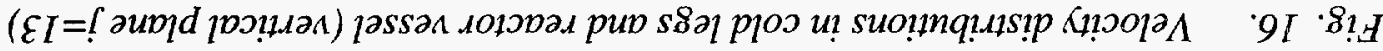

(p)

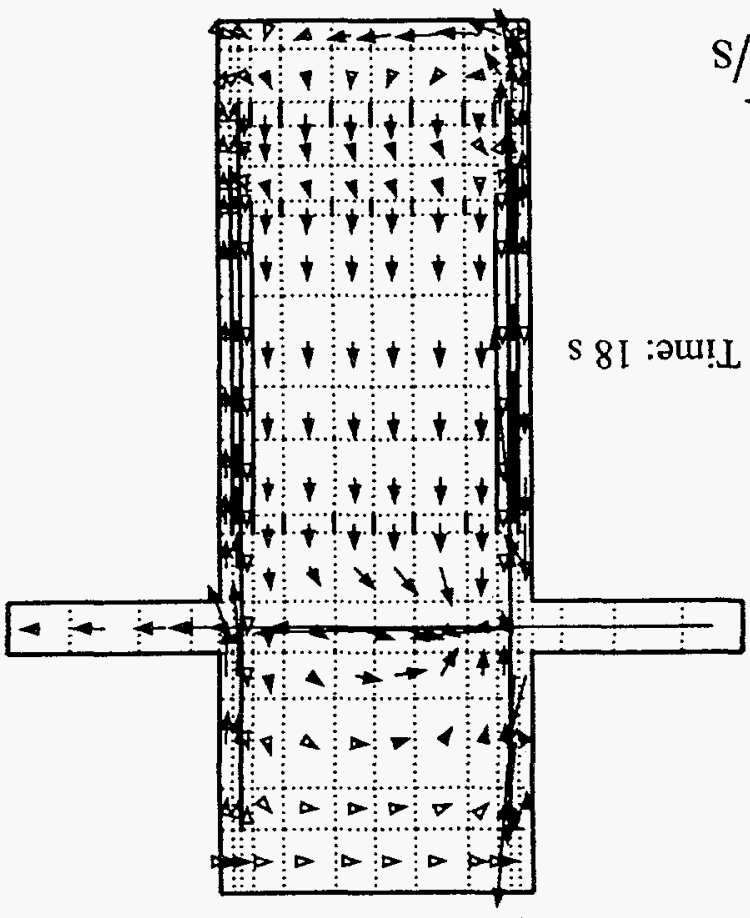

(q)

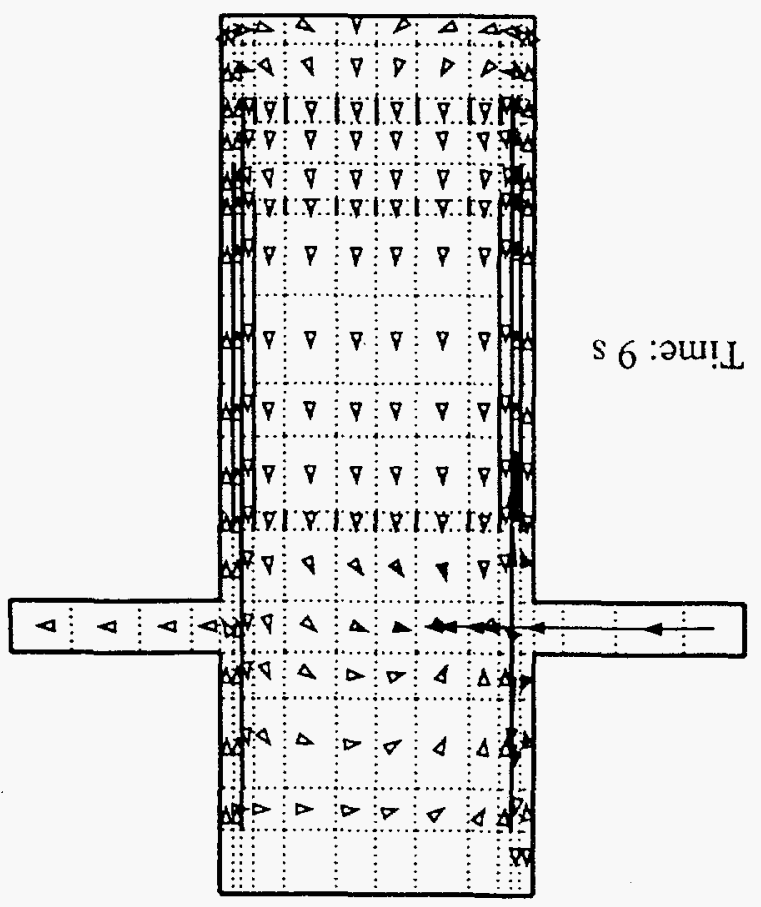

(0)

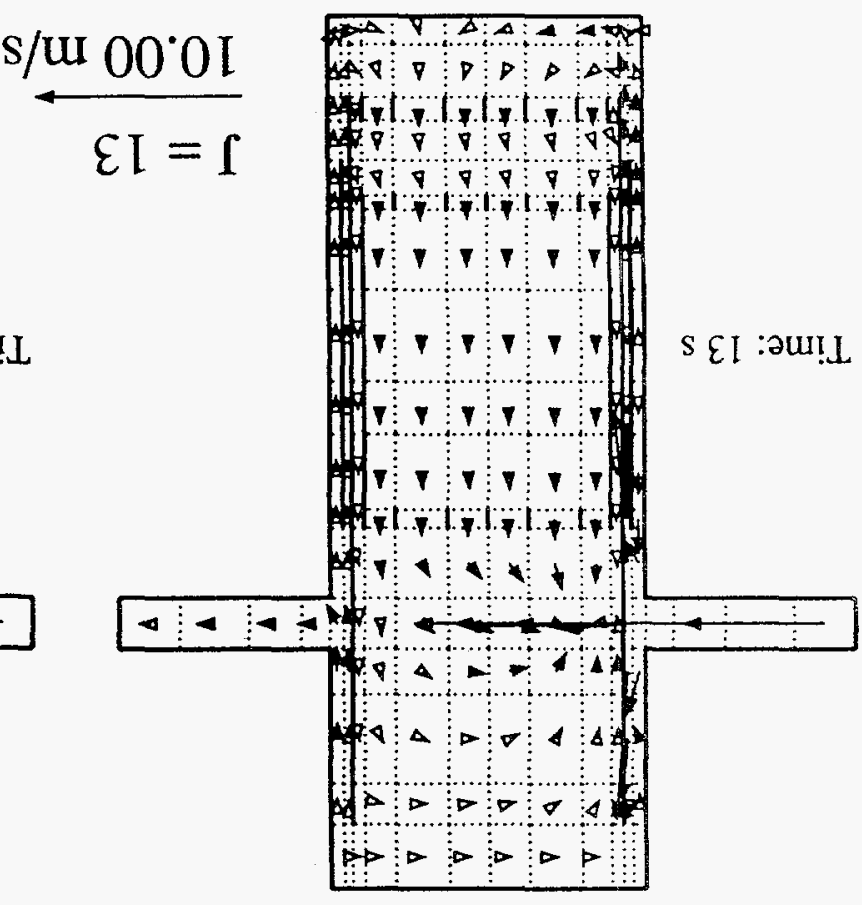

(e)

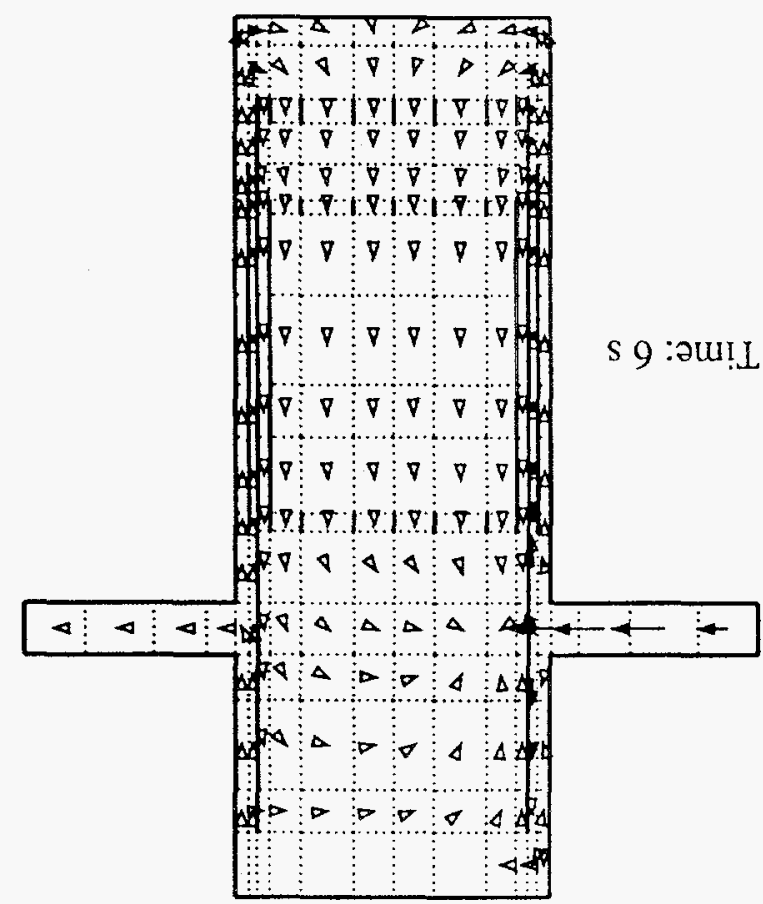




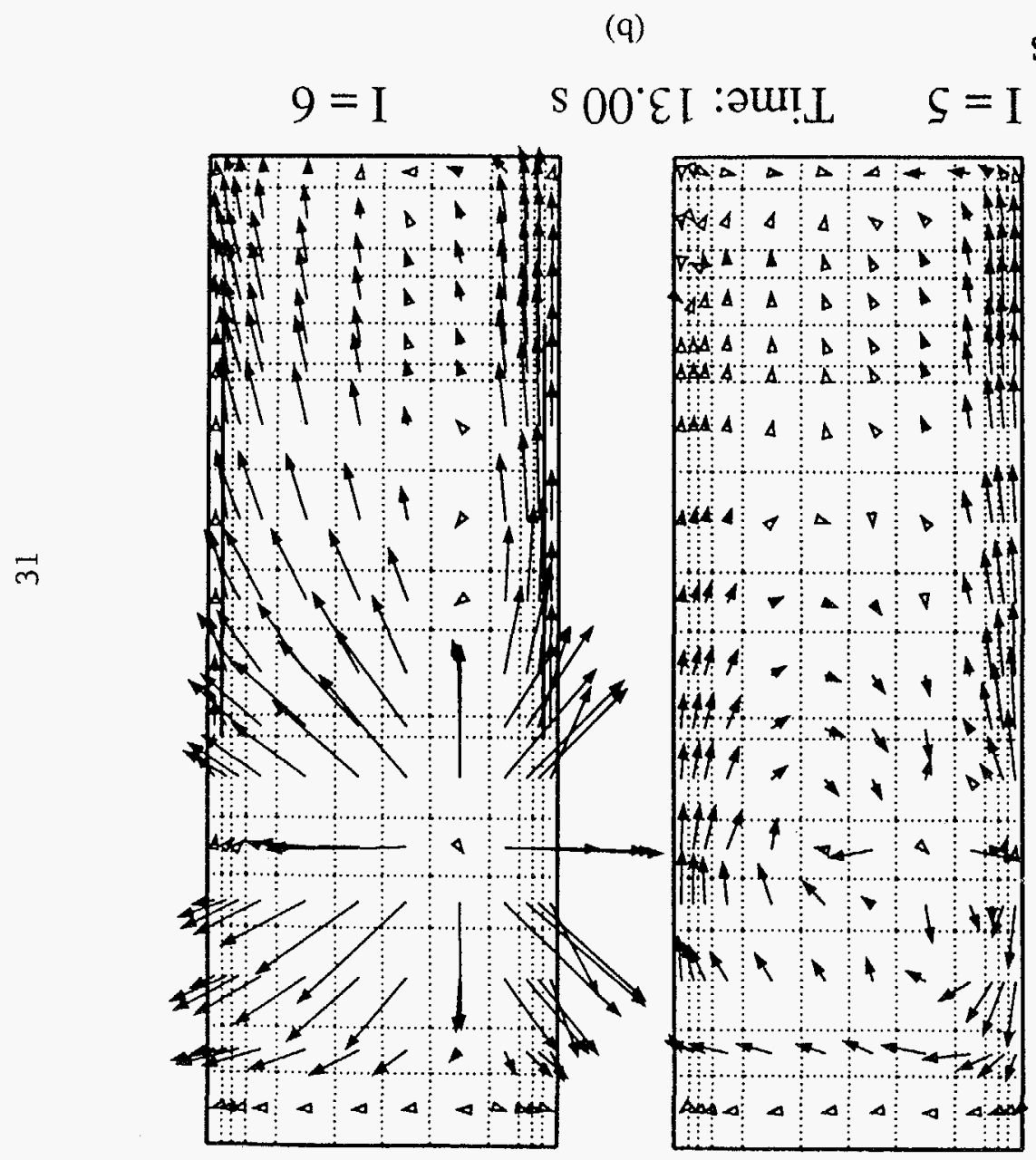

S/ur $00^{\circ} 0 \mathrm{I}$

(e)

s $00^{\circ} 6$ :əuा! $\mathrm{L} \quad \mathrm{S}=\mathrm{I}$
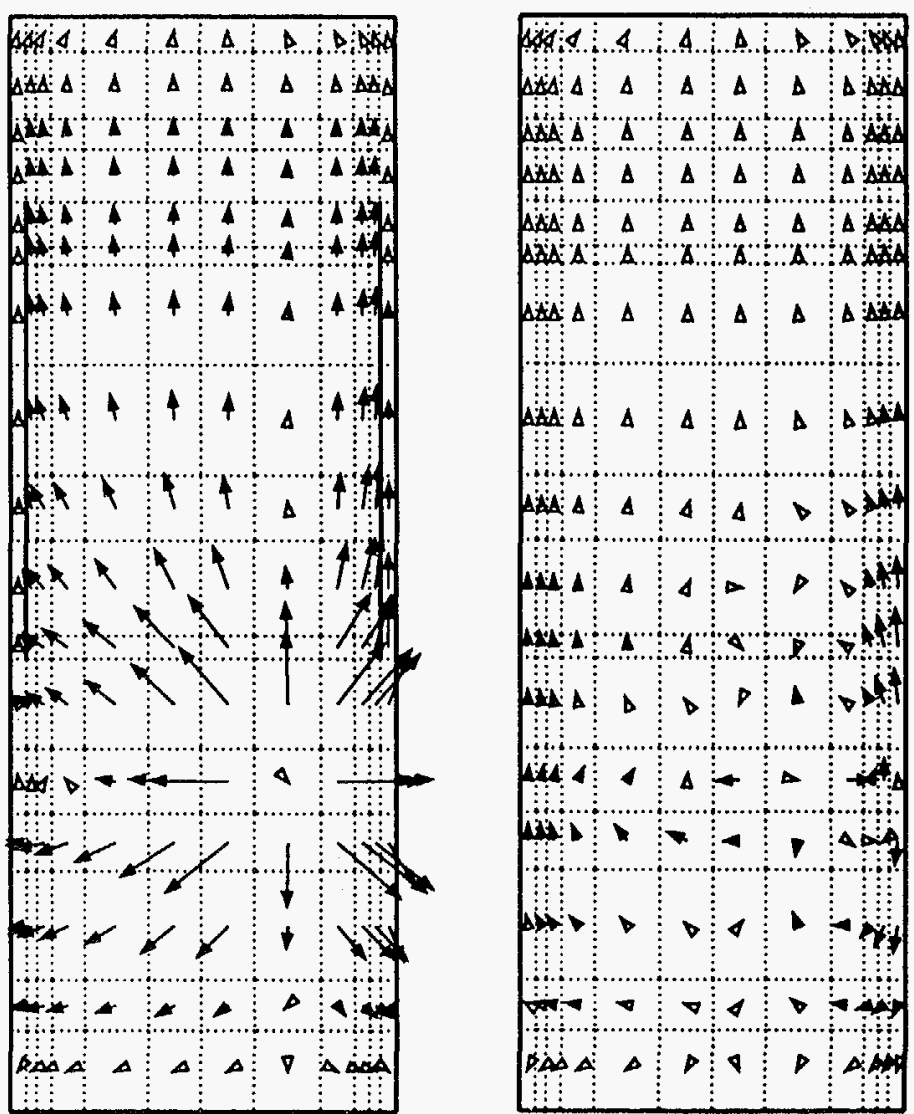


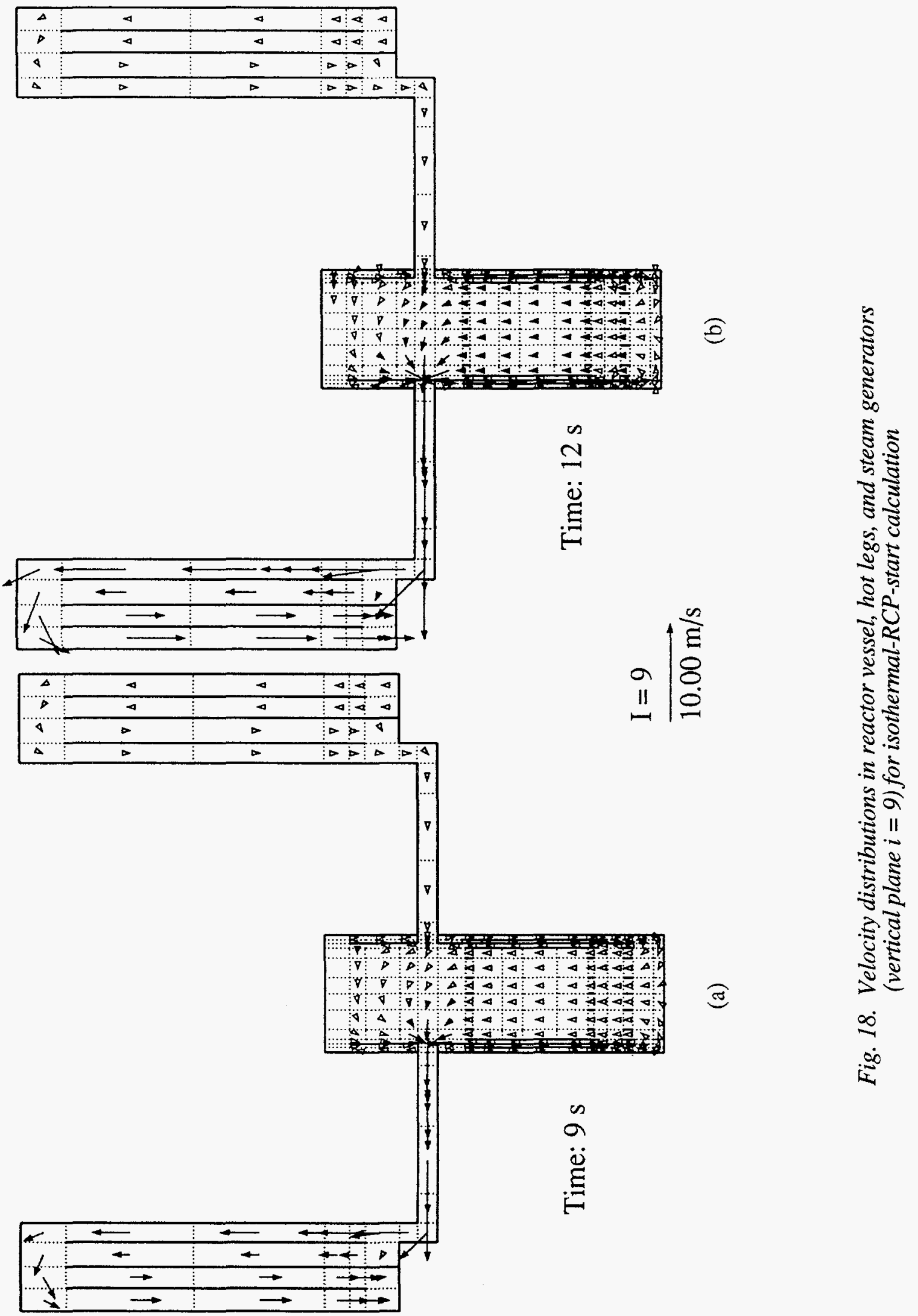



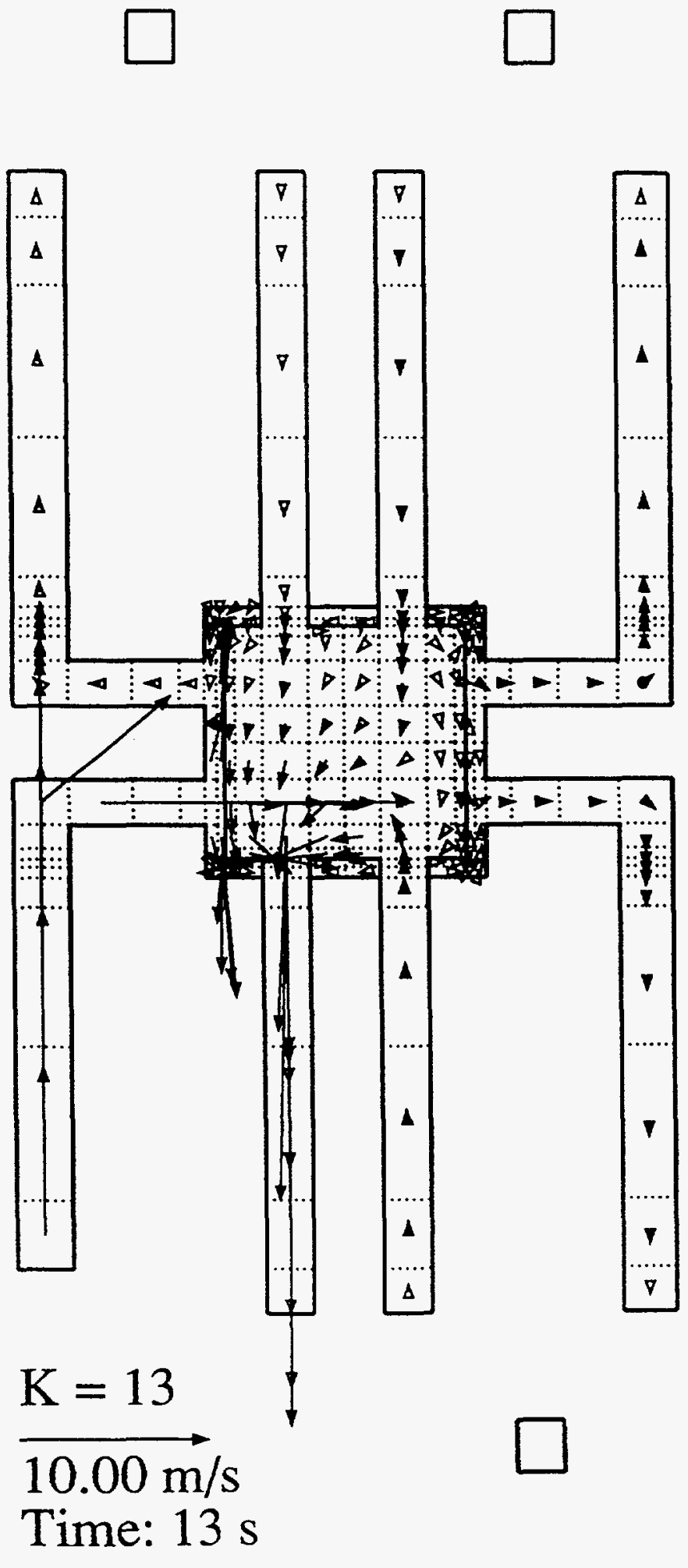

Fig. 19. Velocity distributions in reactor vessel and cold and hot legs (horizontal plane $k=13$ ) for isothermal-RCP-start calculation 


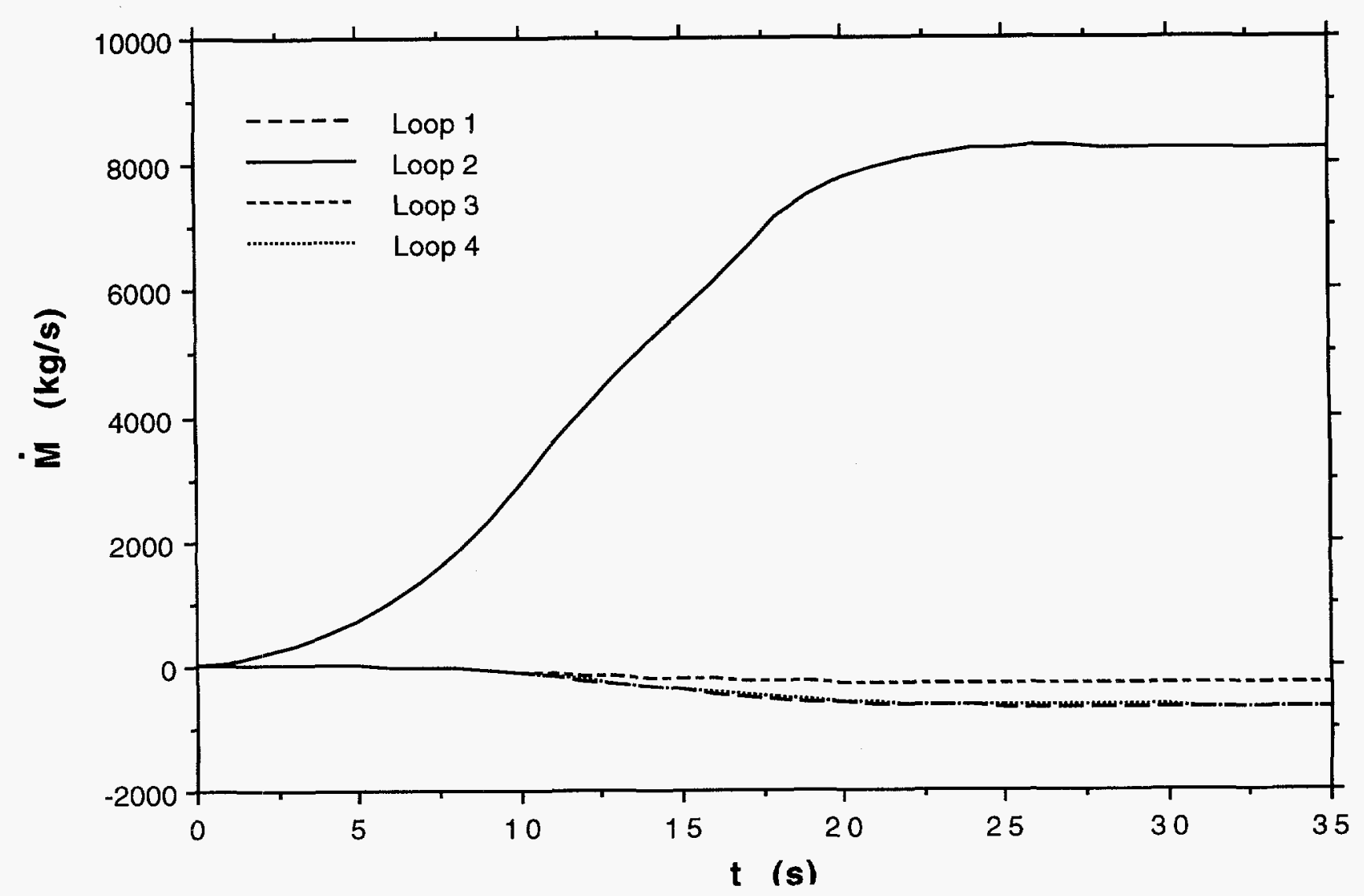

Fig. 20. Variation of mass flow rates with time in four loops for isothermal-RCP-start calculation 


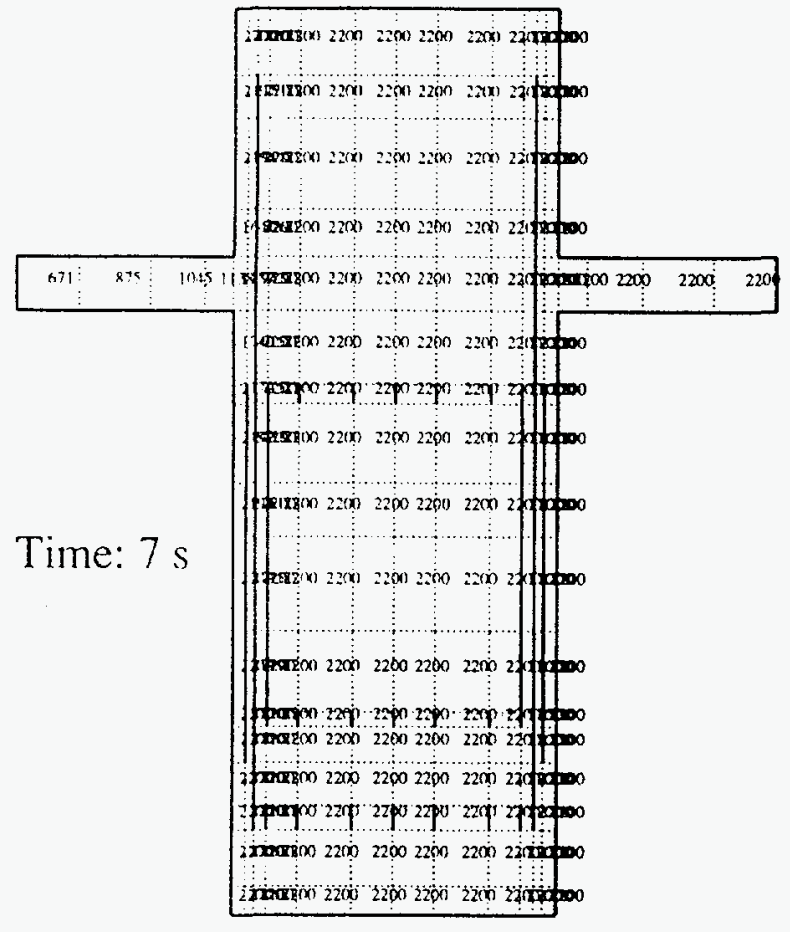

(a)

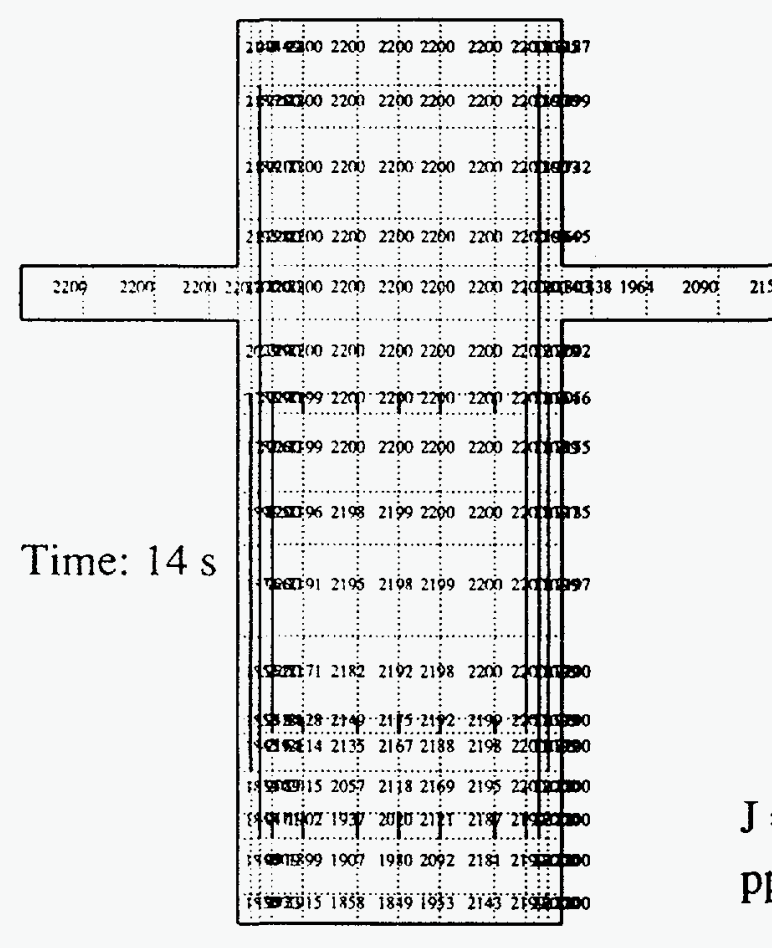

(c)

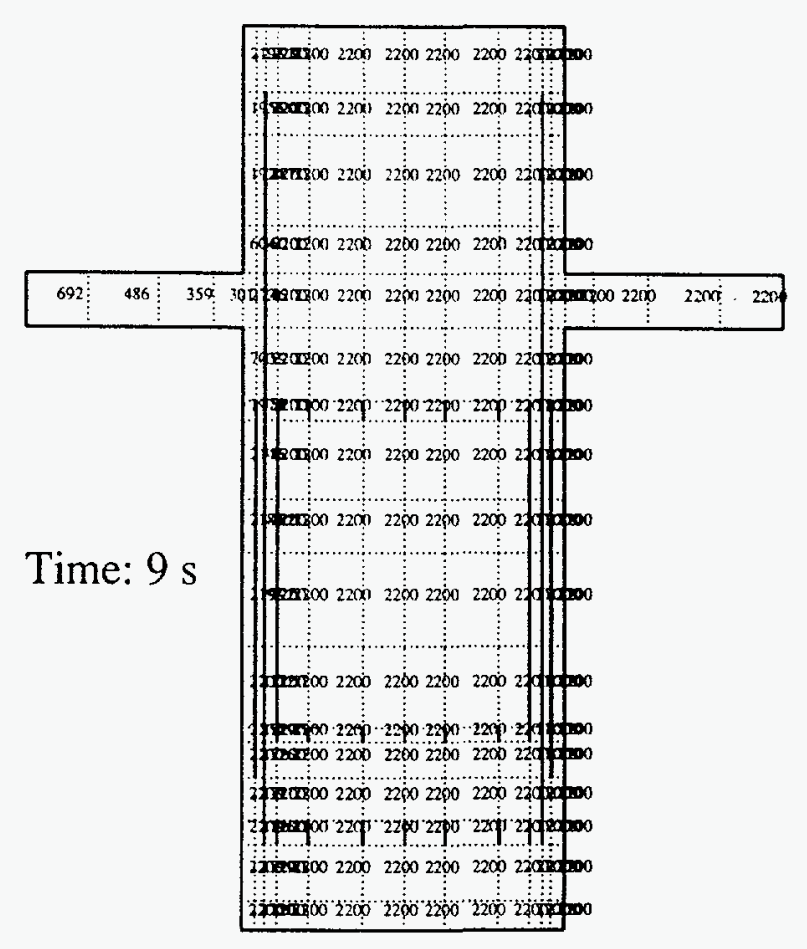

(b)

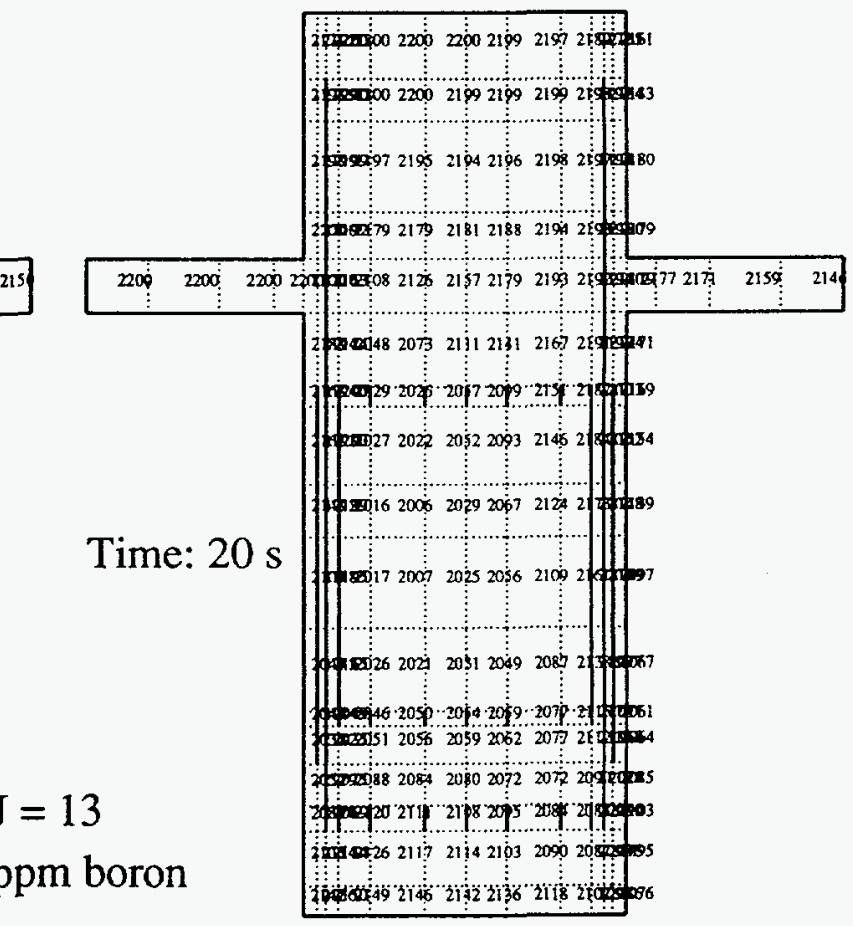

(d)

Fig. 21. Distributions of boron concentration in cold legs and reactor vessel (vertical plane $j=13$ ) for isothermal-RCP-start calculation 


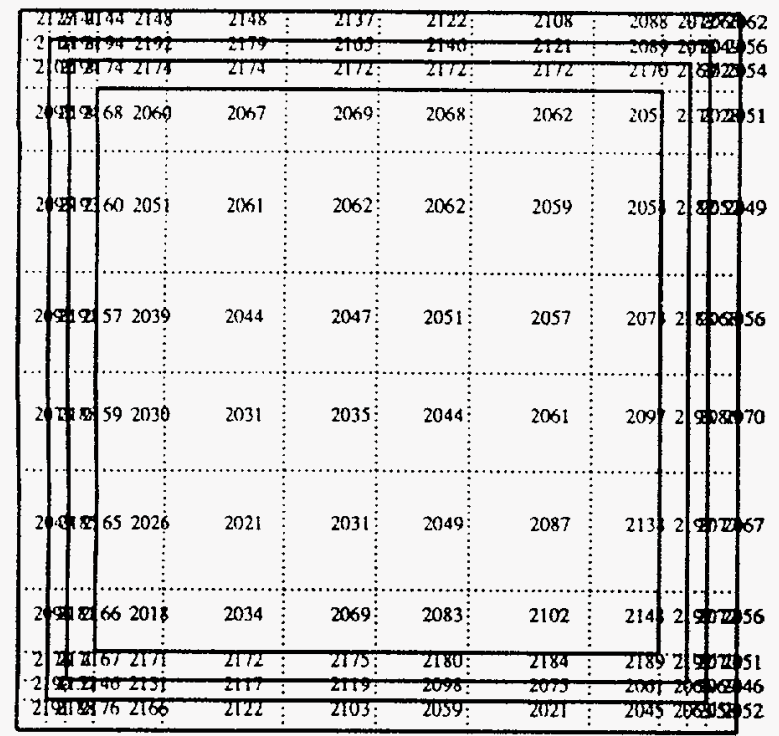

$\mathrm{K}=7$

(a)

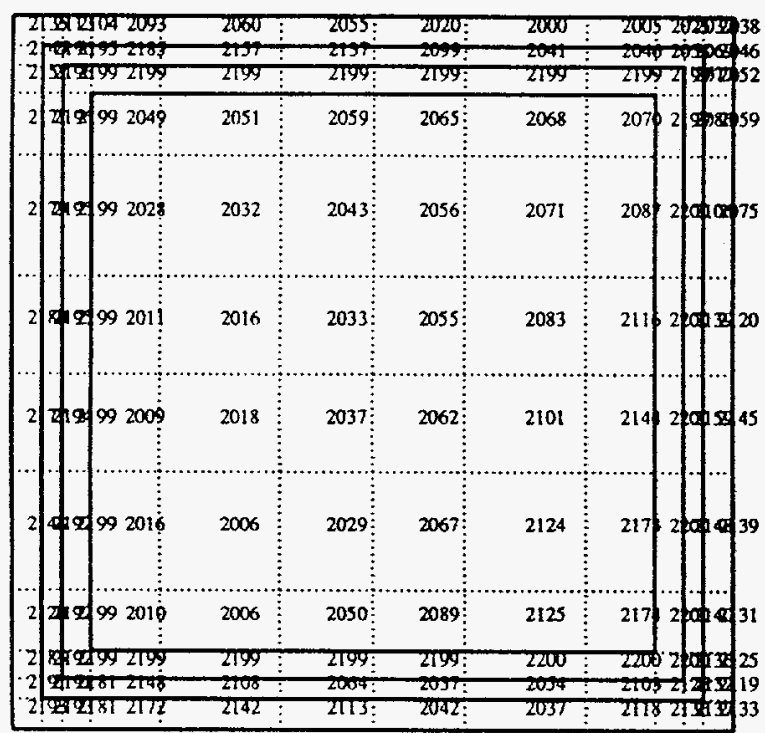

$K=9$

(c)

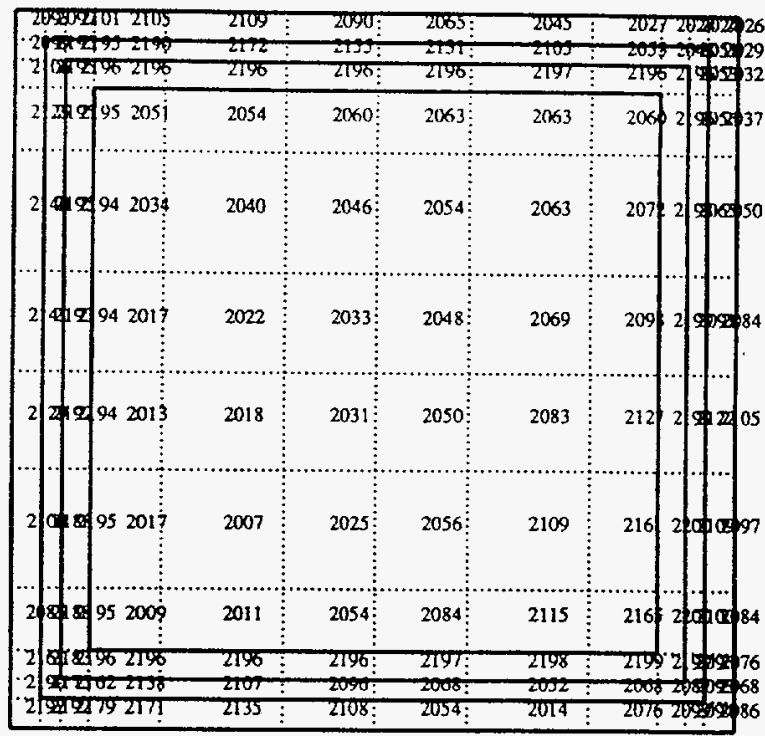

$\mathrm{K}=8$

(b)

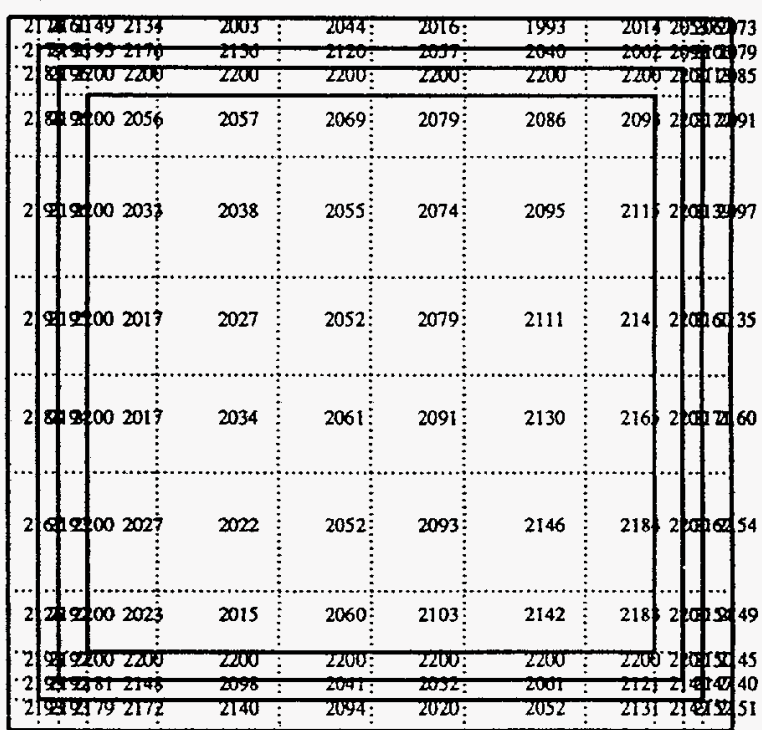

$\mathrm{K}=10$

(d)

Fig. 22. Distributions of boron concentration in reactor core (horizontal planes $k=7-10$ ) at 20 s into transient for isothermal-RCP-start calculation 


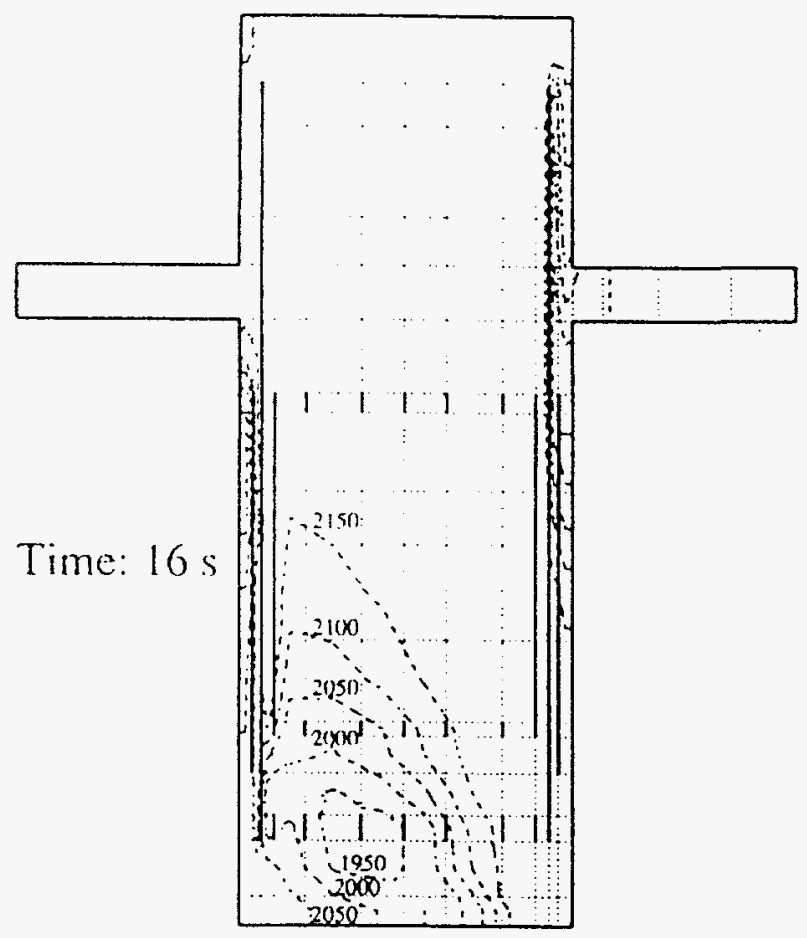

(a)

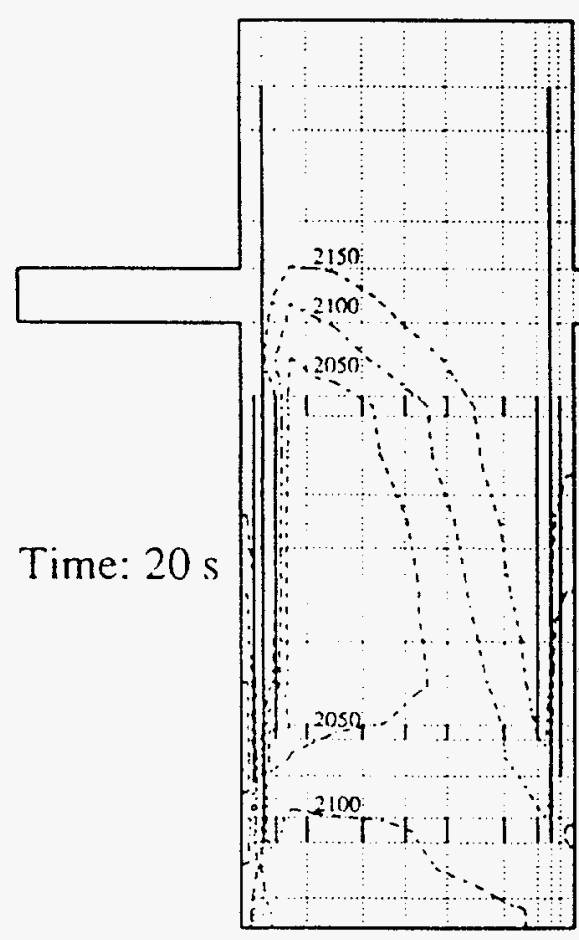

(c)

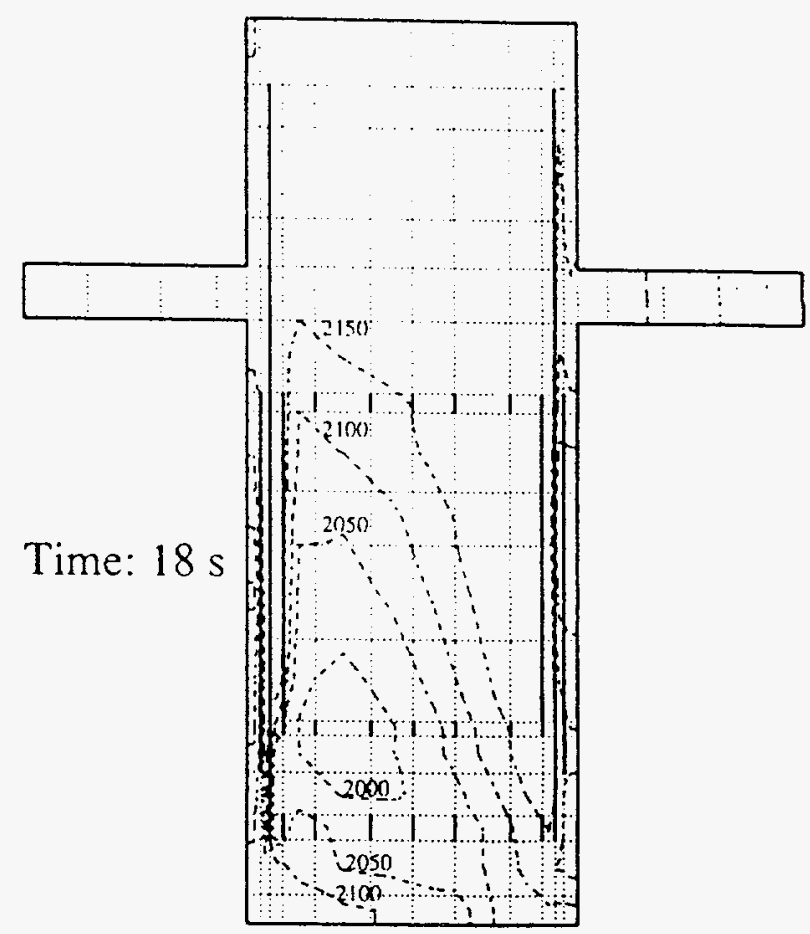

(b)

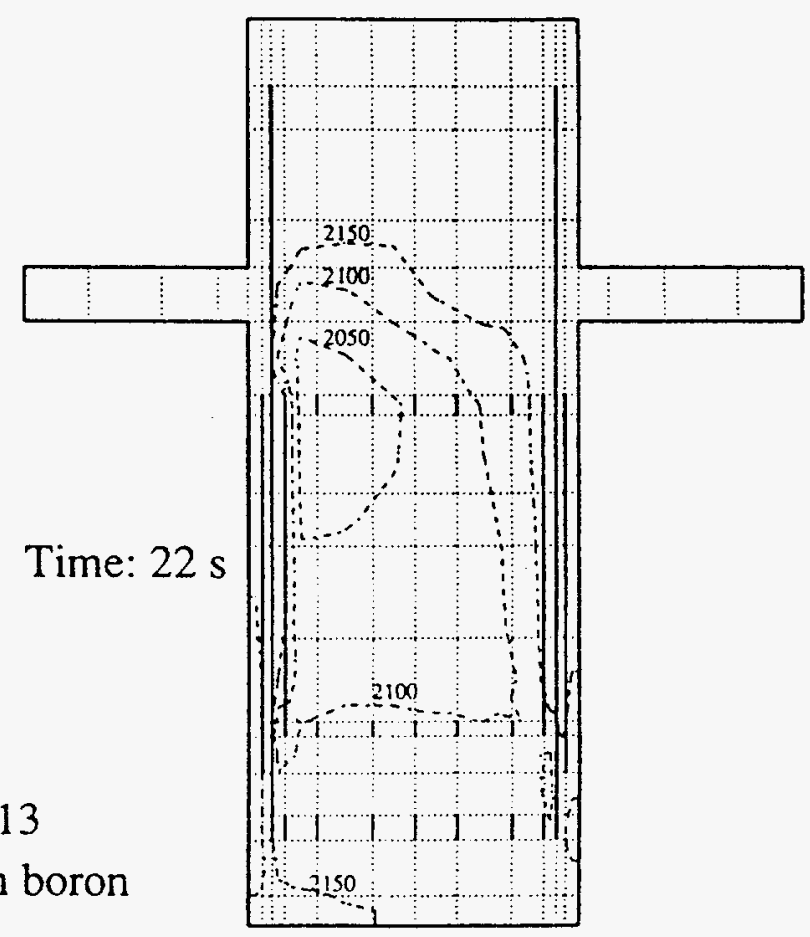

(d)

Fig. 23. Contours of boron concentration in reactor vessel (vertical plane $j=13$ ) for isothermal-RCP-start calculation 


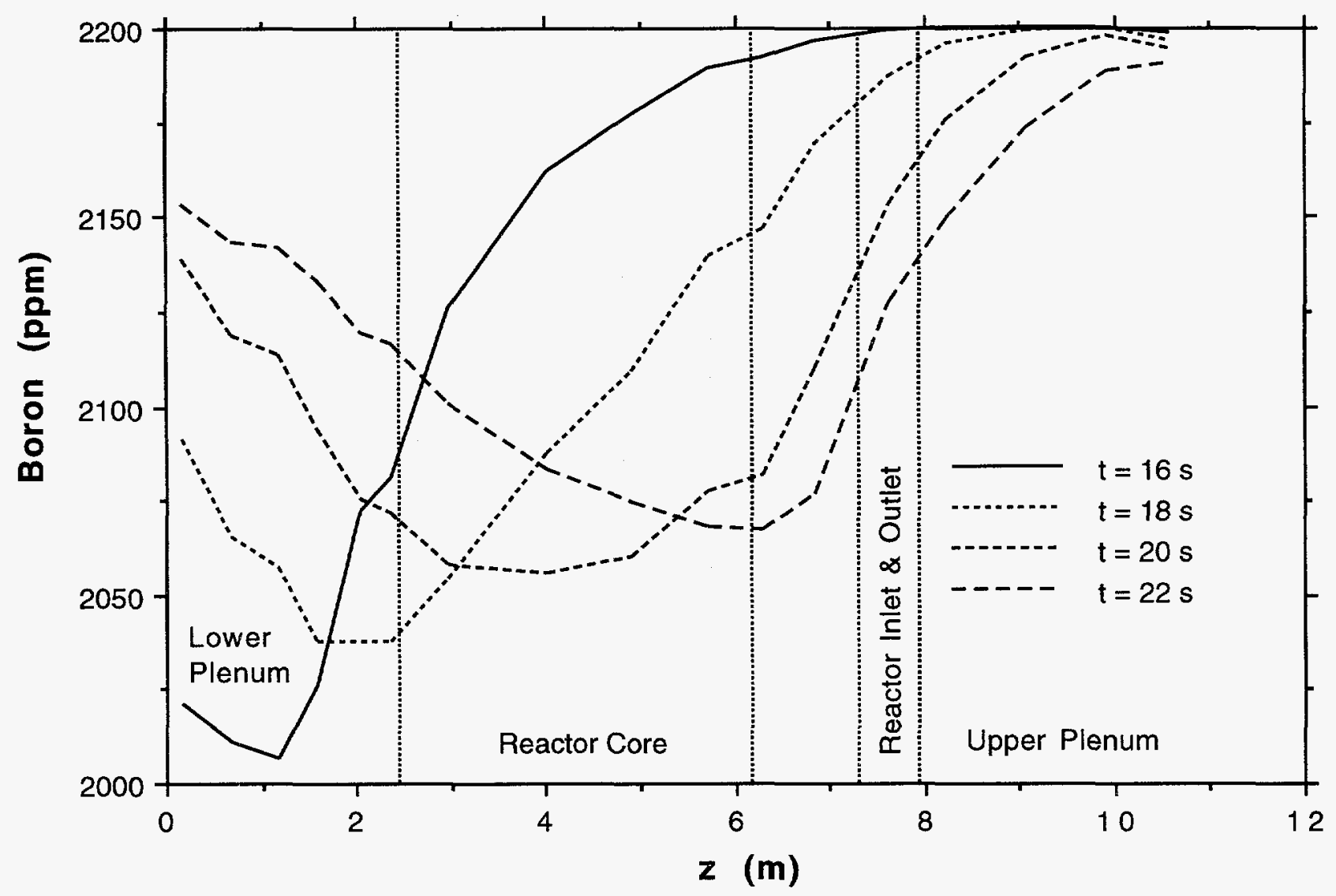

Fig. 24. Variation of boron concentration along axis of reactor vessel at 16, 18 , 20 , and 22 s into transient for isothermal-RCP-start calculation 


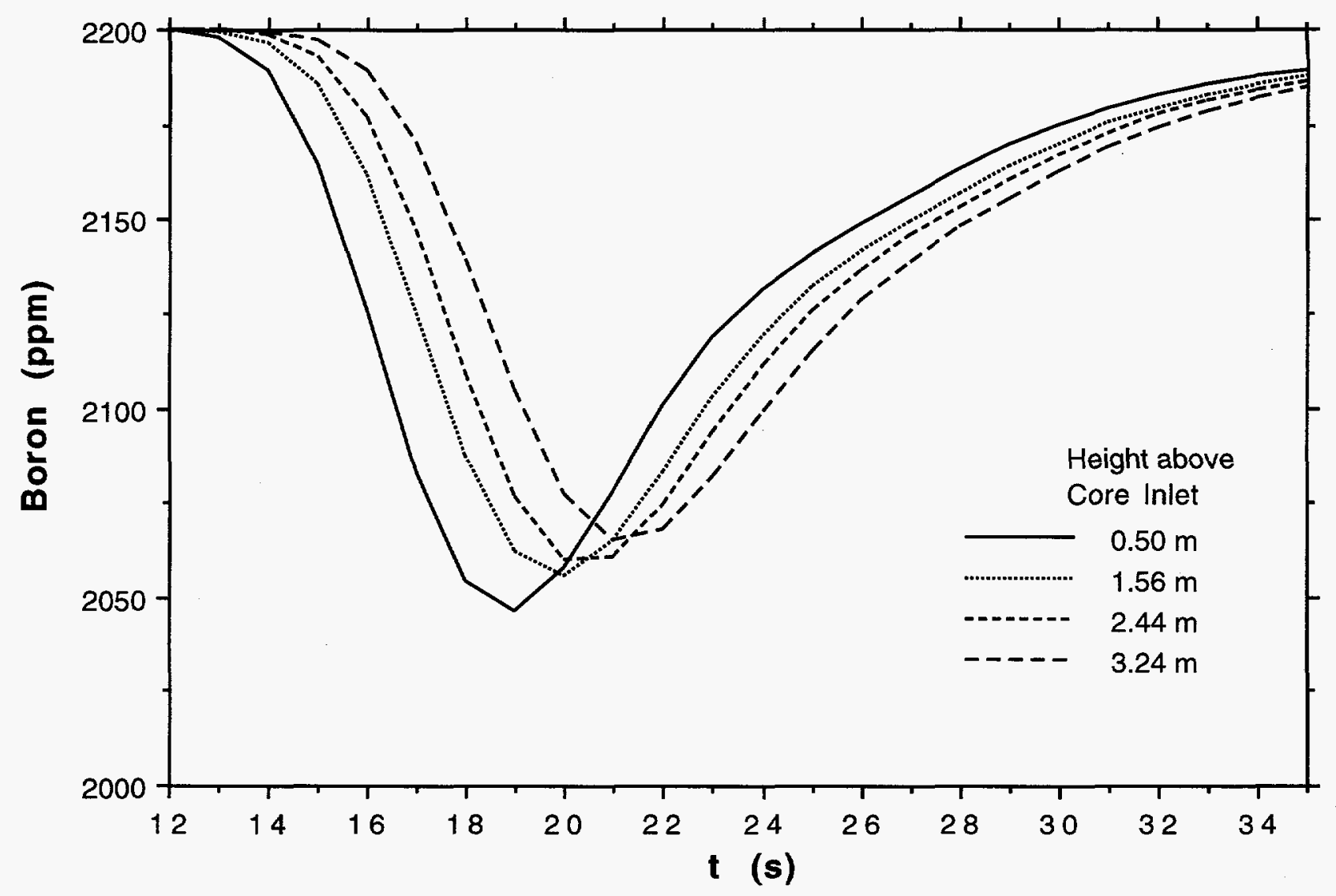

Fig. 25. Variation of mean boron concentration with time in reactor core for isothermal-RCP-start calculation 


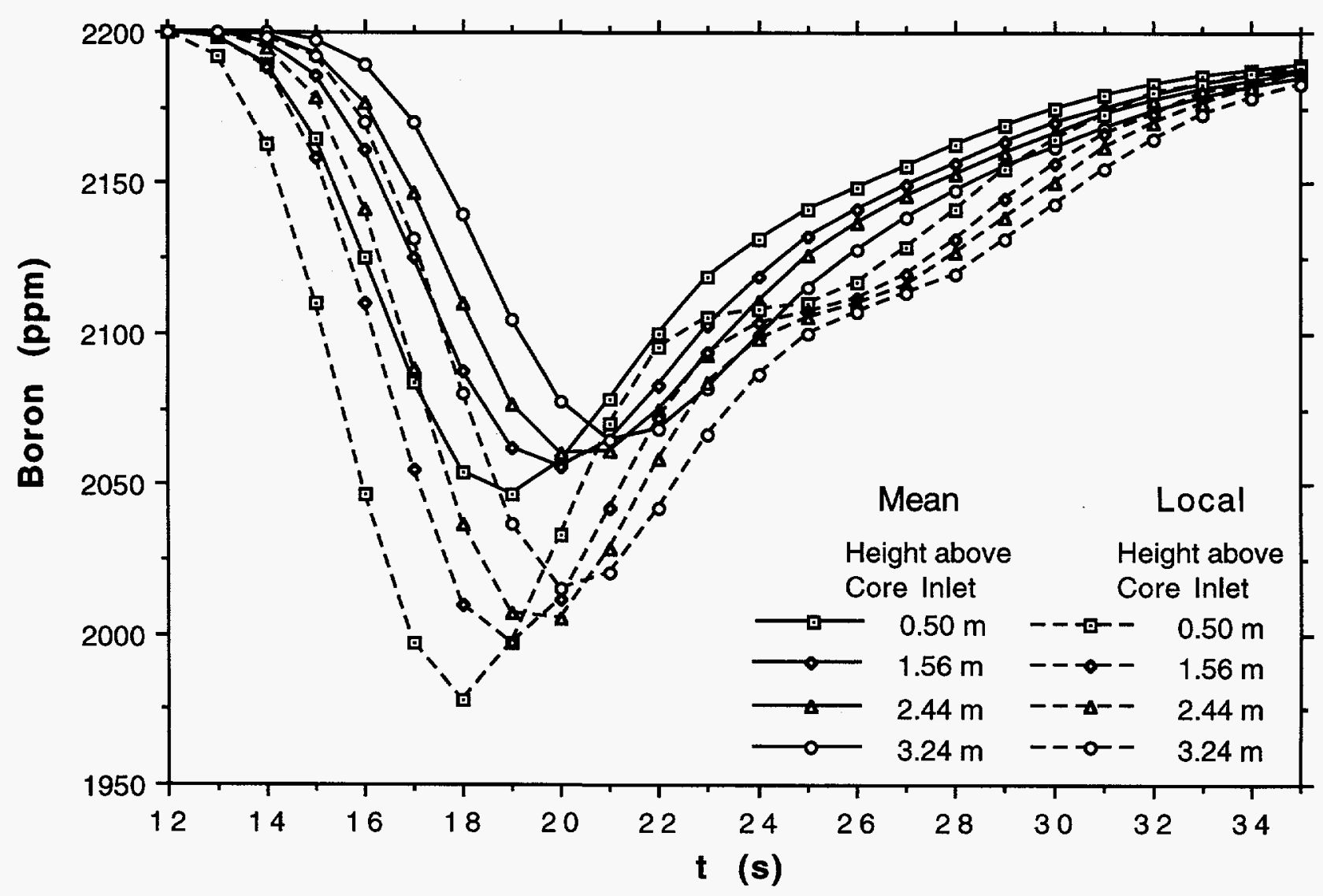

Fig. 26. Mean and local minimum boron concentration variation with time in reactor core for isothermal-RCP-start calculation 


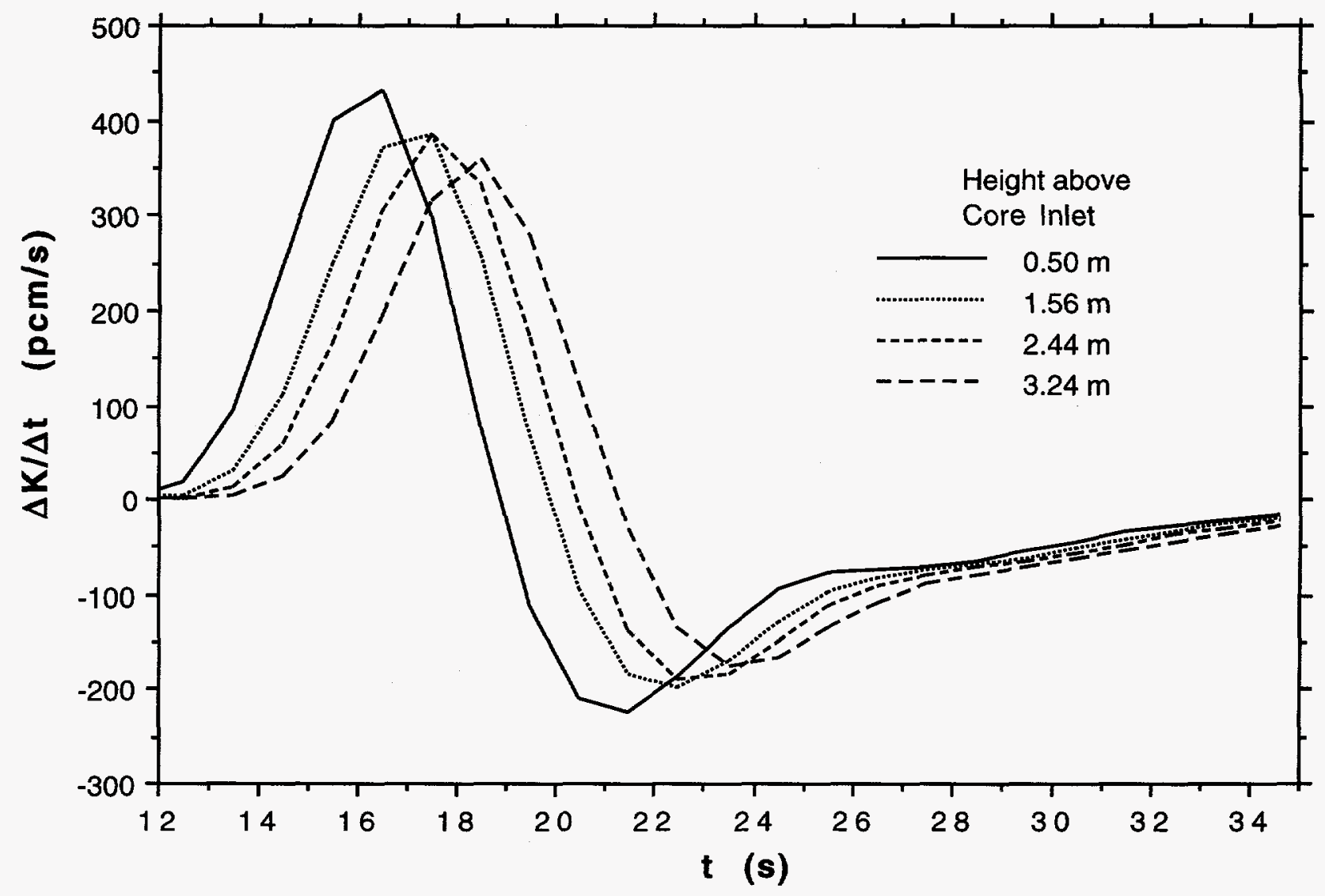

Fig. 27. Variation of mean reactivity insertion rate with time in reactor core for isothermal-RCP-start calculation 


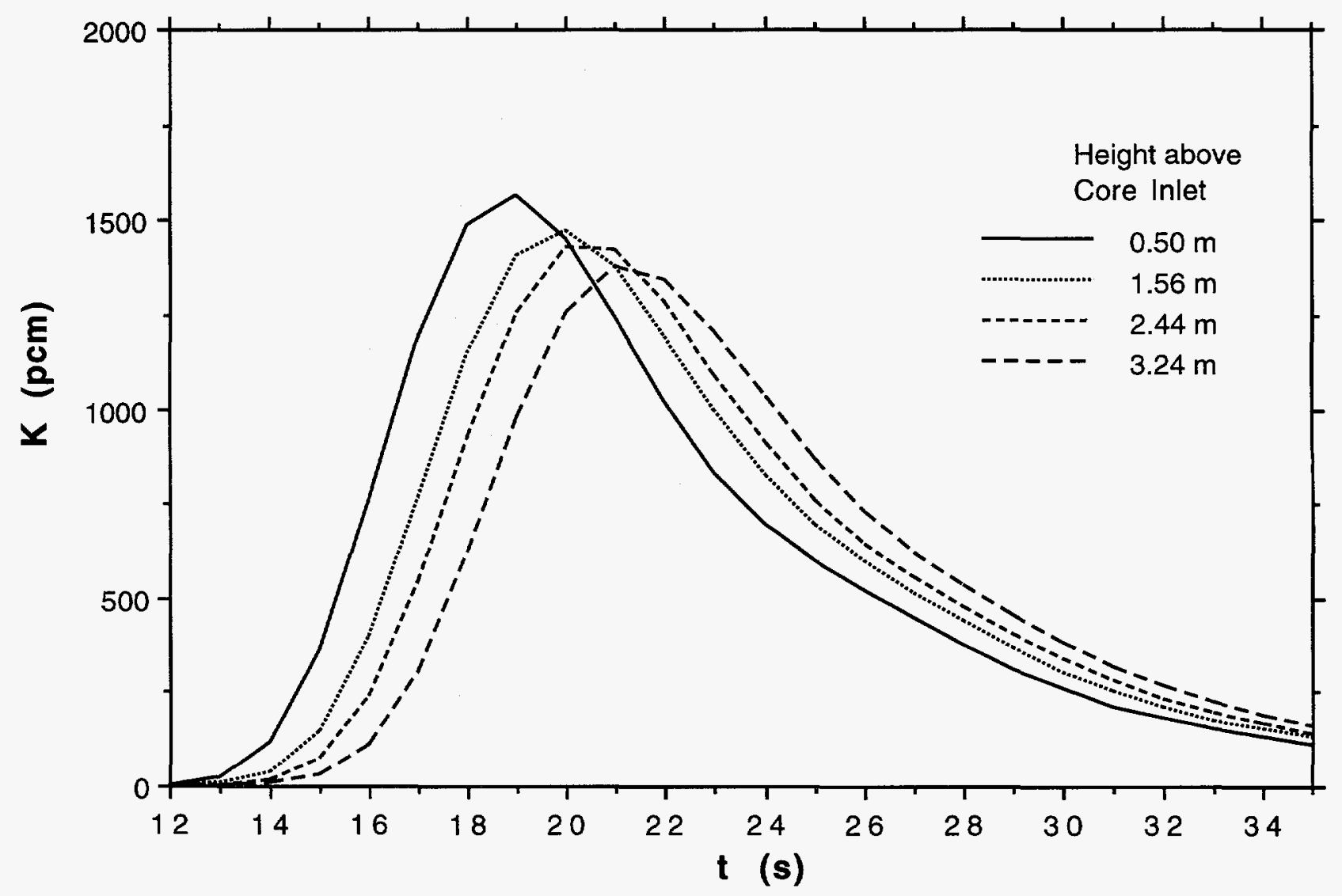

Fig. 28. Variation of mean reactivity with time in reactor core for isothermal-RCP-start calculation 


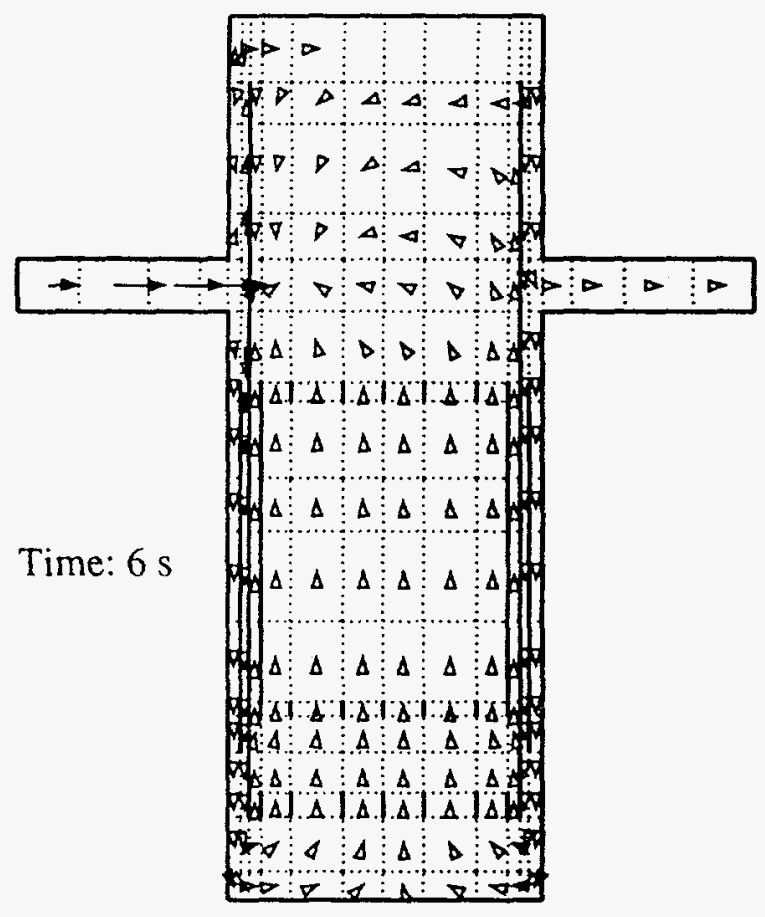

(a)

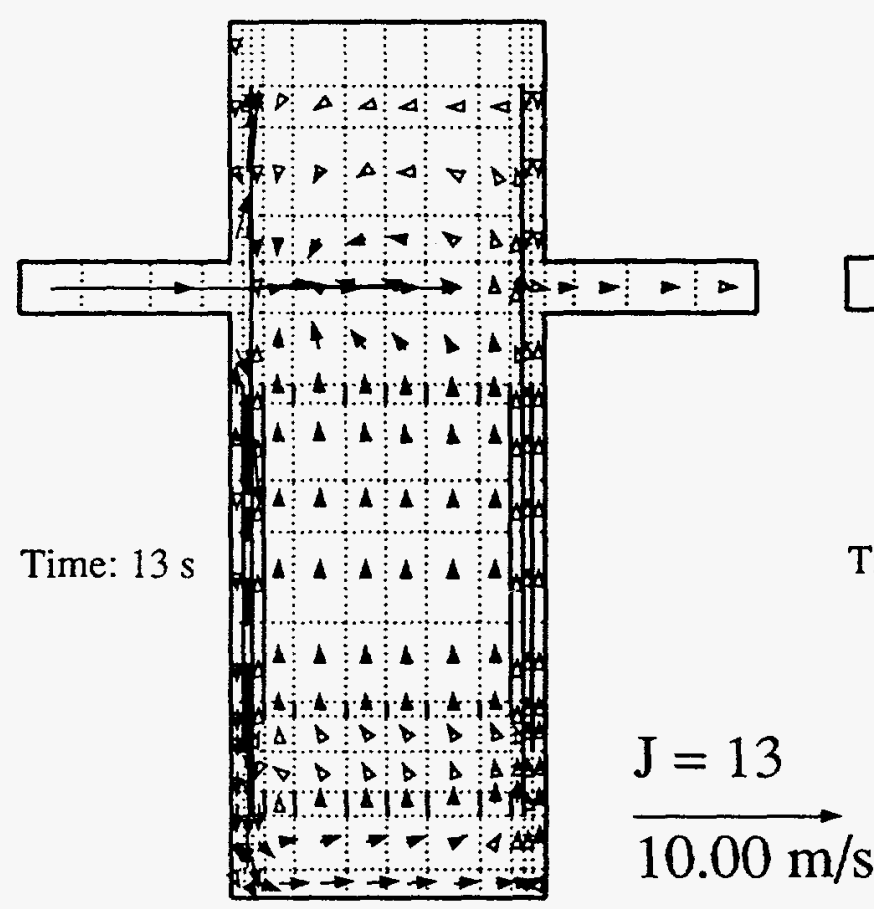

(c)

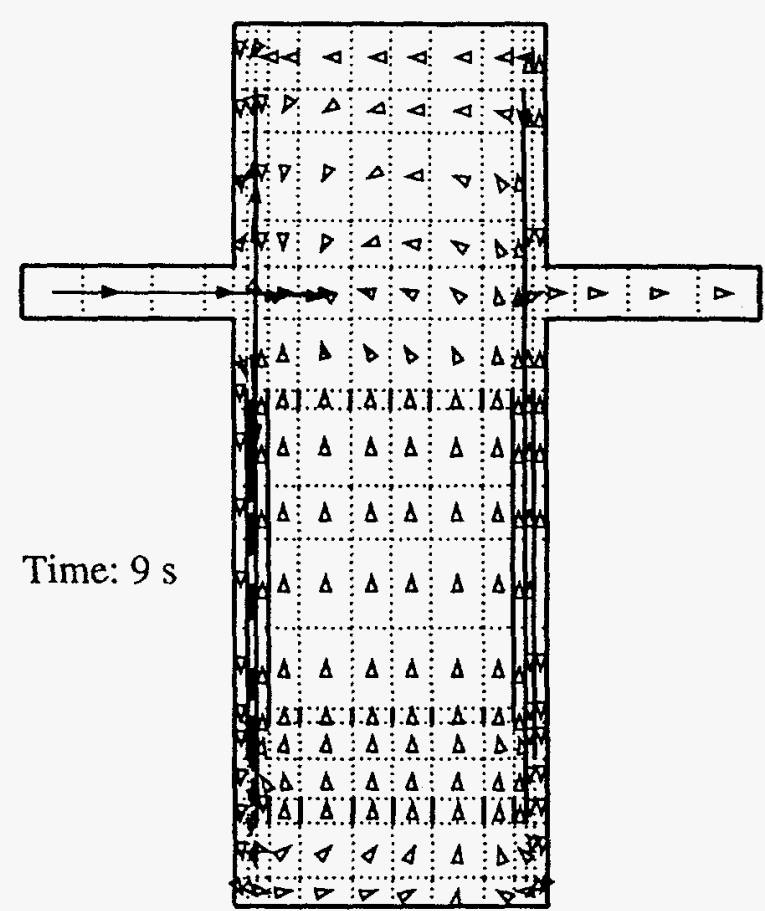

(b)

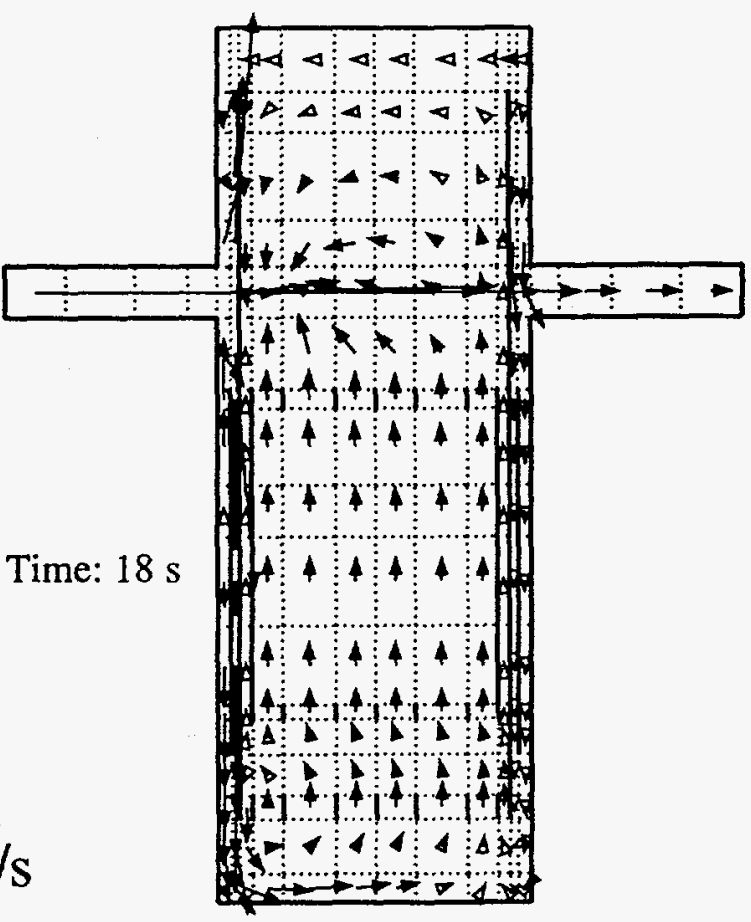

(d)

Fig. 29. Velocity distributions in cold legs and reactor vessel (vertical plane $j=13$ ) for hot-RCP-start calculation 


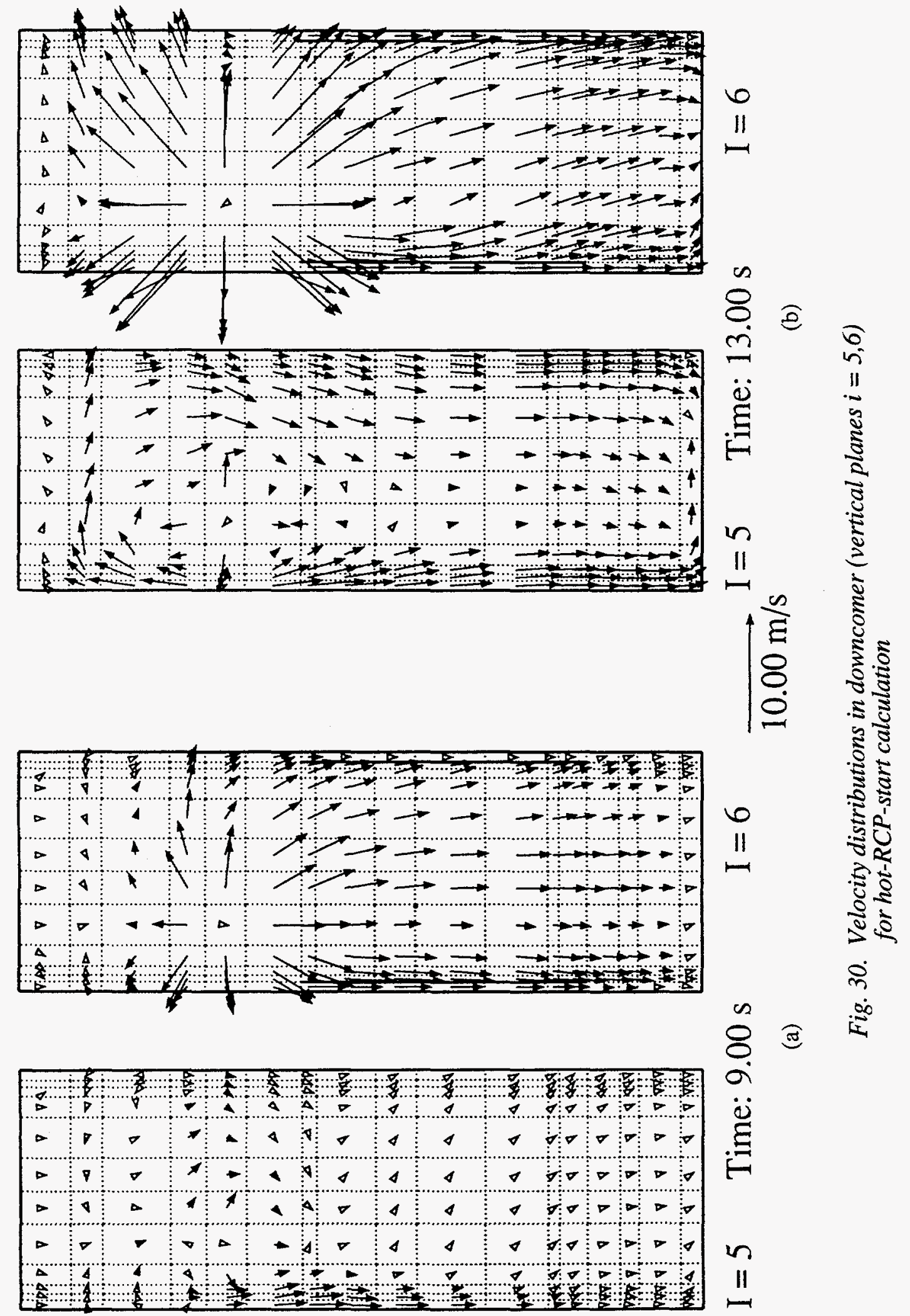




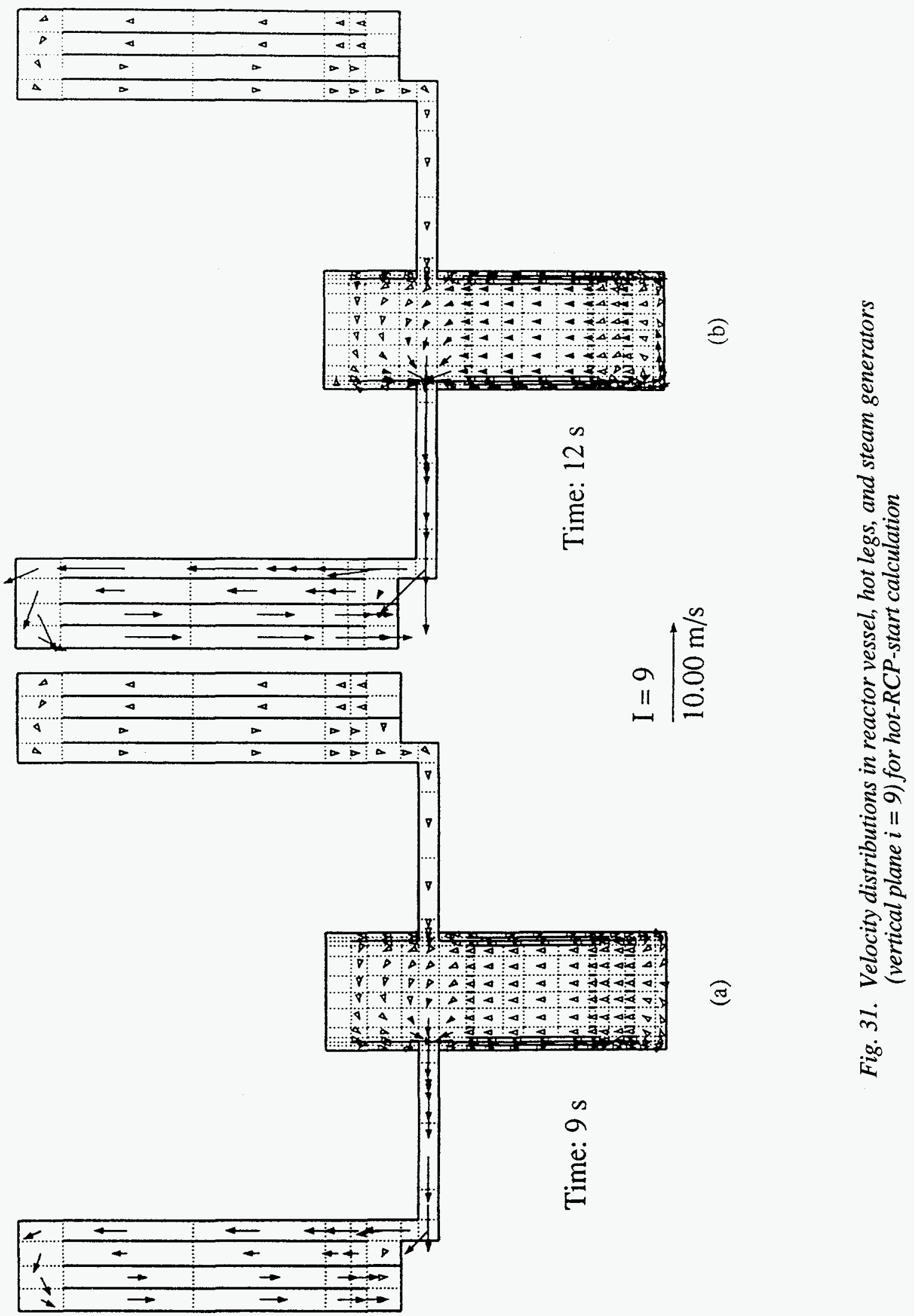



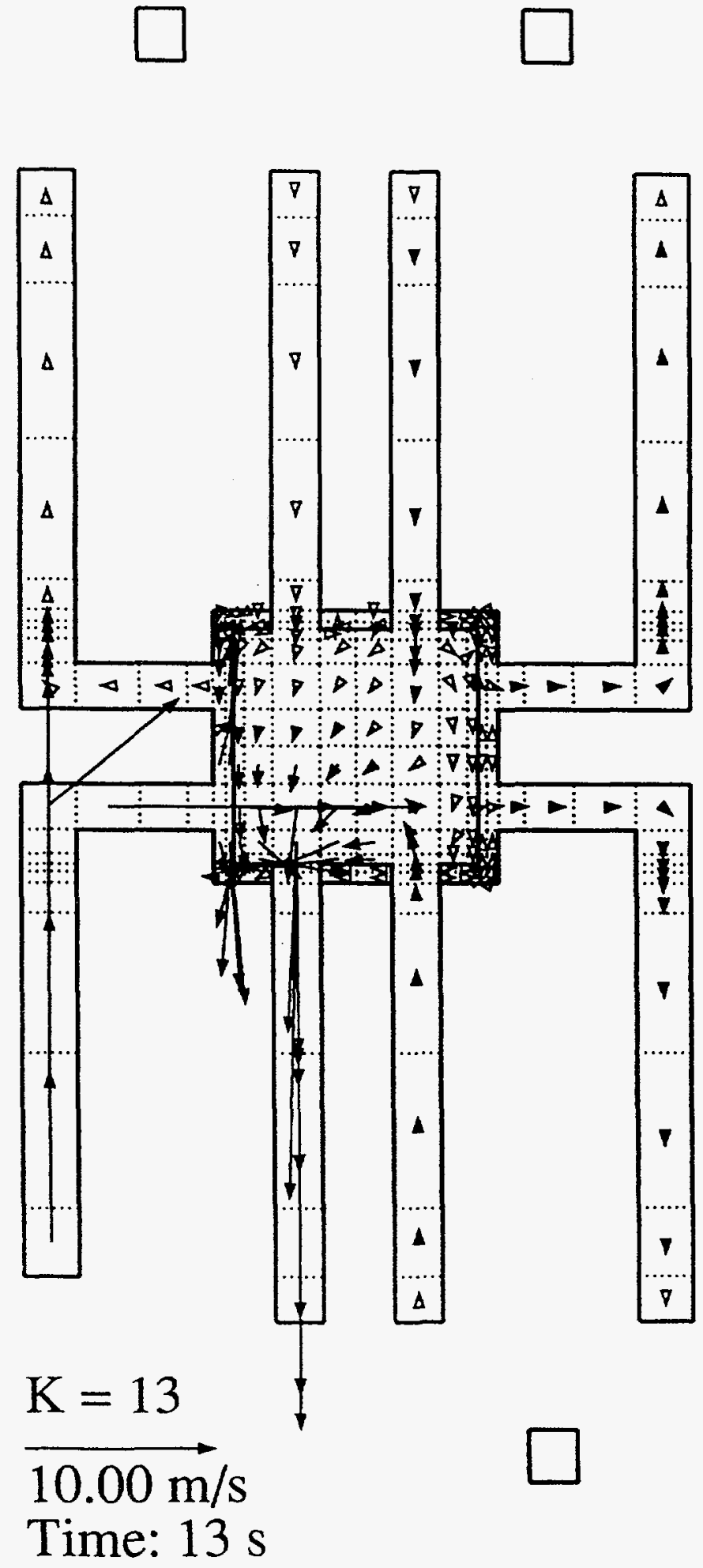

Fig. 32. Velocity distributions in reactor vessel and cold and hot legs (horizontal plane $k=13$ ) for hot-RCP-start calculation 


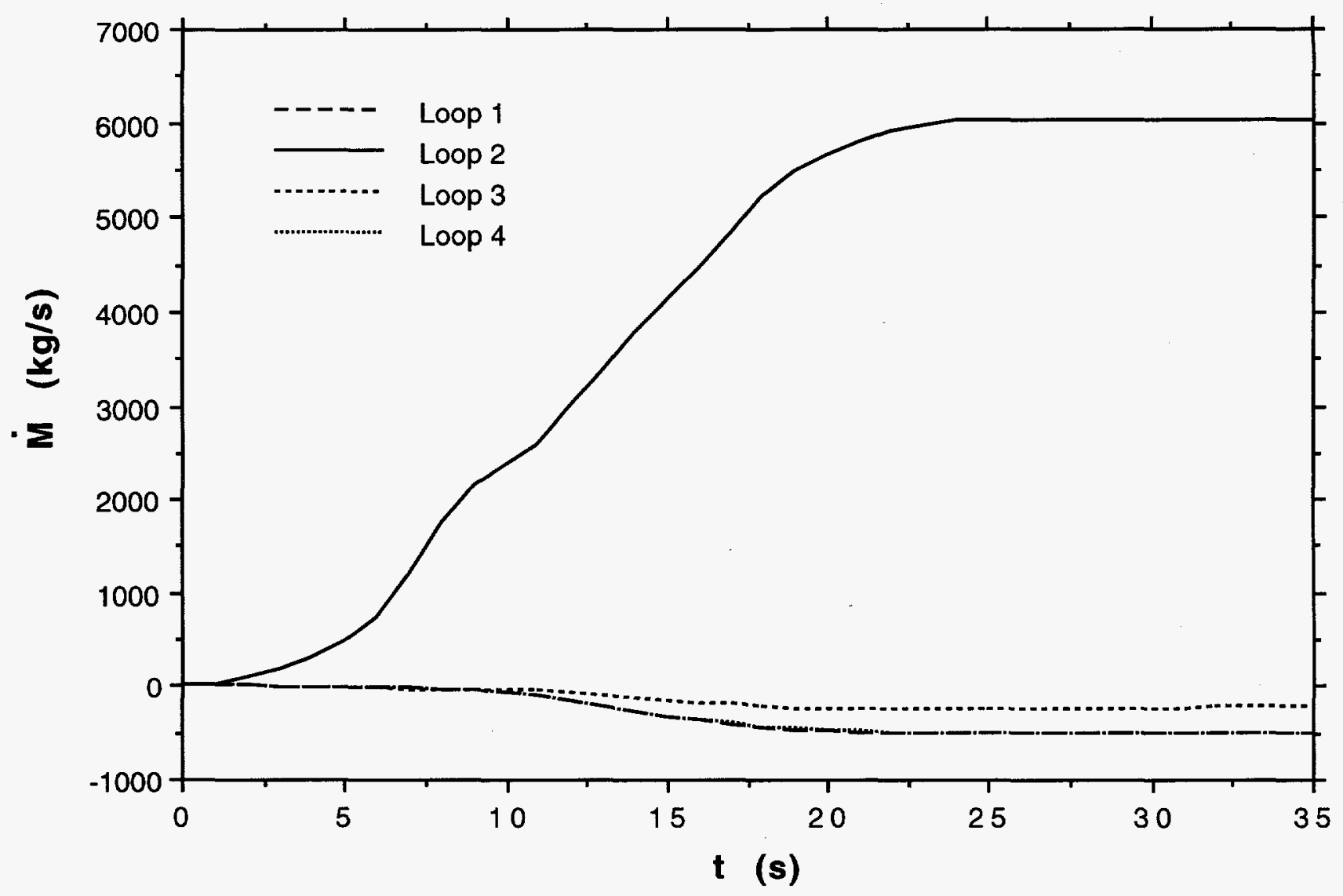

Fig. 33. Variation of mass flow rates with time in four loops for hot-RCP-start calculation 


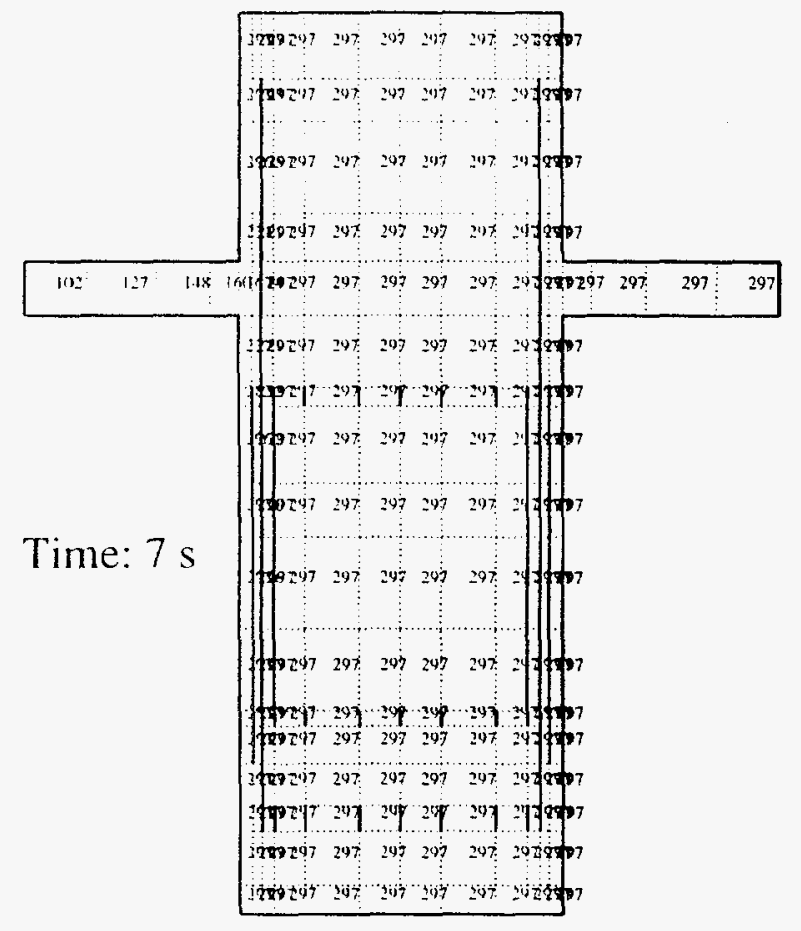

(a)

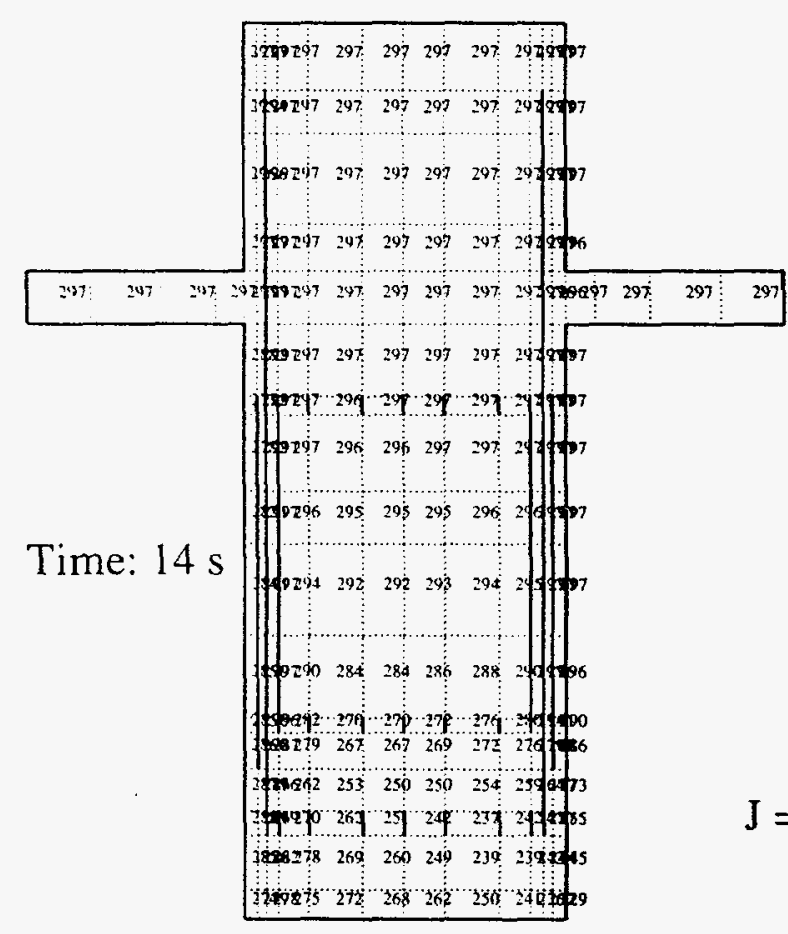

(c)

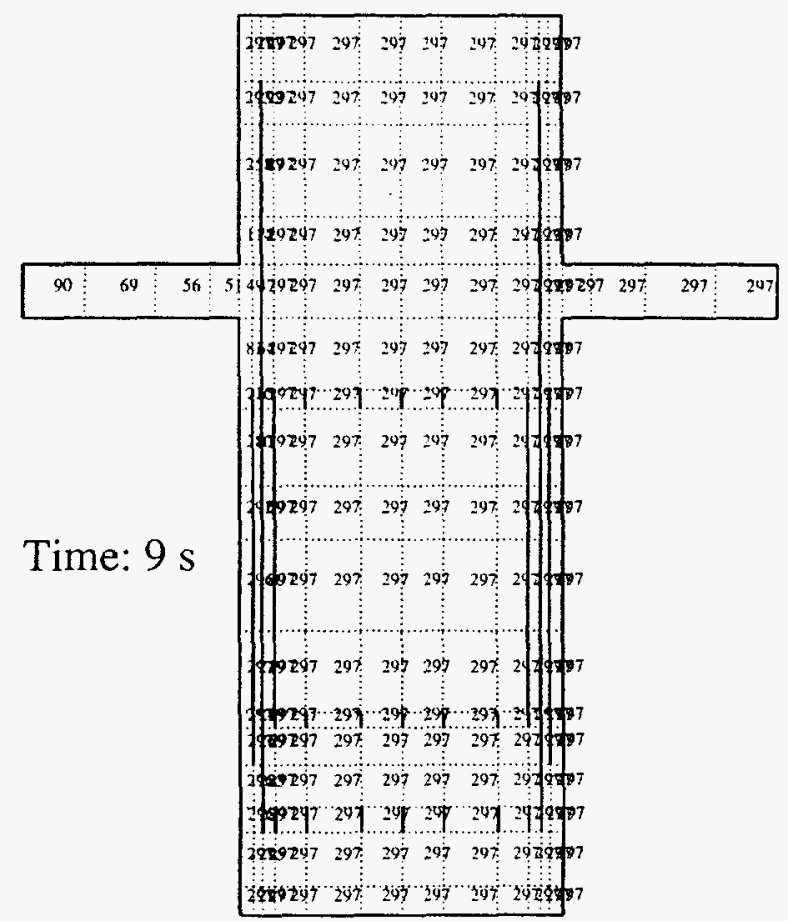

(b)

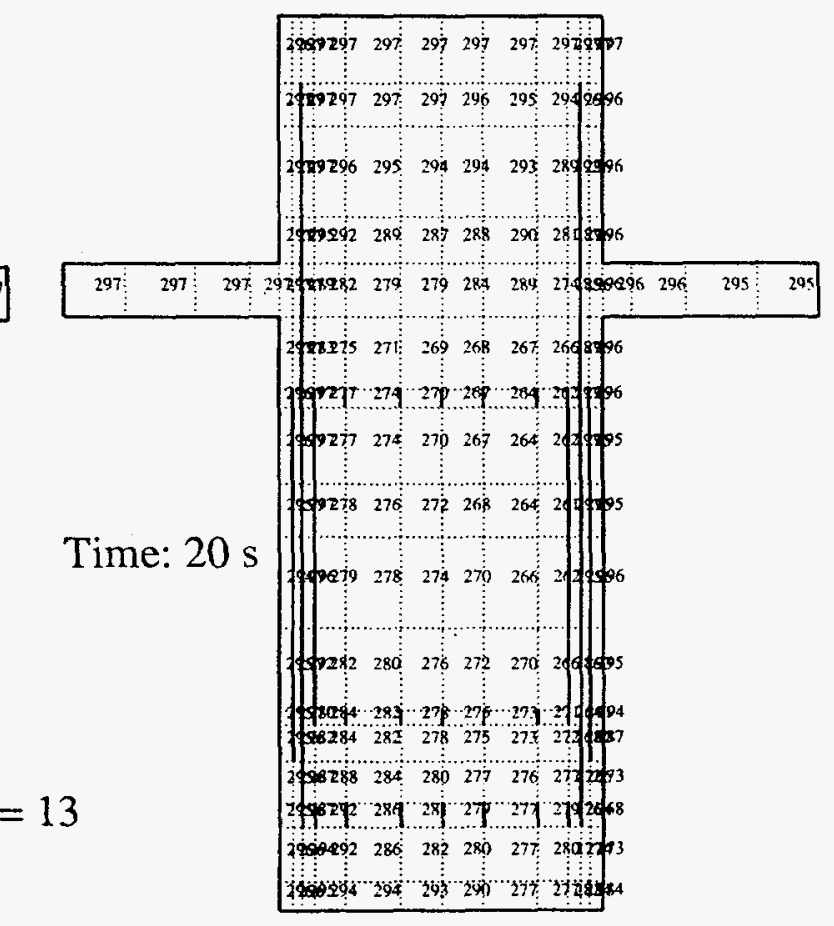

(d)

Fig. 34. Temperature $\left({ }^{\circ} \mathrm{C}\right)$ distributions in cold legs and reactor vessel (vertical plane $=13$ ) for hot-RCP-start calculation 


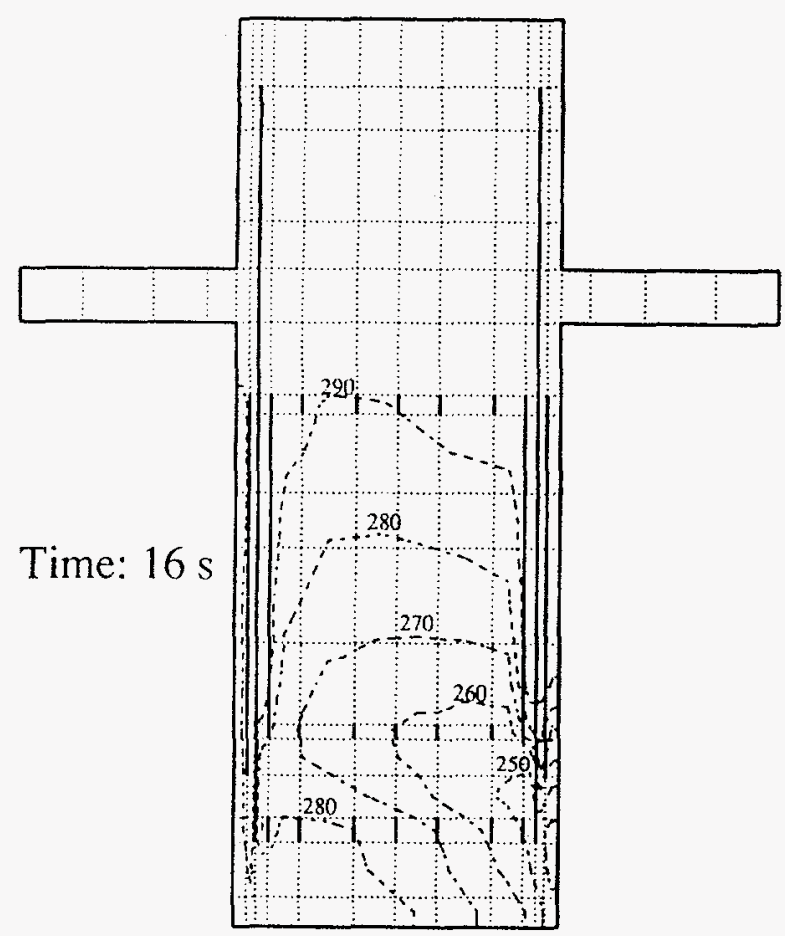

(a)

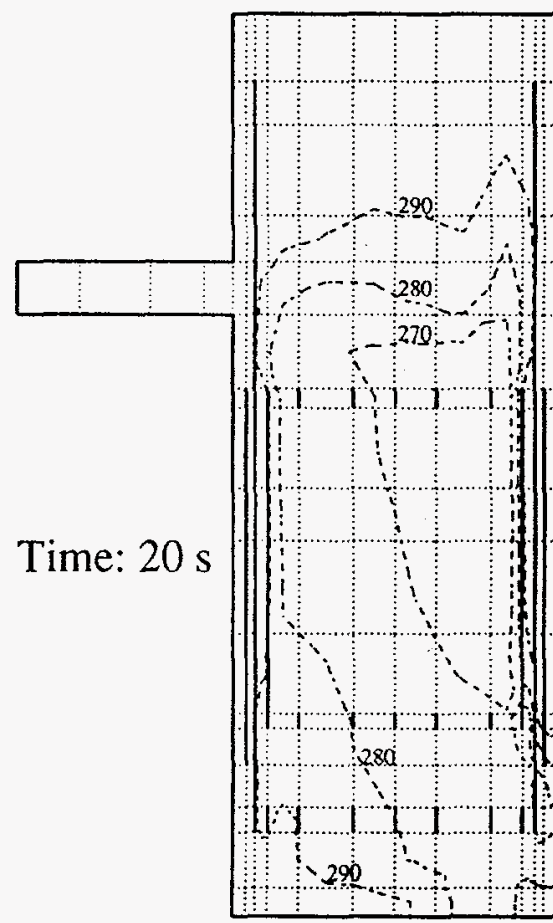

(c)

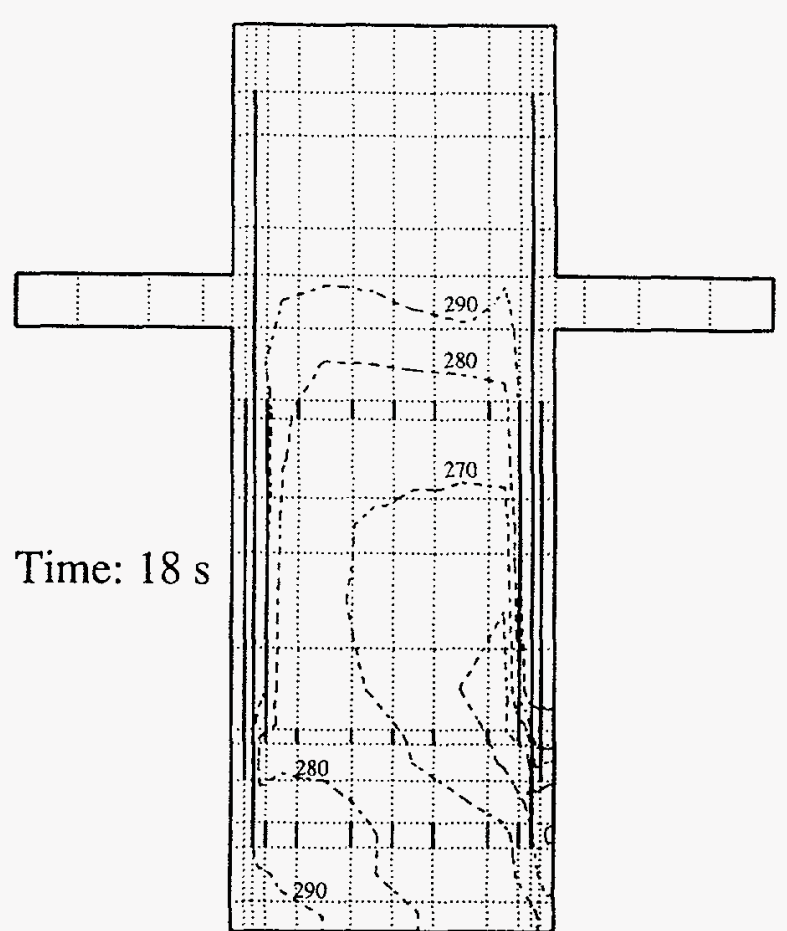

(b)

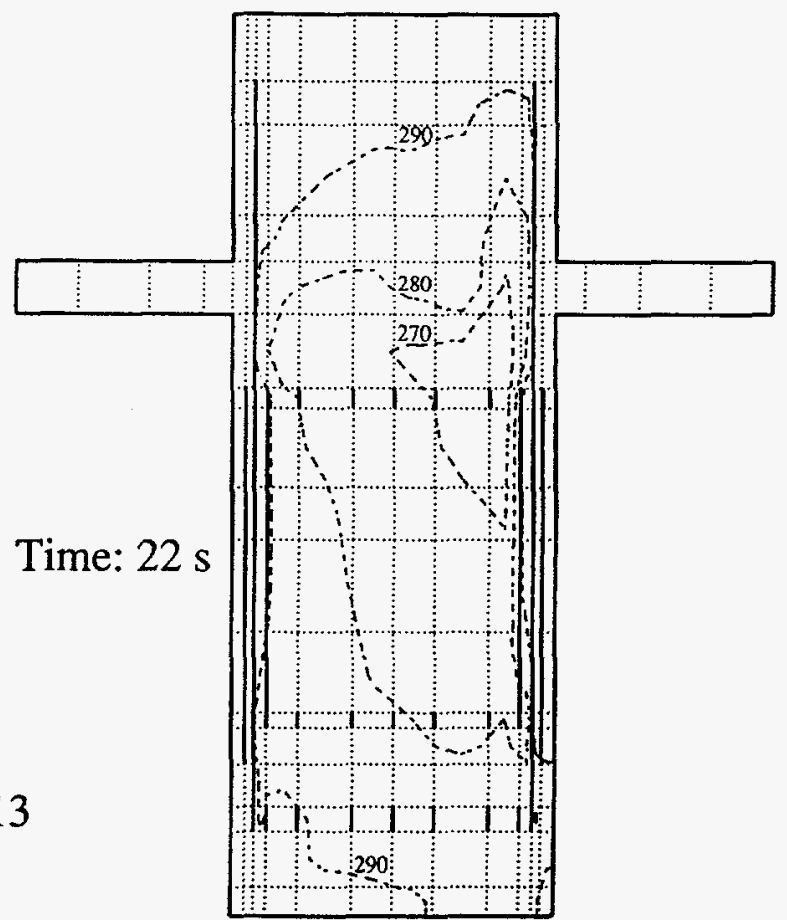

(d)

Fig. 35. Temperature $\left({ }^{\circ} \mathrm{C}\right.$ ) contours in reactor vessel (vertical plane $j=13$ ) for hot-RCP-start calculation 


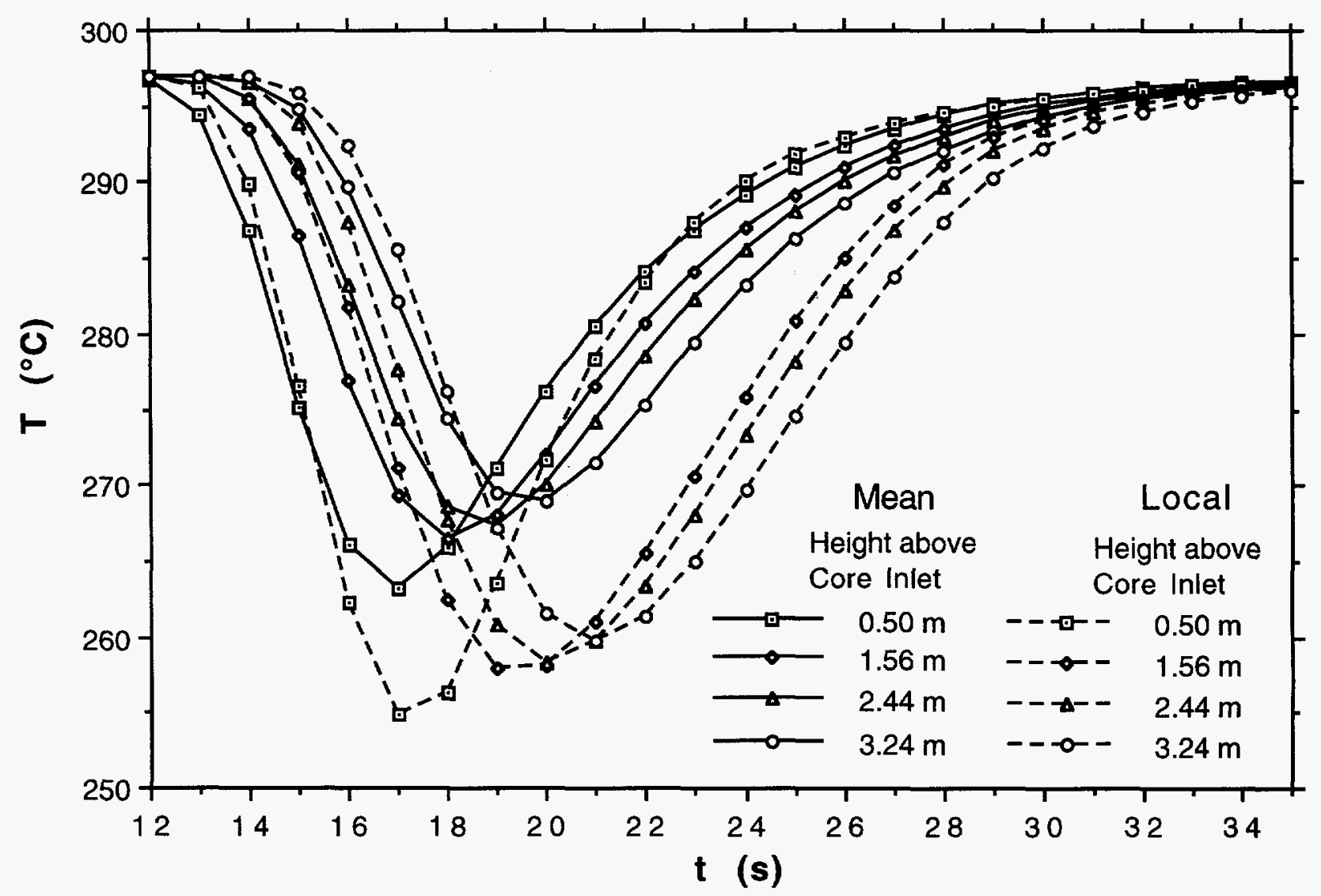

Fig. 36. Variations of mean and local minimum temperature with time in reactor core for hot-RCP-start calculation 


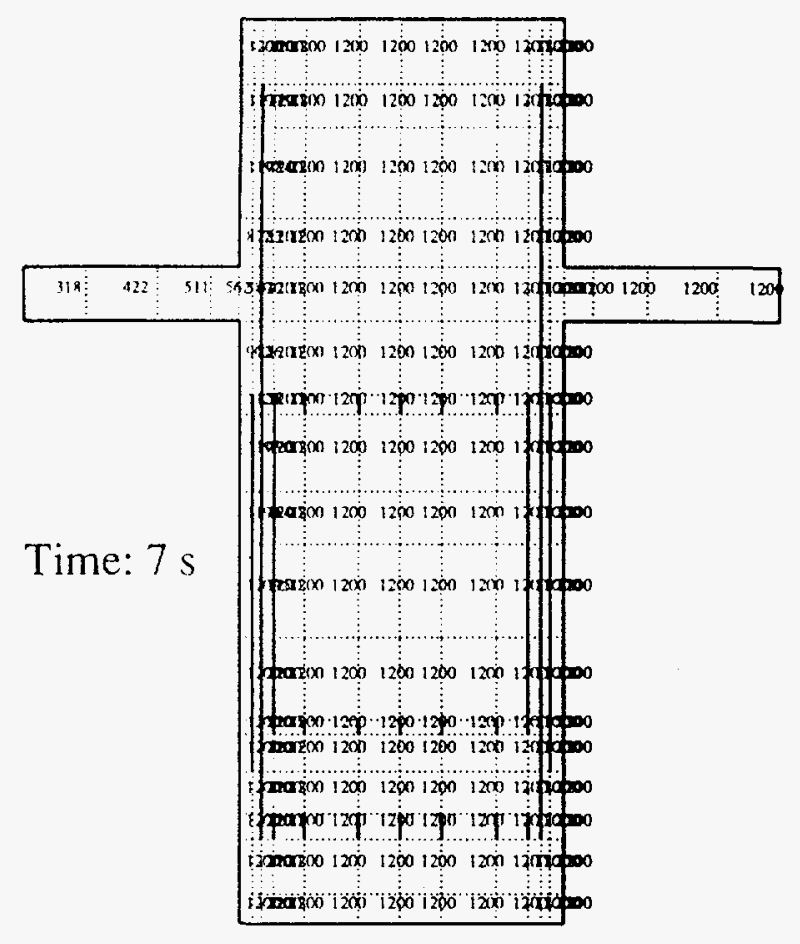

(a)

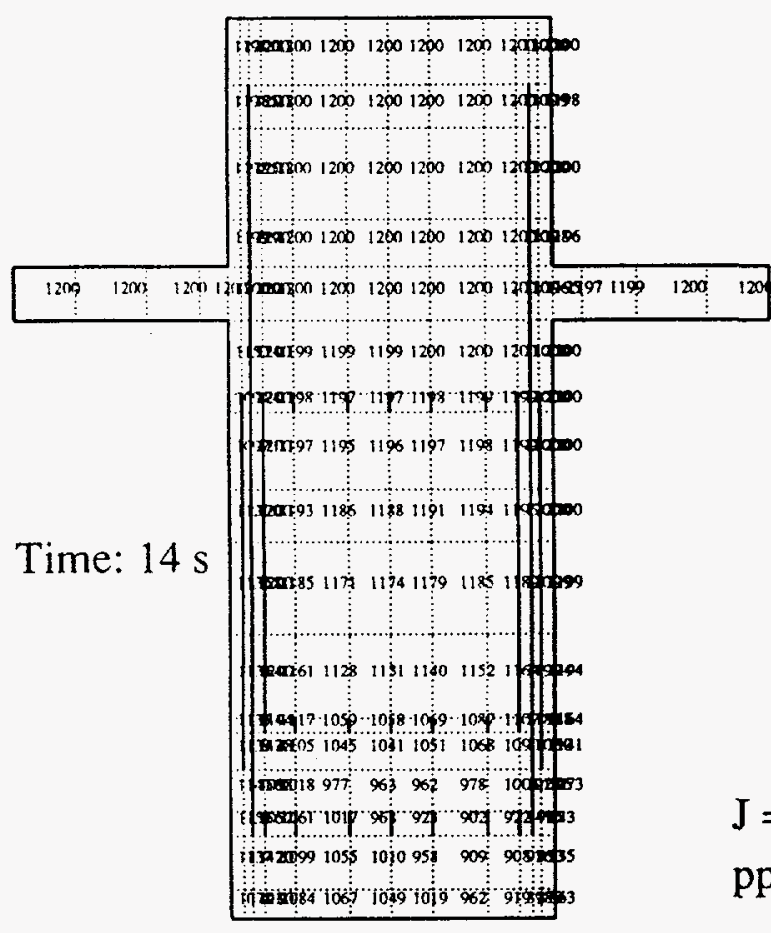

(c)

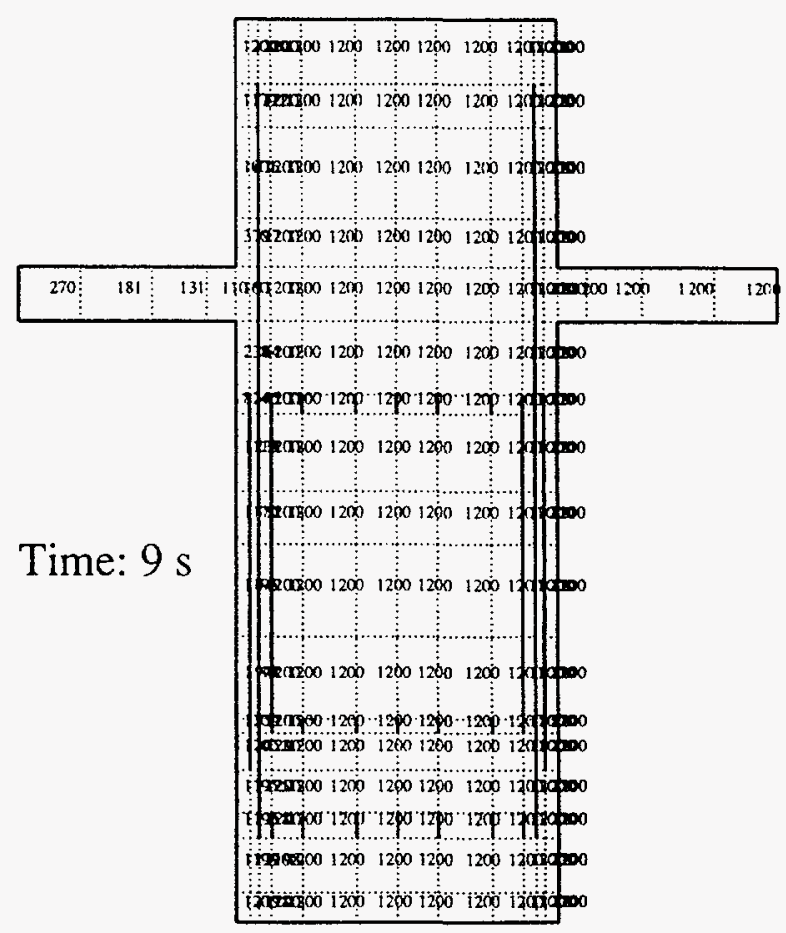

(b)

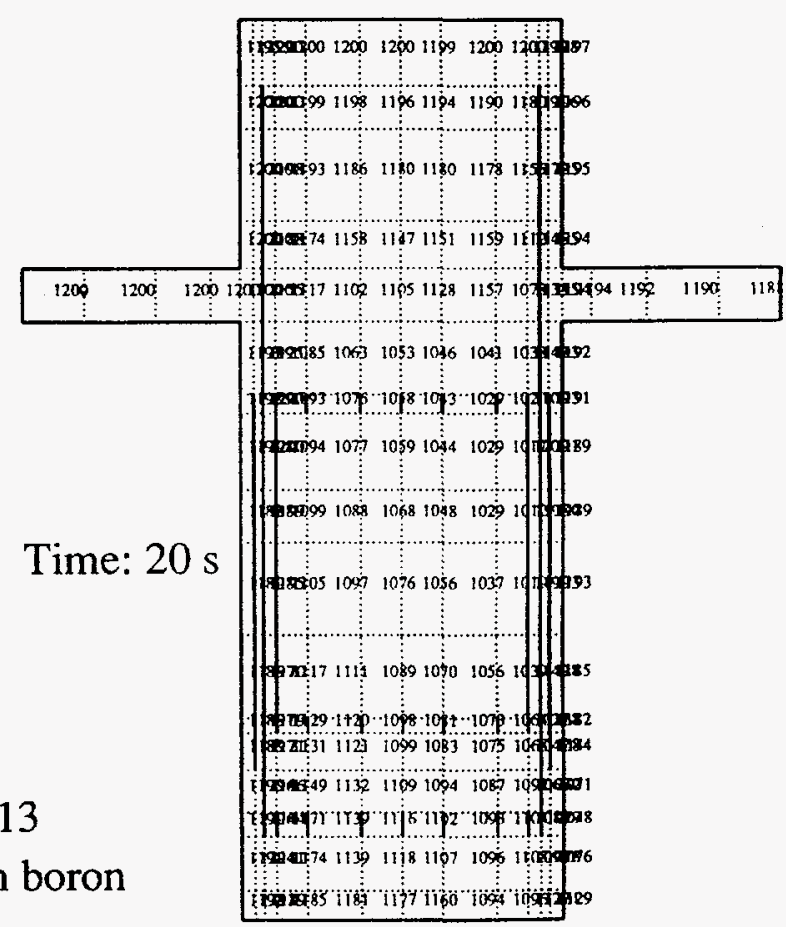

(d)

Fig. 37. Distributions of boron concentration in cold legs and reactor vessel (vertical plane $j=13$ ) for hot-RCP-start calculation 


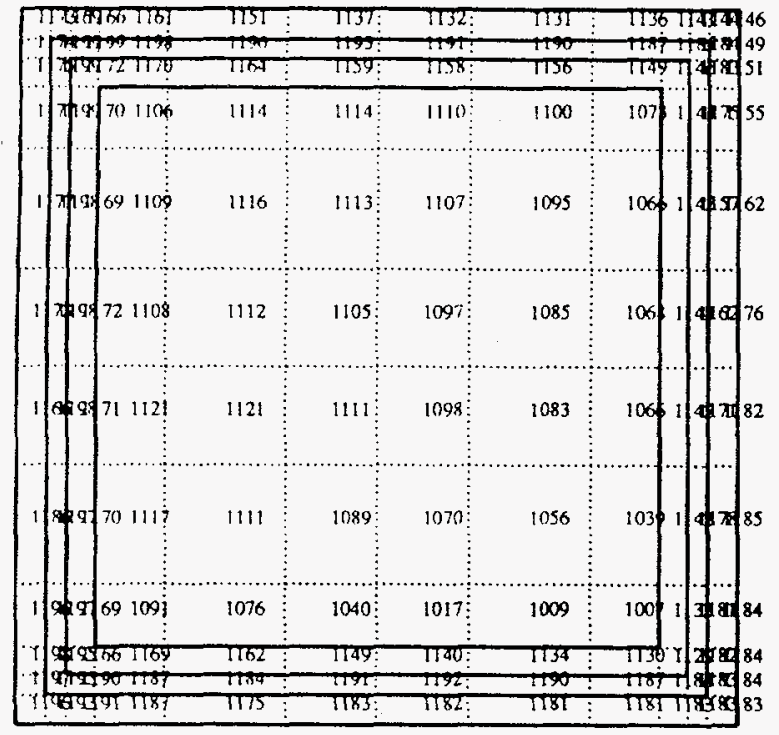

$\mathrm{K}=7$

(a)

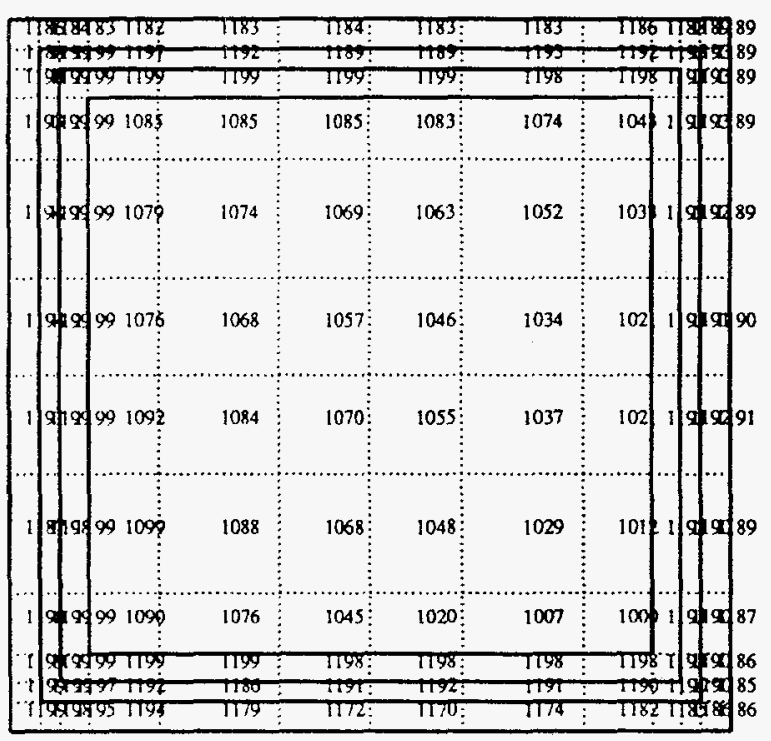

$\mathrm{K}=9$

(c) ppm boron

Time: $20 \mathrm{~s}$

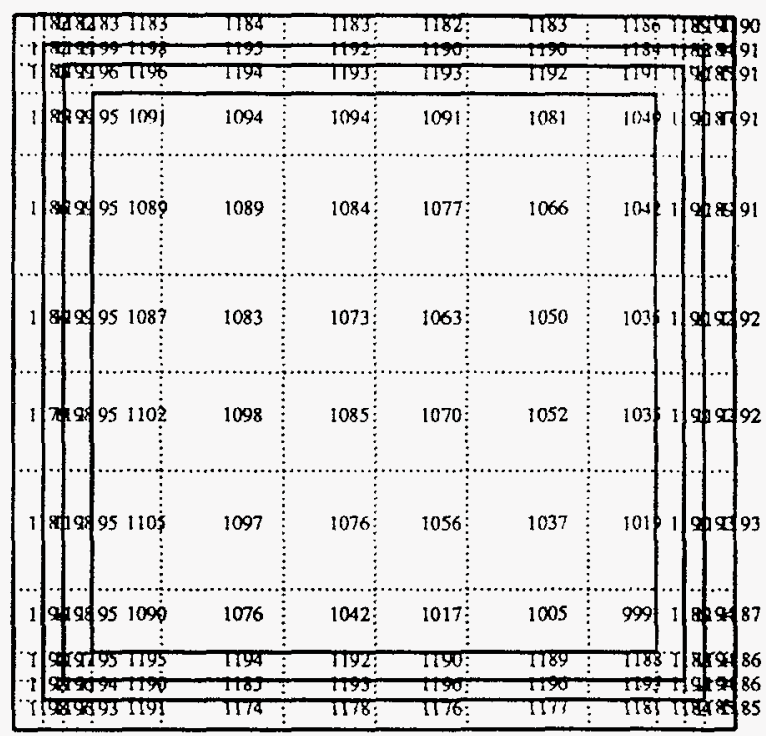

$K=8$

(b)

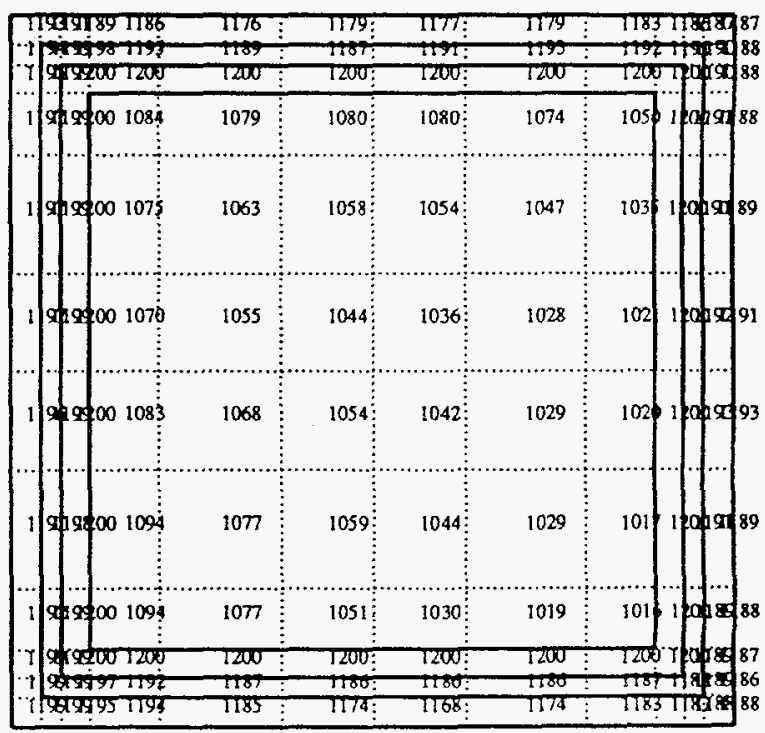

$K=10$

(d)

Fig. 38. Distributions of boron concentration in reactor core (horizontal planes $k=7-10$ ) at $20 \mathrm{~s}$ into transient for hot-RCP-start calculation 


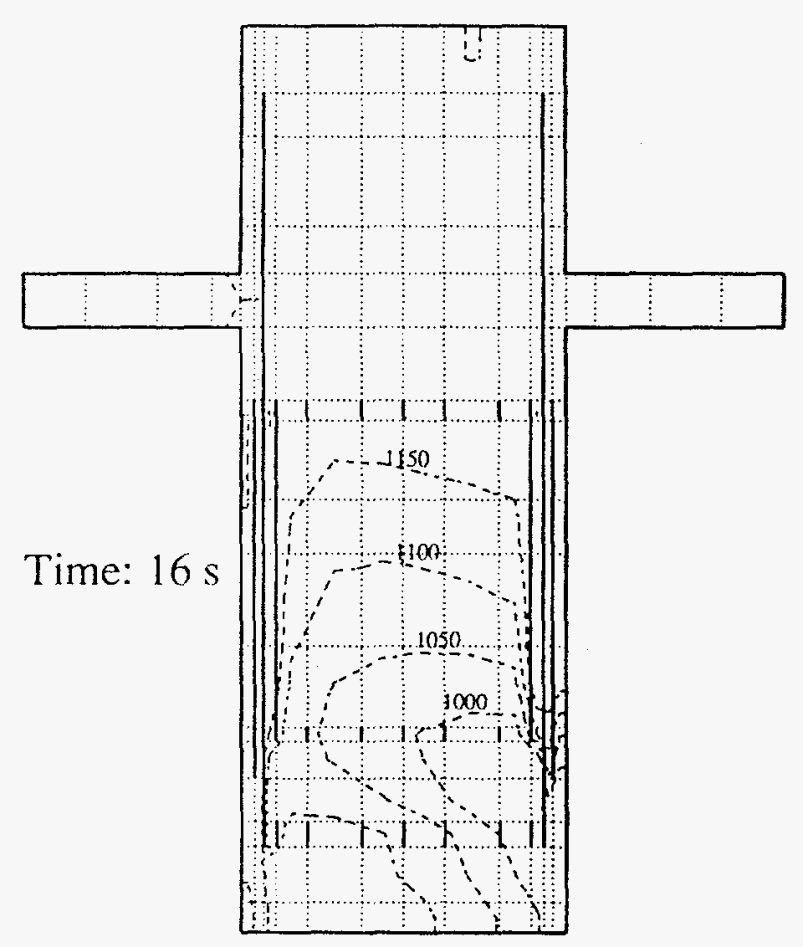

(a)

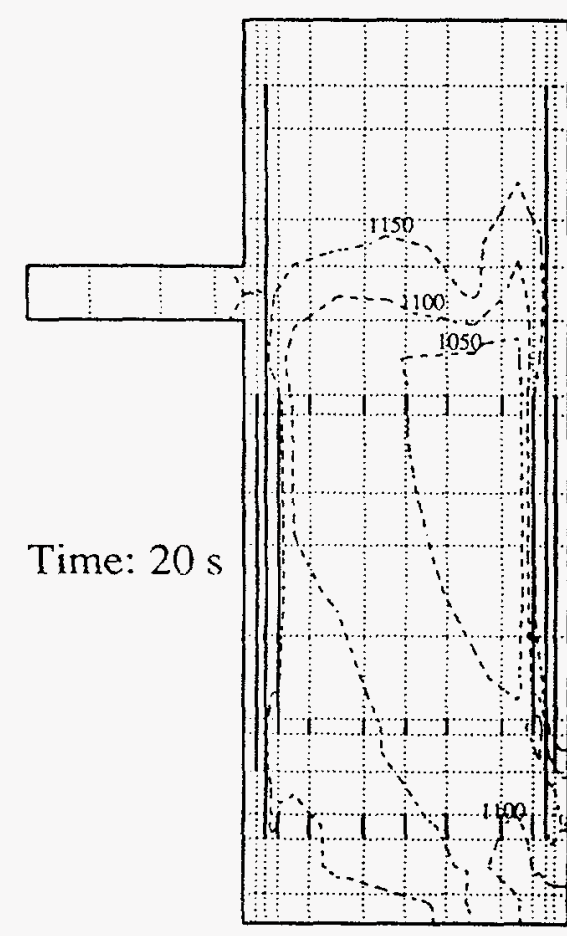

(c)

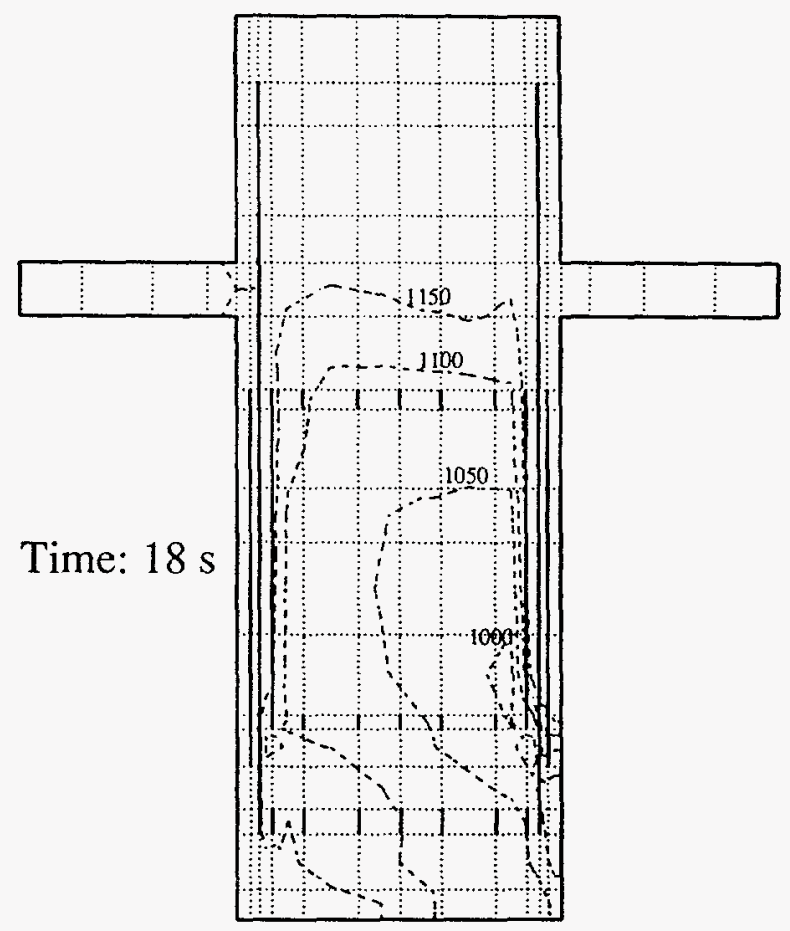

(b)

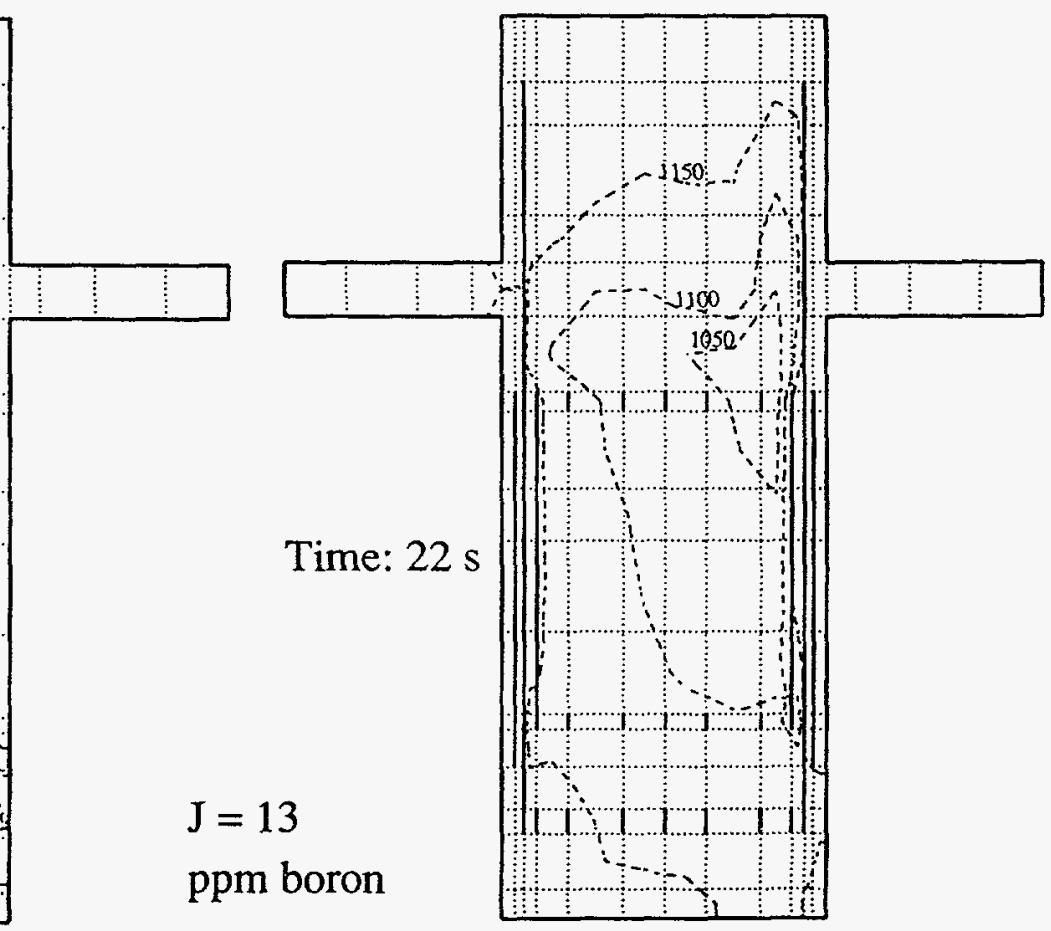

(d)

Fig. 39. Contours of boron concentration in reactor vessel (vertical plane $j=13$ ) for hot-RCP-start calculation 


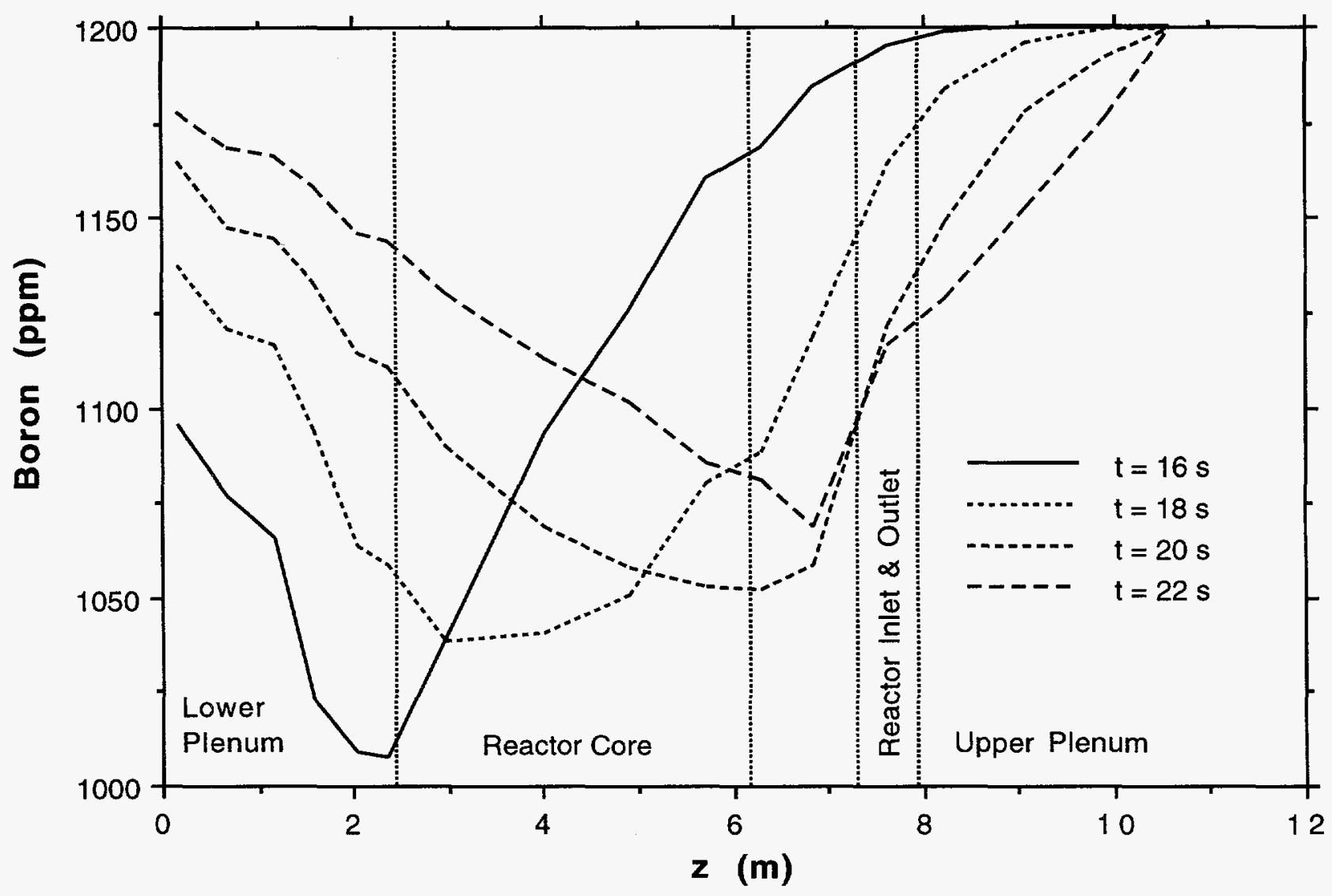

Fig. 40. Variation of mean boron concentration along axis of reactor vessel at $16,18,20$, and $22 \mathrm{~s}$ into the transient for hot-RCP-start calculation 


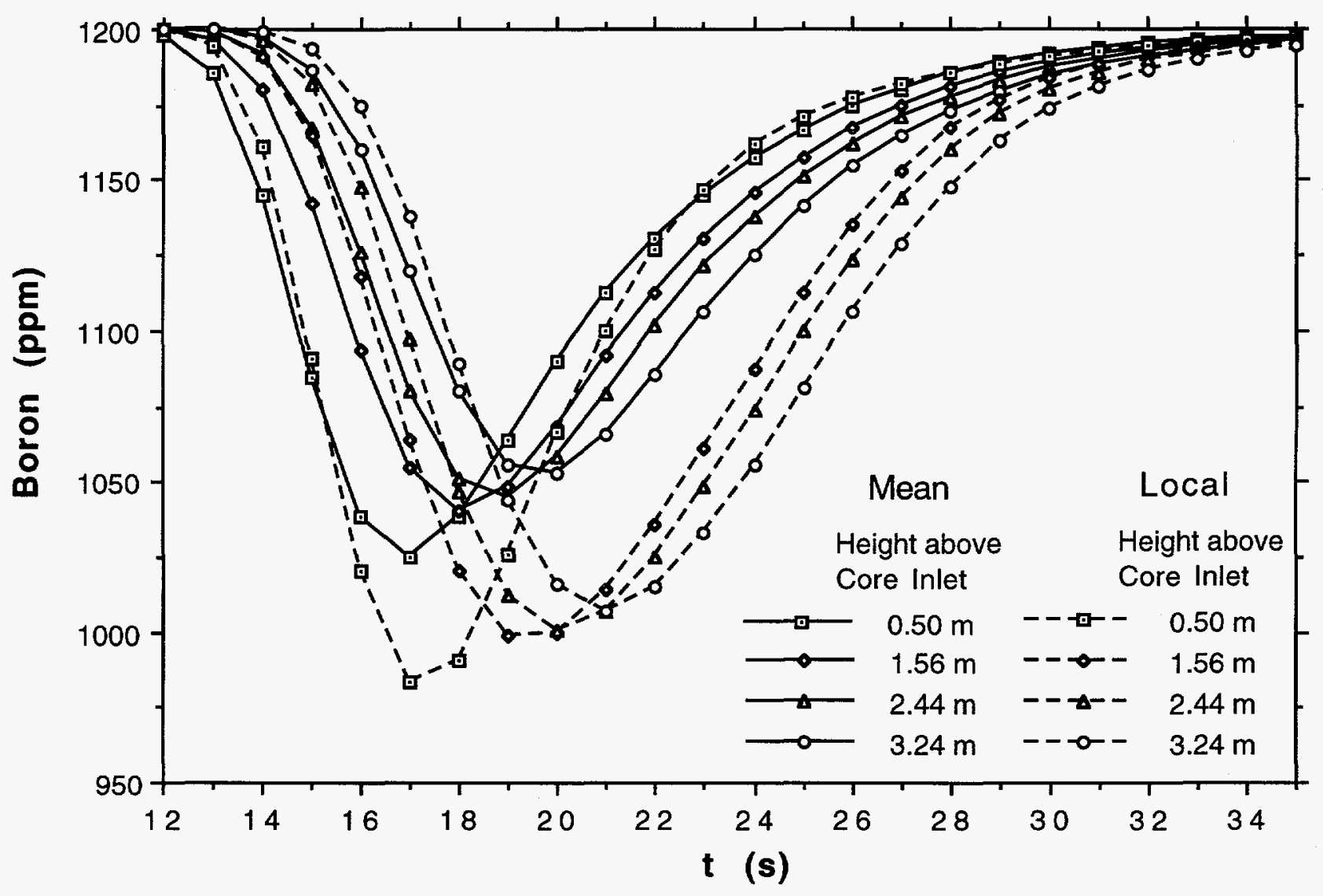

Fig. 41. Variation of mean and local minimum boron concentrations with time in reactor core for hot-RCP-start calculation 


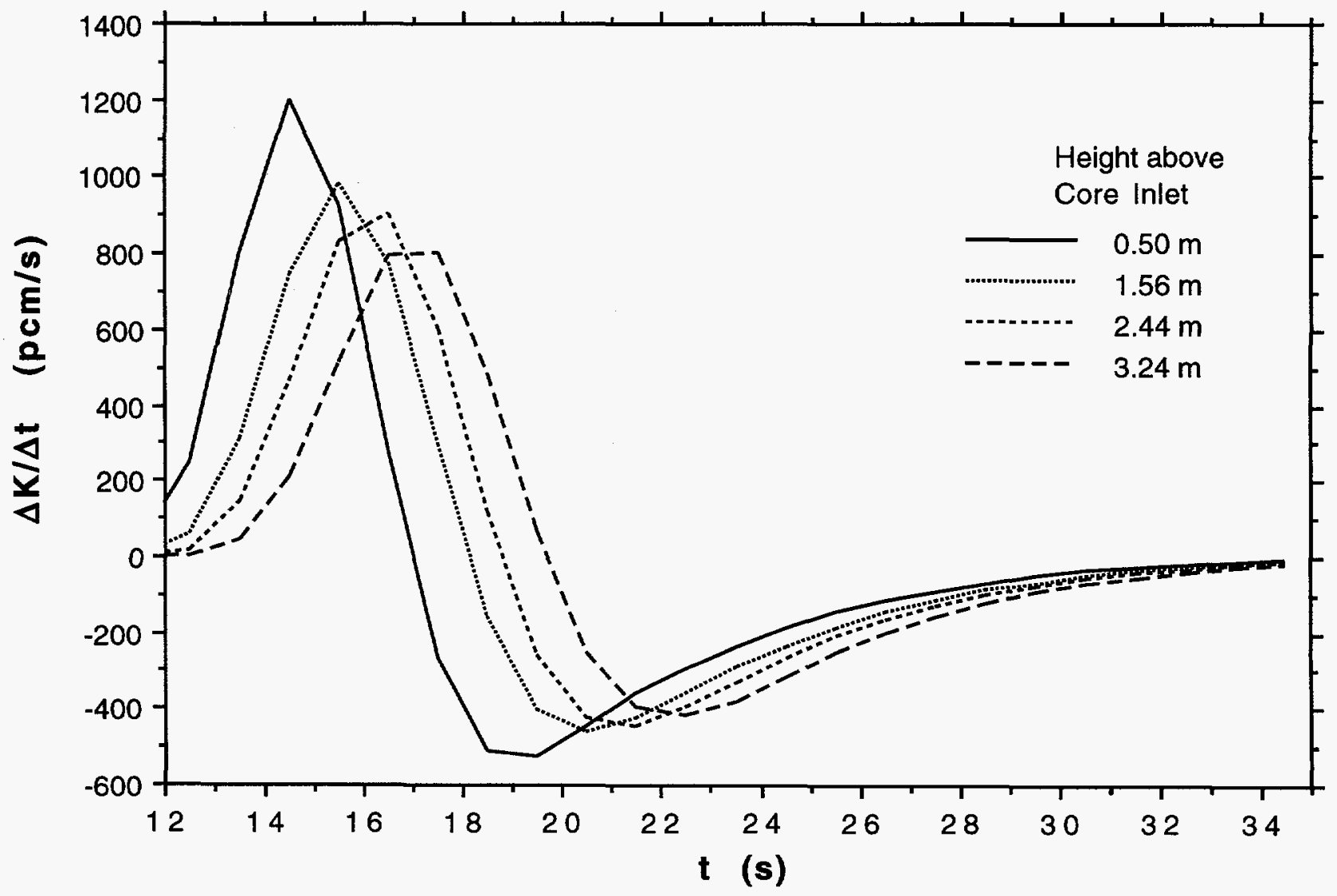

Fig. 42. Variation of mean reactivity insertion rate with time in reactor core for hot-RCP-start calculation 


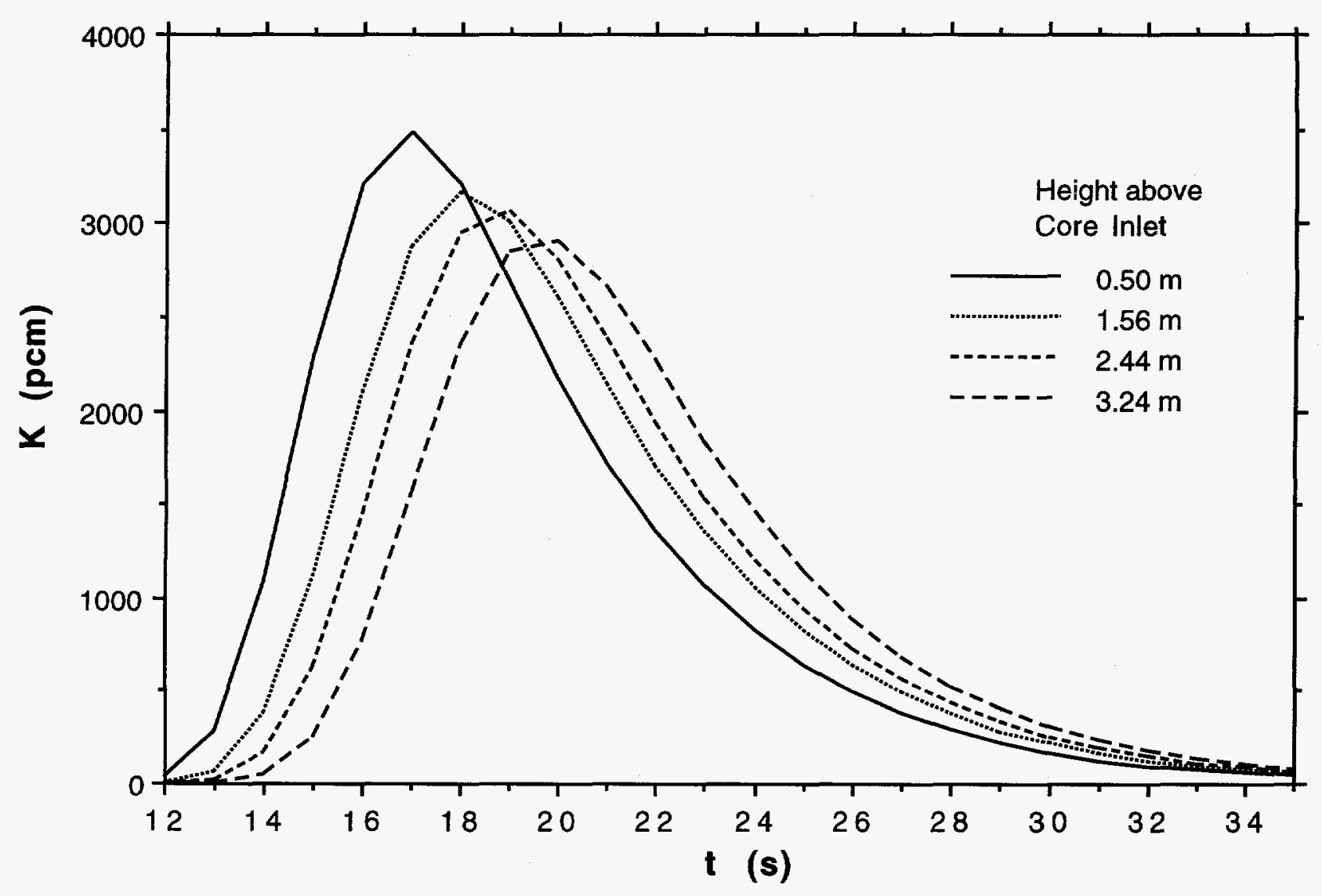

Fig. 43. Variation of mean reactivity with time in reactor core for hot-RCP-start calculation 


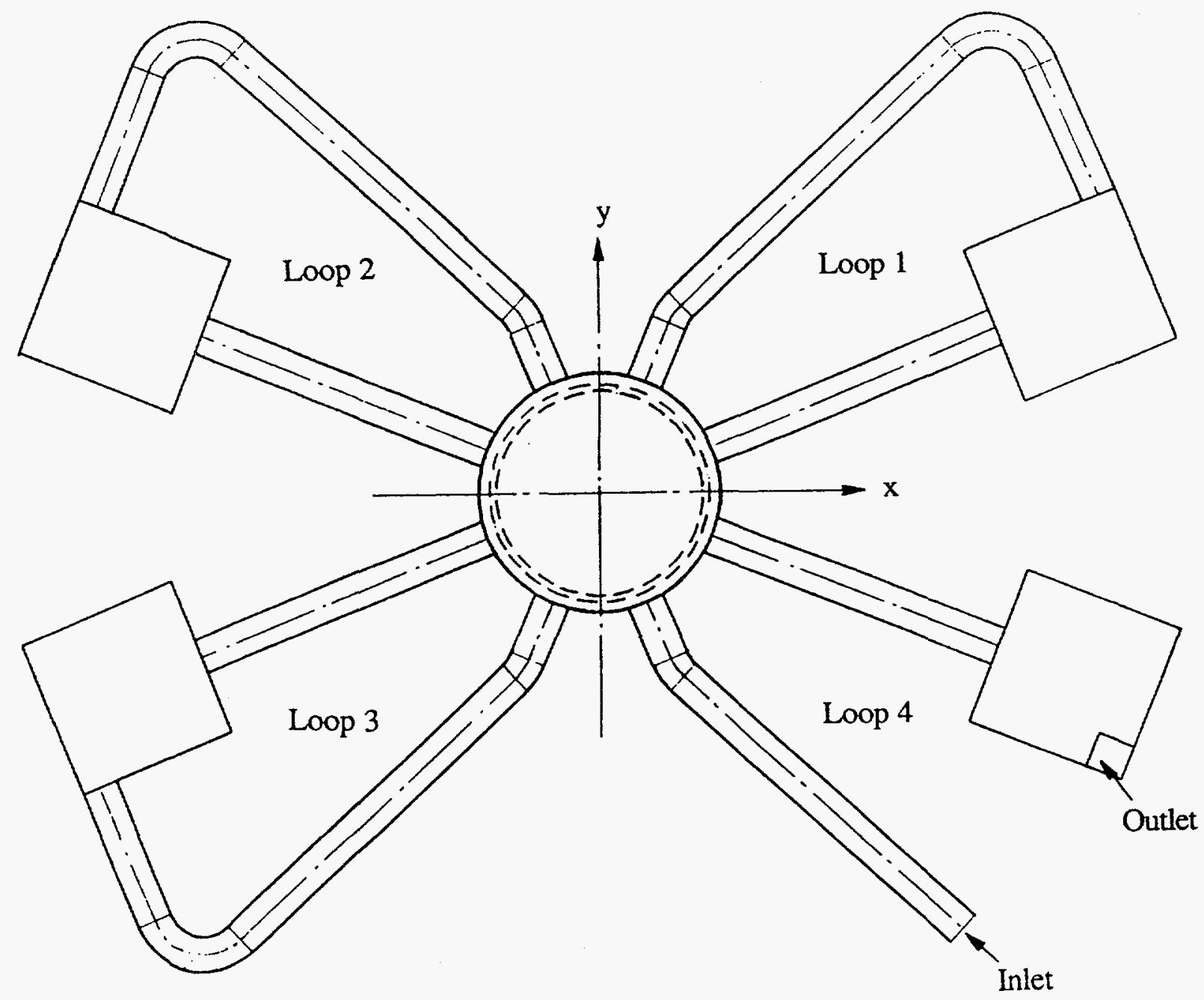

Fig. 44. Top view of computational geometry with multicoordinate model 


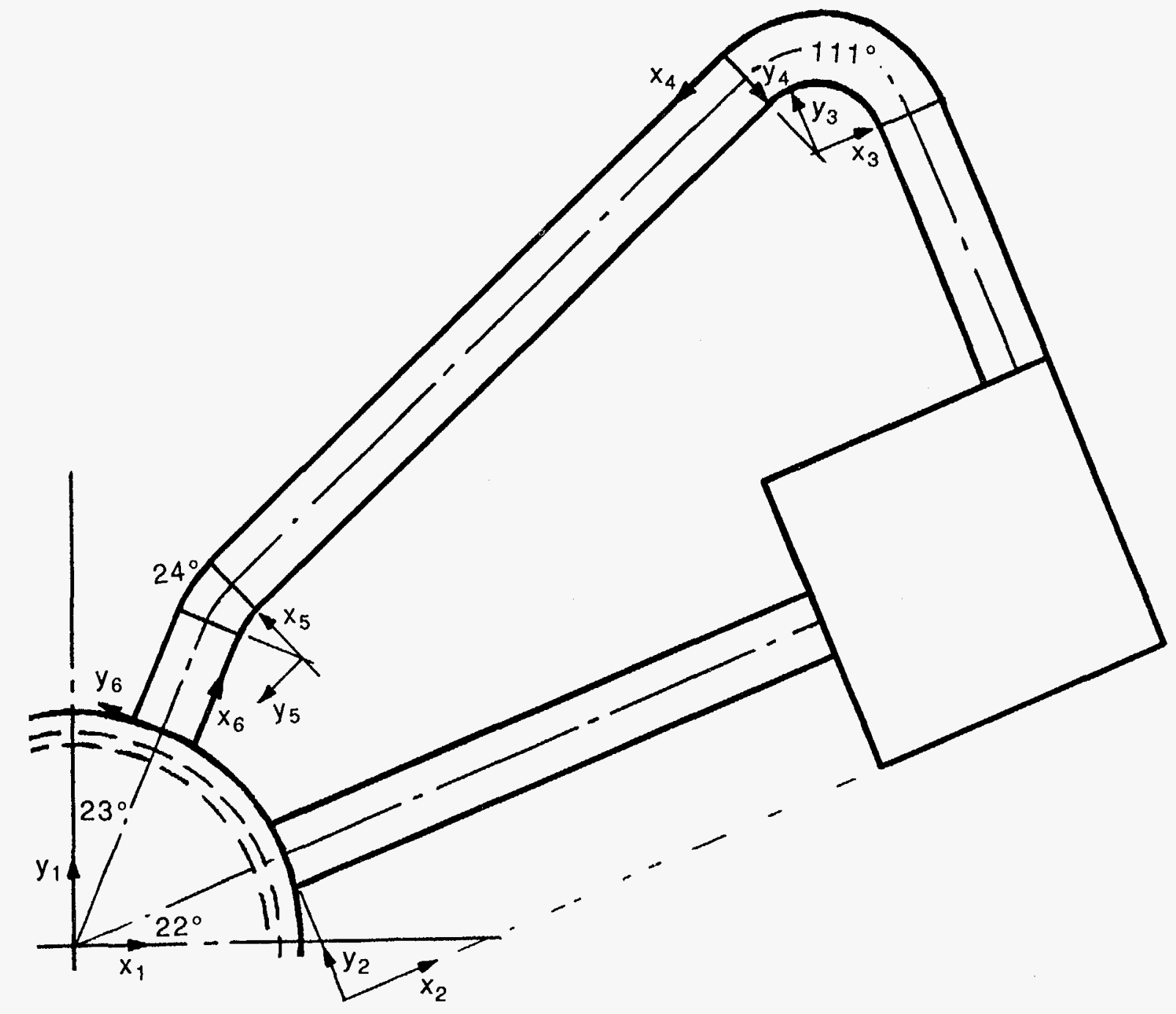

Fig. 45. Coordinate systems for one loop of reactor coolant system 


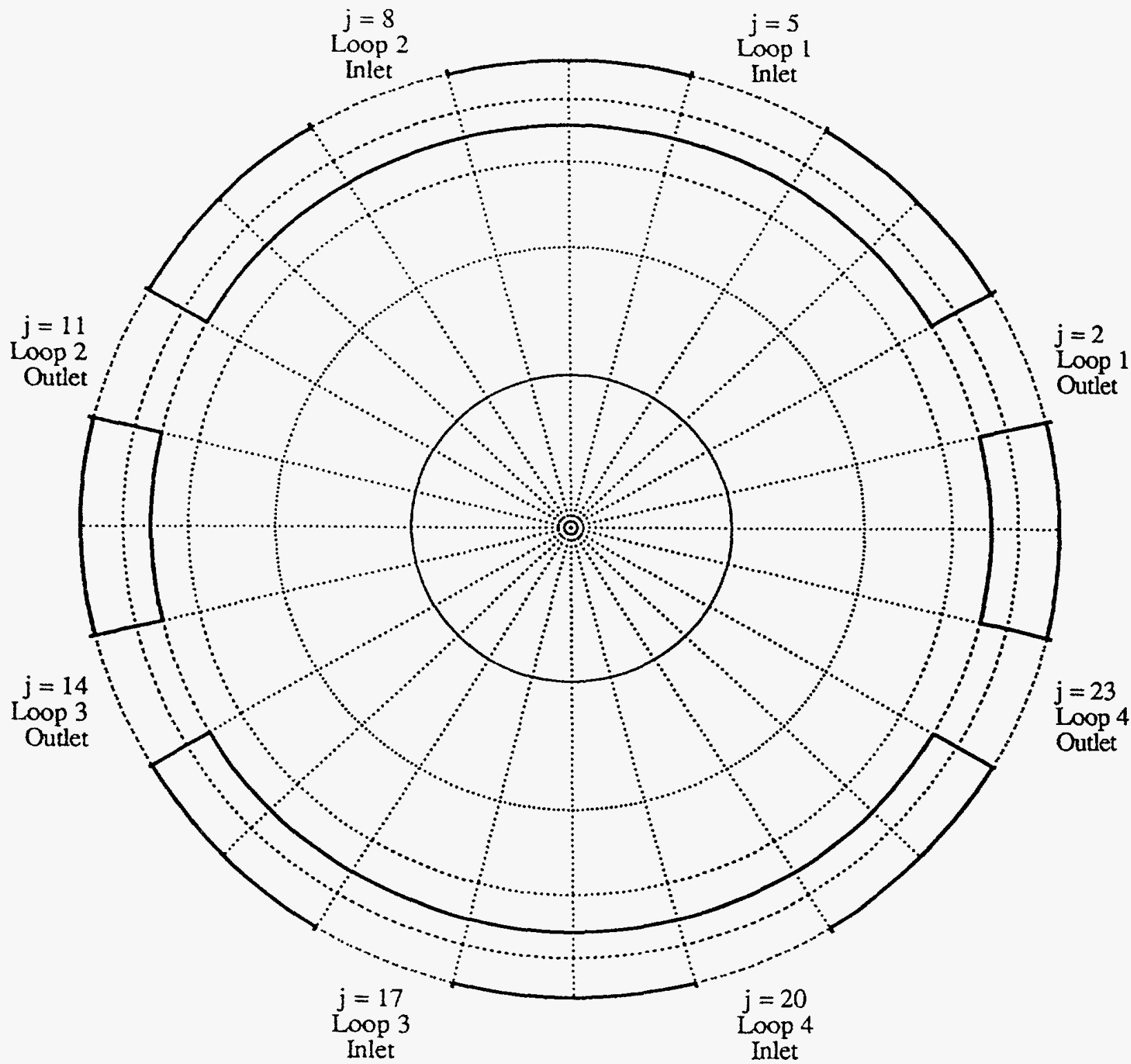

Fig. 46. Horizontal partitions in reactor vessel with multicoordinate model 


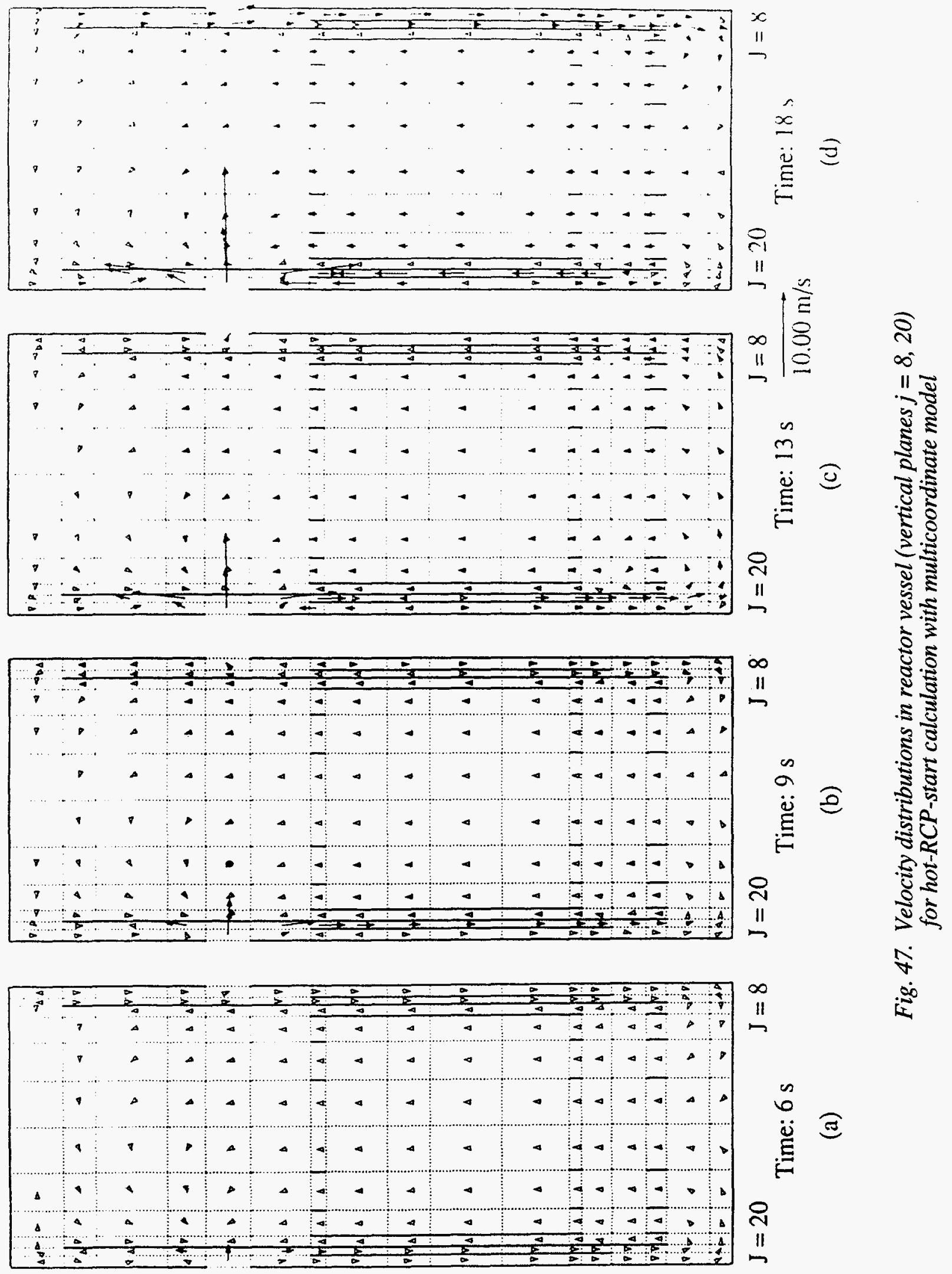



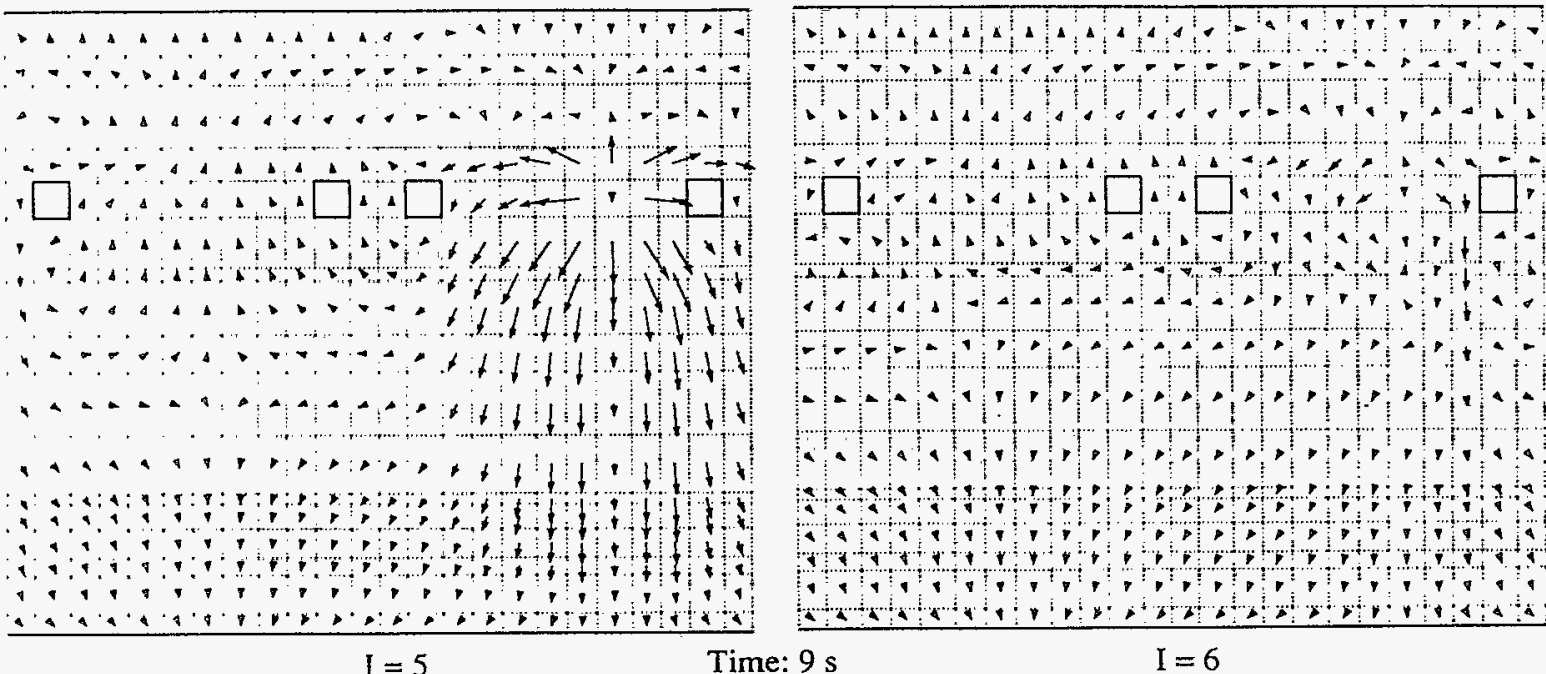

(a)
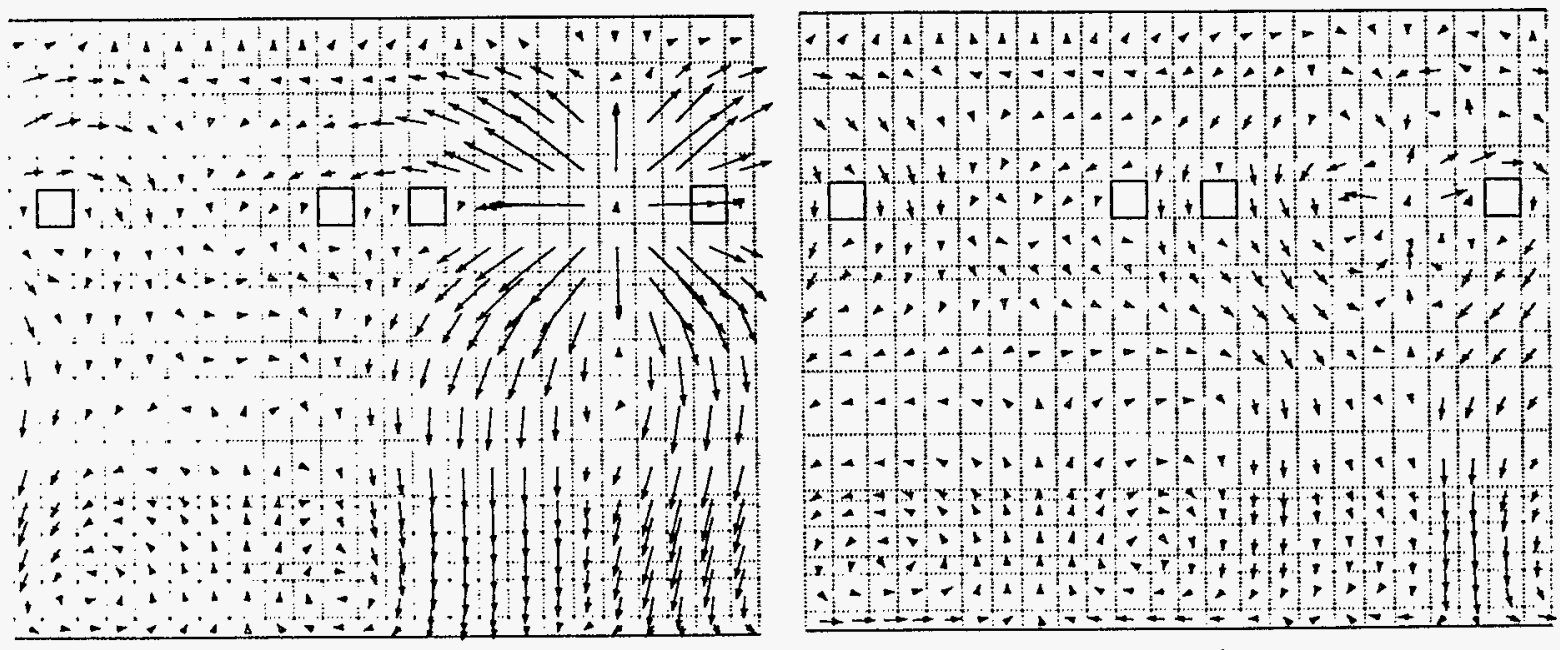

$I=5$

Time: $13 \mathrm{~s}$

$I=6$

$10.00 \mathrm{~m} / \mathrm{s}$

(b)

Fig. 48. Velocity distributions in downcomer (vertical planes $i=5,6$ ) for hot-RCP-start calculation with multicoordinate model 


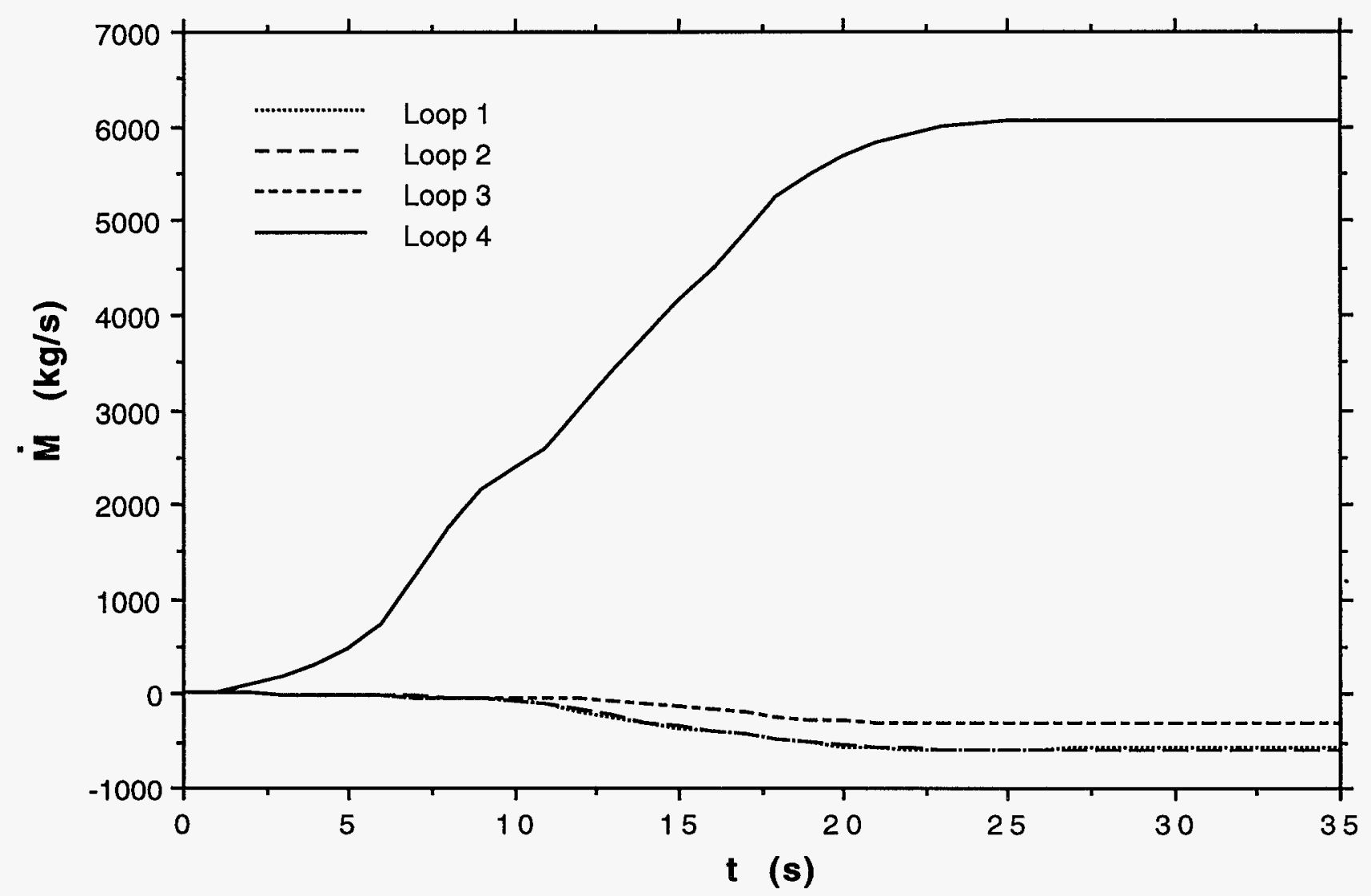

Fig. 49. Variation of mass flow rates with time in four loops for hot-RCP-start calculation with multicoordinate model 


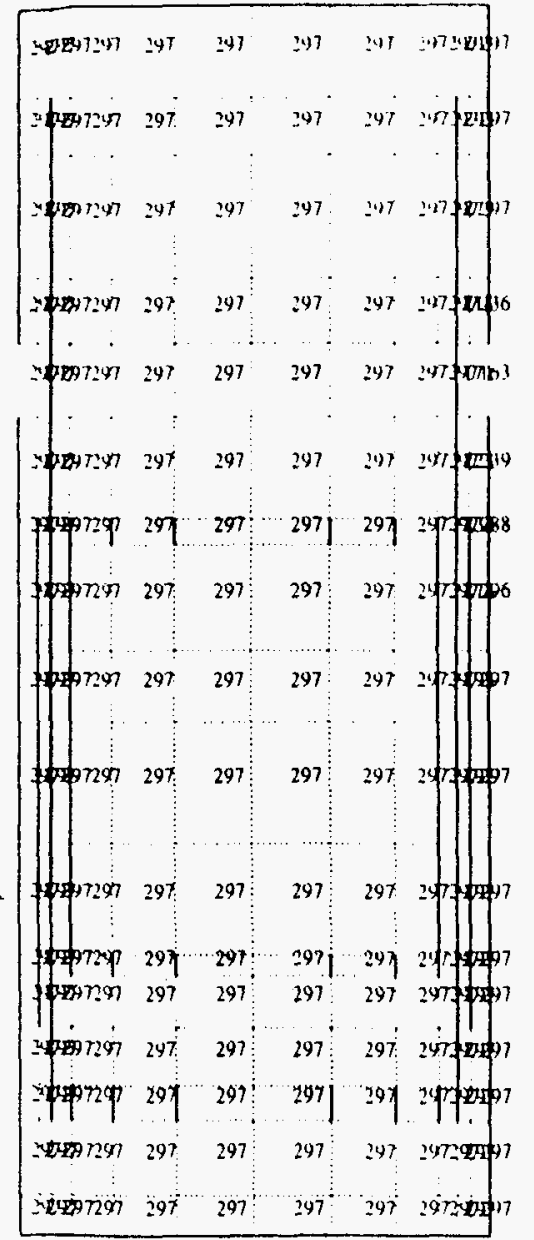

$\mathrm{J}=20$

Time: $7 \mathrm{~s}$

(a)

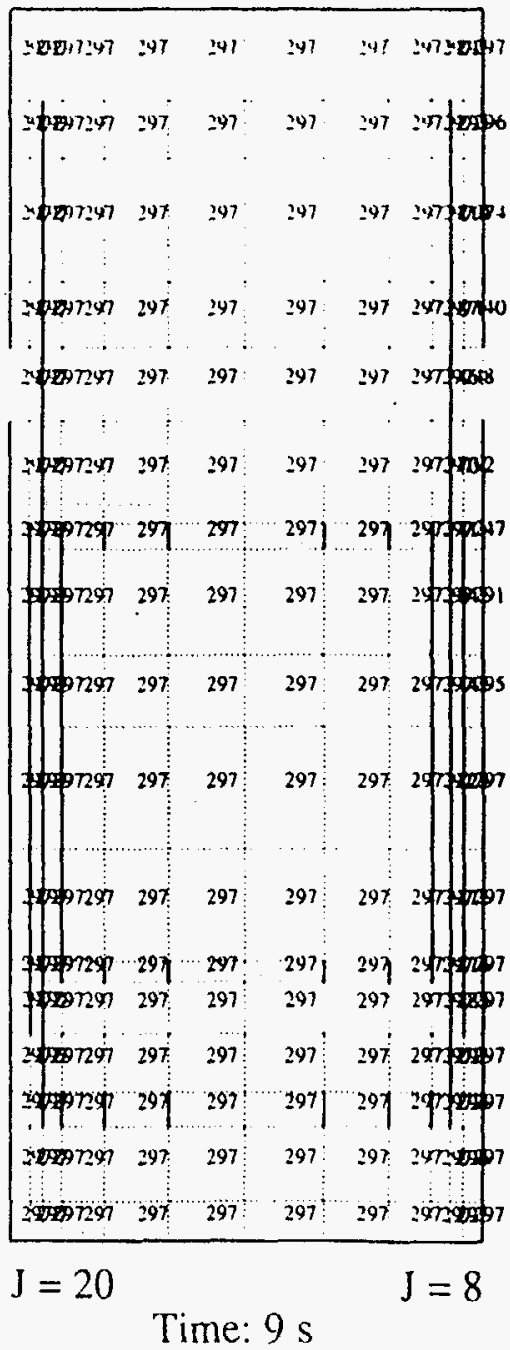

(b)

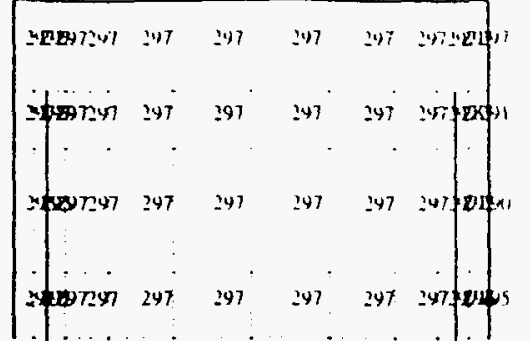

$\begin{array}{lllllll}30007297 & 297 & 297 & 297 & 297 & 297\end{array}$

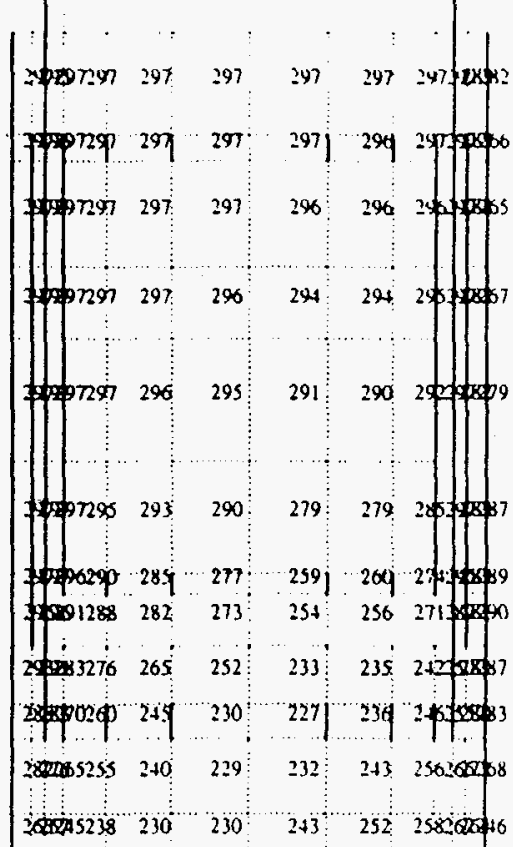

$\mathrm{J}=20$
Time: $14 \mathrm{~s}$

(c)

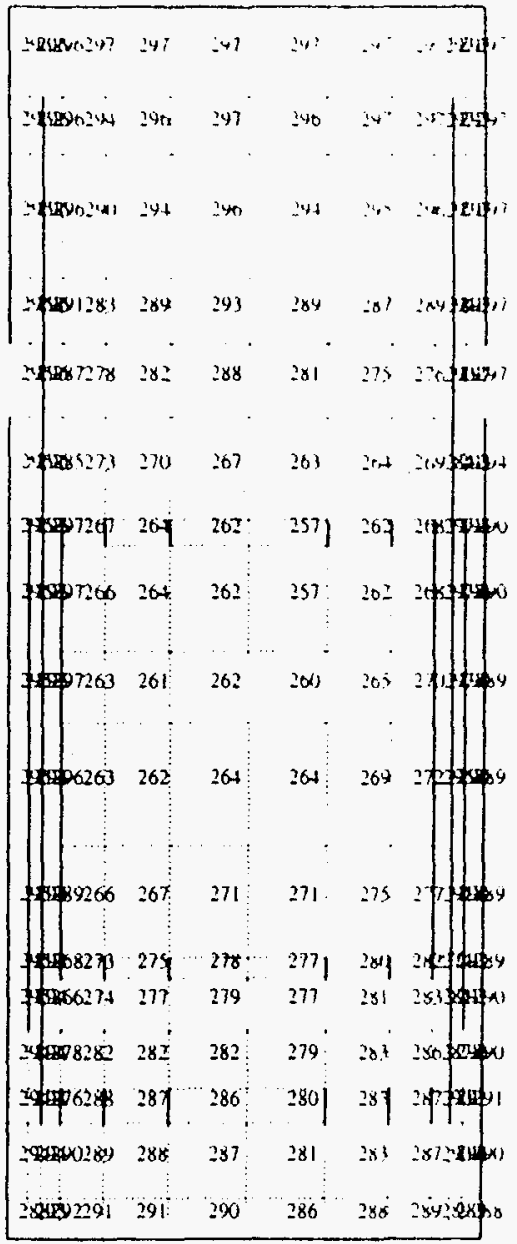

$\mathrm{J}=8$

Fig. 50. Temperature $\left({ }^{\circ} \mathrm{C}\right.$ ) distributions in reactor vessel (vertical planes $j=8,20$ ) for hot-RCP-start calculation with multicoordinate model 


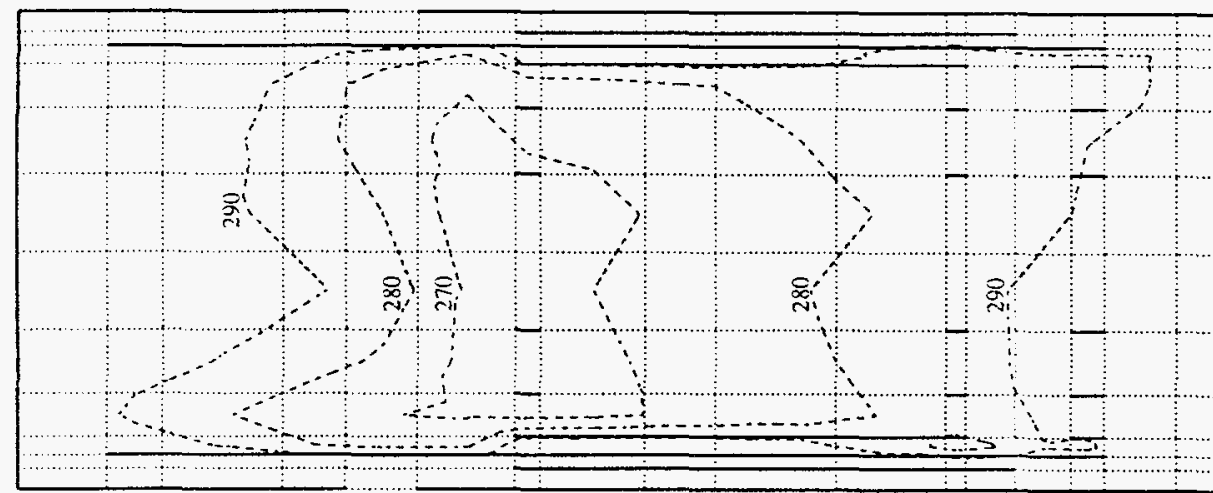

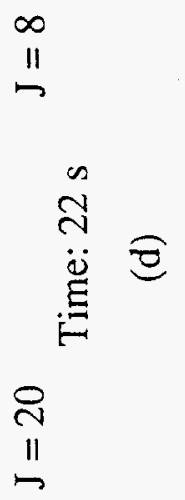
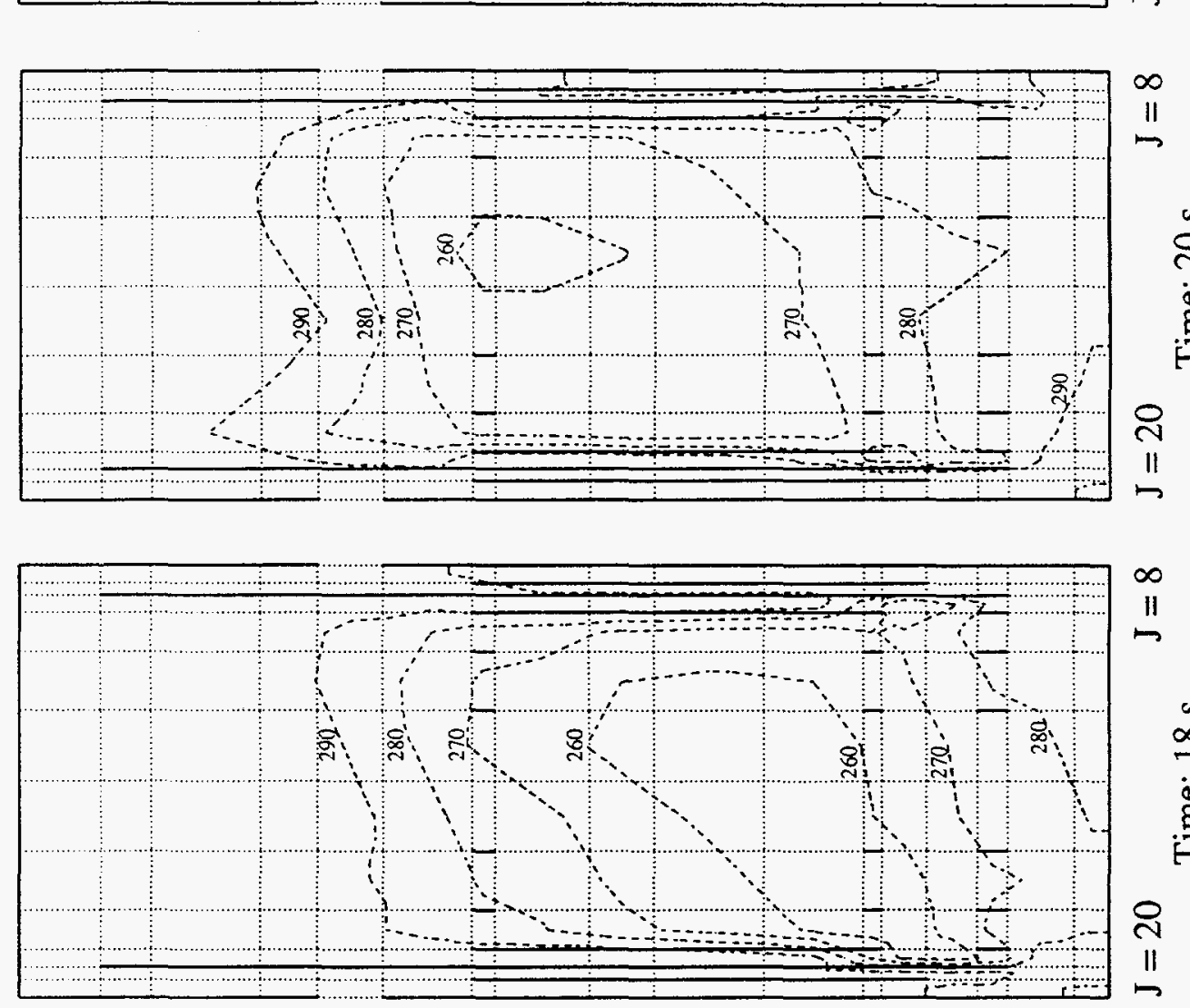

고

$\infty$

$\infty$

$\longrightarrow$

$\stackrel{8}{0}$

$\ddot{\Xi}$ 仓

II

(2)

e

용

క

$\sqrt[3]{2}$

8 )

늘

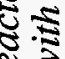

$\infty$

II

5

这

$\infty \quad 8 \frac{0}{\infty}$

$\ddot{\dot{\omega}}$ อ

1)

हैं

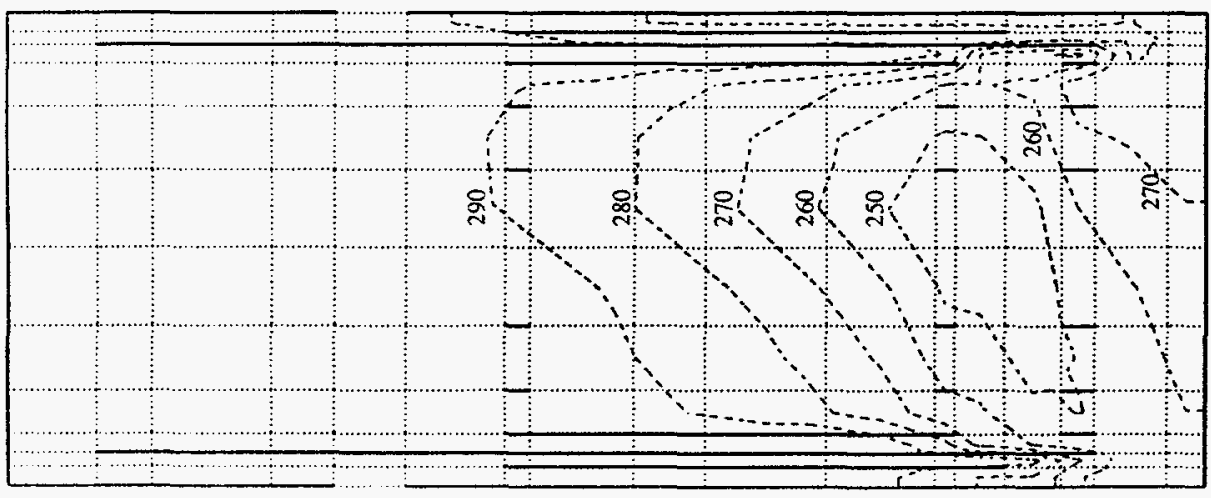

$\stackrel{\infty}{11} \quad$ in

$\frac{\mathscr{0}}{\ddot{0}} \pi$

오

II 


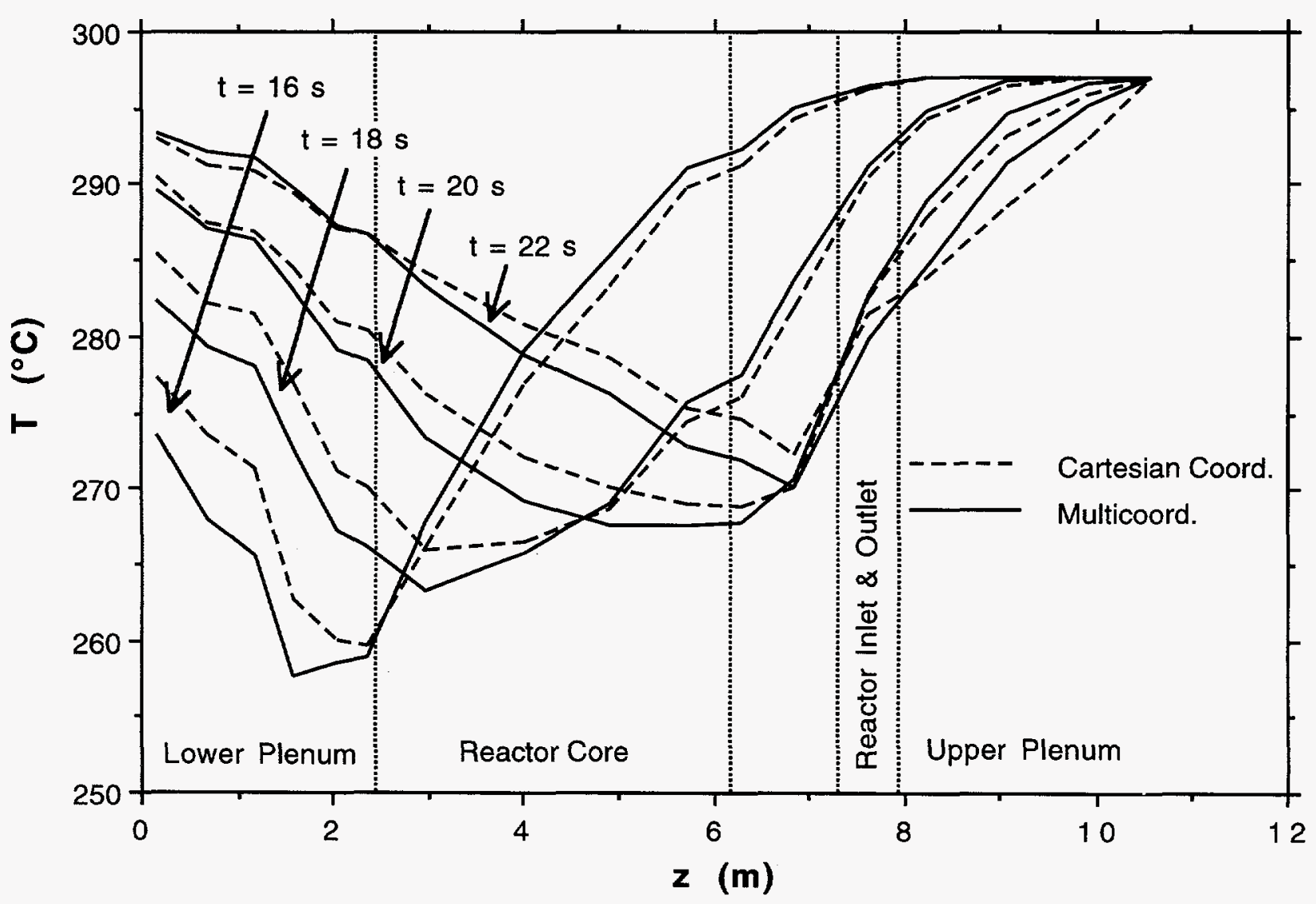

Fig. 52. Temperature variation along axis of reactor vessel at 16, 18,20, and $22 \mathrm{~s}$ into transient for hot-RCP-start calculation with and without multicoordinate model 


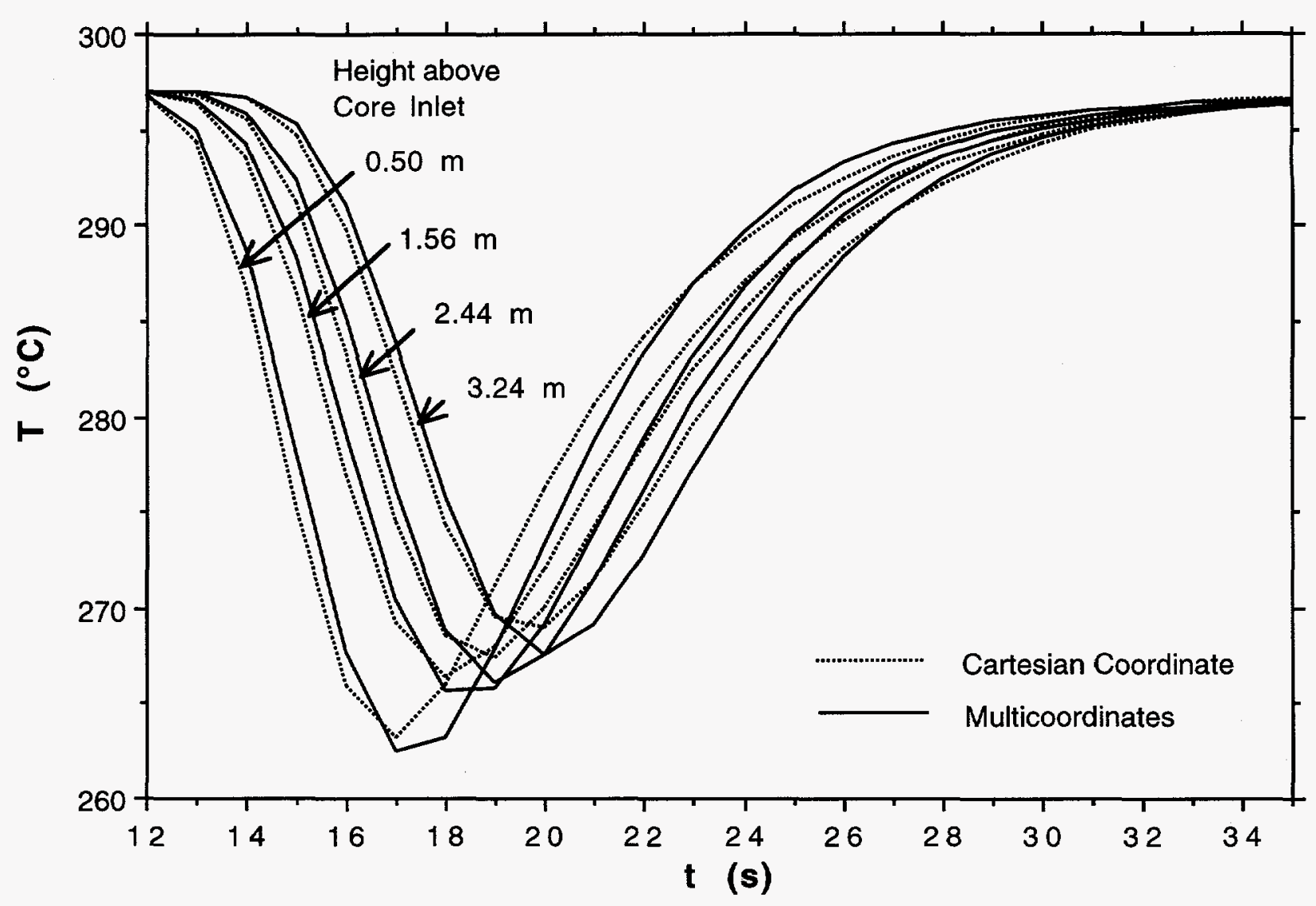

Fig. 53. Mean temperature variation with time in reactor core for hot-RCP-start calculation with and without multicoordinate model 
Internal:
C. A. Malefyt
J. G. Sun
R. W. Weeks
R. B. Poeppel
C. E. Till
TIS Files
W. T. Sha
R. A. Valentin

\section{External:}

NRC, Washington, for distribution per R4

ANL Libraries

$$
\begin{aligned}
& \text { ANL-E (2) } \\
& \text { ANL-W }
\end{aligned}
$$

Manager, Chicago Field Office, DOE

Energy Technology Division Review Committee:

H. K. Birnbaum, University of Illinois, Urbana

R. C. Buchanan, University of Cinncinnati, Cinncinnati, $\mathrm{OH}$

M. S. Dresselhaus, Massachusetts Institute of Technology, Cambridge, MA

B. G. Jones, University of Illinois, Urbana

C.-Y. Li, Cornell University, Ithaca, NY

S. N. Liu, Freemont, CA

R. E. Smith, Sci Tech Inc., Morrisville, NC

G. Trager, U.S. Nuclear Regulatory Commission, Washington, DC

G. Lanik, U.S. Nuclear Regulatory Commission, Washington, DC

J. Rosenthal, U.S. Nuclear Regulatory Commission, Washington, DC

N. Su, U.S. Nuclear Regulatory Commission, Washington, DC 


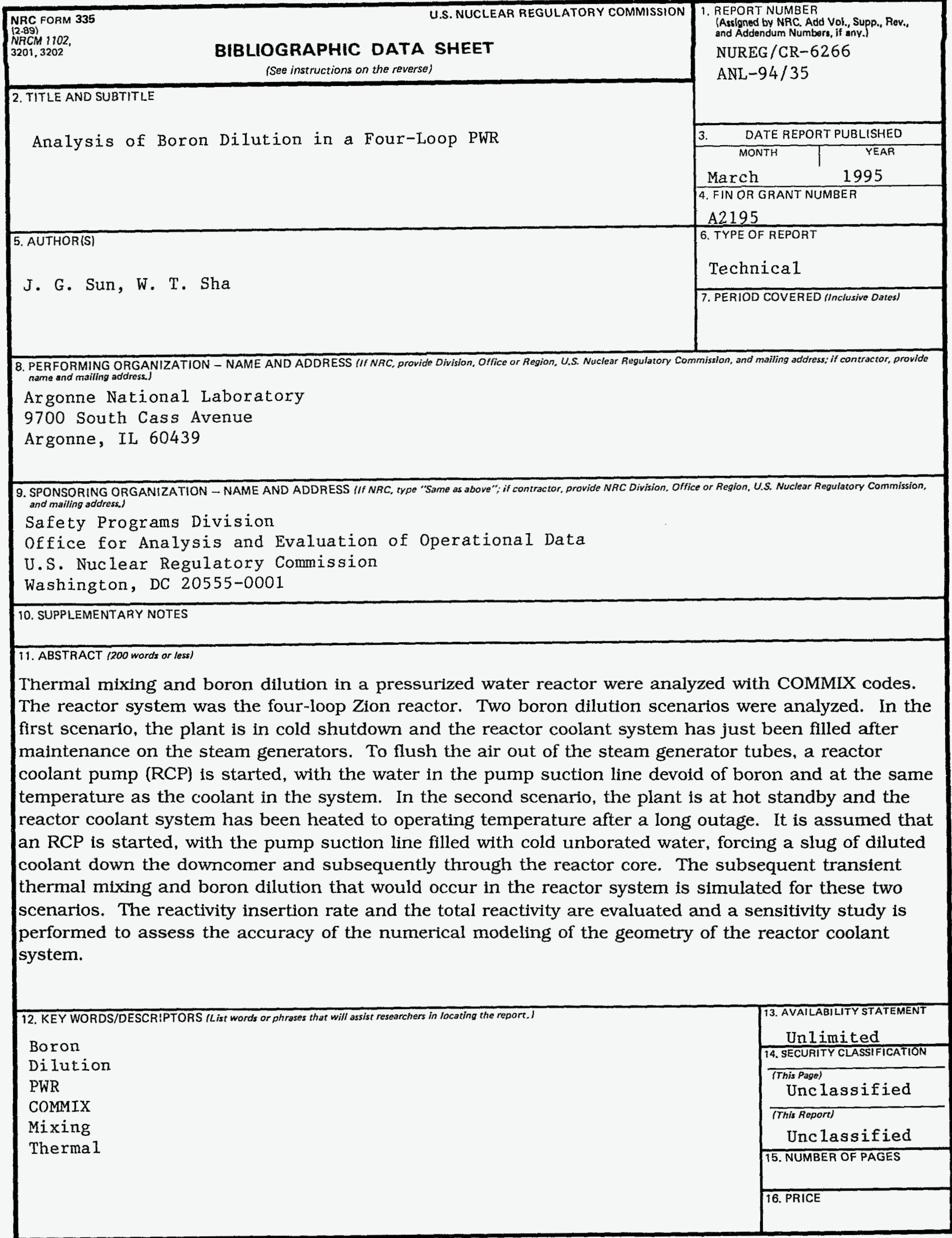

